\title{
Benchmarking and standardizing of dietetic practices in hemodialysis (HD) patients in Lebanon: clinical and quality of life outcomes
}

Citation for published version (APA):

Karavetian, M. (2014). Benchmarking and standardizing of dietetic practices in hemodialysis (HD) patients in Lebanon: clinical and quality of life outcomes. [Doctoral Thesis, Maastricht University]. Datawyse / Universitaire Pers Maastricht. https://doi.org/10.26481/dis.20140701mk

Document status and date:

Published: 01/01/2014

DOI:

10.26481/dis.20140701mk

Document Version:

Publisher's PDF, also known as Version of record

Please check the document version of this publication:

- A submitted manuscript is the version of the article upon submission and before peer-review. There can be important differences between the submitted version and the official published version of record.

People interested in the research are advised to contact the author for the final version of the publication, or visit the DOI to the publisher's website.

- The final author version and the galley proof are versions of the publication after peer review.

- The final published version features the final layout of the paper including the volume, issue and page numbers.

Link to publication

\footnotetext{
General rights rights.

- You may freely distribute the URL identifying the publication in the public portal. please follow below link for the End User Agreement:

www.umlib.nl/taverne-license

Take down policy

If you believe that this document breaches copyright please contact us at:

repository@maastrichtuniversity.nl

providing details and we will investigate your claim.
}

Copyright and moral rights for the publications made accessible in the public portal are retained by the authors and/or other copyright owners and it is a condition of accessing publications that users recognise and abide by the legal requirements associated with these

- Users may download and print one copy of any publication from the public portal for the purpose of private study or research.

- You may not further distribute the material or use it for any profit-making activity or commercial gain

If the publication is distributed under the terms of Article $25 \mathrm{fa}$ of the Dutch Copyright Act, indicated by the "Taverne" license above, 


\section{Benchmarking and Standardizing of Dietetic Practices in Hemodialysis (HD) Patients in Lebanon: Clinical and Quality of Life outcomes}


The research presented in this thesis was conducted in 12 hospital based hemodialysis units in Lebanon.

The project was carried out in collaboration with the Lebanese Kidney registry, Ministry of Public Health, and with partial financial support from National Centre for Scientific Research in Lebanon.

2014. Mirey Karavetian

(C) Mirey Karavetian, Maastricht 2014

Production: Datawyse | Universitaire Pers Maastricht

ISBN 9789461593474 


\title{
Benchmarking and Standardizing of Dietetic Practices in Hemodialysis (HD) Patients in Lebanon: Clinical and Quality of Life outcomes
}

\author{
PROEFSCHRIFT \\ ter verkrijging van de graad van doctor \\ aan de Universiteit Maastricht, \\ op gezag van de Rector Magnificus, Prof. dr. L.L.G. Soete, \\ volgens het besluit van het College van Decanen, \\ in het openbaar te verdedigen \\ op dinsdag 1 Juli 2014 om 16:00 uur \\ door
}

Mirey Karavetian

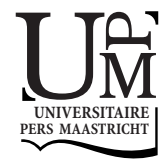




\section{Promoters}

Prof. dr. de Vries Nanne

\section{Copromoter}

Dr. Elzein Hafez

\section{Assessment Committee}

Prof. dr. Jeroen P. Kooman (chairman)

Prof. dr. Juergen Floege

Prof. dr. Karel Leunissen

Dr. Jascha de Nooijer

Prof. dr. Piet M ter Wee 


\section{Contents}

$\begin{array}{lll}\text { Chapter } 1 \text { General Introduction } & 7\end{array}$

$\begin{array}{lll}\text { Chapter } 2 \text { Nutritional Education for the Management of } & 17\end{array}$

Osteodystrophy (NEMO) in Patients on Haemodialysis: A

Randomised Controlled Trial - PILOT

Chapter 3 Dietetic Practices in Hemodialysis Units in Lebanon and Their

Conformity with KDOQI Nutrition Guidelines

Chapter 4 Dietary Educational Interventions for Hyperphosphatemia Management in Hemodialysis (HD) Patients: A Systematic Review and Meta-Analysis

Chapter 5 Nutritional Education for Management of Osteodystrophy (NEMO) Trial: Design and Patient Characteristics, Lebanon

Chapter 6 Effect of Behavioral Stage-Based Nutrition Education on Hyperphosphatemia Management among Hemodialysis Patients: NEMO Trial, Lebanon

Chapter 7 The Nutritional Education for Management of Osteodystrophy (NEMO) Trial: Impact on Quality of Life and Malnutrition status

Chapter 8 General Discussion

Chapter 9 Summary of the Study

Chapter 10 Valorization

Acknowledgments

Curriculum Vitae 

CHAPTER 1

General Introduction 
CHAPTER 1 


\section{GENERAL INTRODUCTION}

Dialysis is a Renal Replacement Therapy (RRT) for the later stage (stage 5) of Chronic Kidney Disease (CKD). It cleans the blood and removes metabolic wastes and excess water from the body. The other alternative RRT is renal transplant (Mahan, 2004). The numbers of hemodialysis (HD) patients are increasing worldwide as well as their rates of morbidity and mortality (Wish, 2001). In Lebanon, there are 55 hospital-based HD units hosting about 2500 patients ( $0.66 \%$ of population - Elzein et al., et al, 2010) and costing the Lebanese Ministry of Public Health alone $7.8 \%$ of its budget (Ammar et al, 2009).

HD patients suffer from multiple co-morbidities that increase the burden of life. Bone demineralization, better known as CKD-MBD (mineral bone disorder) is by far the most common problem among HD patients (Durose et al 2004) and is known as the 'silent killer' of HD patients (Locatelli 2002). CKD-MBD results from chronic uncontrolled hyperphosphatemia (>5.5 mg/ dl). With the failure of the kidney, the excretion of serum Phosphorus ( $\mathrm{P}$ ) decreases; when accompanied with a dietary $\mathrm{P}$ in positive balance with excreted serum $P$, hyperphosphatemia results. Chronic disruption of the $P$ balance will affect the calcium (Ca) balance and thus lead to uncontrolled secretion of parathyroid hormone (PTH). The latter causes hypertrophy of the parathyroid gland and excessive mobilization of $\mathrm{Ca}$ and $\mathrm{P}$ from the bones, which disturbs bone homeostasis and results in CKD-MBD. The increase in serum $\mathrm{Ca}$ and $\mathrm{P}$ levels and thus the Ca* $\mathrm{P}$ byproduct can result in metastatic calcification in bone, joint, and tissue. Other symptoms of this condition are: muscle cramps, cardiovascular disease, skin problems, decreased quality of life $(\mathrm{QOL})$ and increased mortality and health care cost (Amann et al. 1999).

In 2003, the Kidney Disease Outcomes Quality Initiative (K/QODI) published its original set of guidelines for CKD-MBD management in all stages of CKD. The following were identified as the key strategies: 1 ) $\mathrm{P}$ restricted diet and $\mathrm{P}$ chelating medication, 2) vitamin $D$ therapy, 3) follow-up of relevant biochemical parameters, 4) dialysis adequacy and management of metabolic acidosis, and 5) availability of qualified staffing in the dialysis clinics (K/DOQI Clinical Practice Guidelines 2002, McCann L 2009).

Adherence to these dietary restrictions imposed on HD patients by KDOQI guidelines has been reported in the literature to be very low, ranging from $19 \%$ to $57 \%$ (Denhaerynck et al, 2010). Patients have labeled the P restricted diet as the most complicated dietary prescription in the renal diet (Durose et al, 2004). Unfortunately, decreased adherence to medical nutrition therapy (MNT) in HD patients leads to hyperphosphatemia and co-morbidities resulting form hyperphosphatemia mentioned earlier (Denhaerynck K et al, 2010).

The renal diet specific for HD patient requires $1-1.2$ grams per kilogram of body weight per day protein which provides up to $800-1400 \mathrm{mg} / \mathrm{d}$ P (Afifi et al. 2005) which exceeds the allowed amount of dietary P (1000mg/d) (McCann 2009). This can be 
achieved by limiting protein sources to the ones with a $\mathrm{P}$ to protein ration of $10-13 \mathrm{~g} P$ per $1 \mathrm{~g}$ of protein (McCann 2009). All of these rules and regulations make the diet challenging for the patient to follow. This highlights the important role of the competent renal dietitian in the HD unit, to carefully plan a well balanced diet to maintain an optimal nutritional status yet prevent serum $\mathrm{P}$ rise. Throughout the literature patients have shown to improve their adherence when dietitians individualized the diet for each patient based on his/her kidney function, co-morbid conditions, medications, binders, serum lab values, culture, food preference and intake, tolerance, socioeconomic status, religious status, and beliefs (Tsay \& Hung 2004, Ashurst \& Dobbie 2003, Baker et al. 2005, Bodenheimer et al. 2002). Moreover, Caldeira et al (2011) showed that educational counseling can ease adherence to this diet. Strong evidence exists to support the use of a combination of behavioral change models and cognitive behavioral therapy, in facilitating dietary lifestyle changes (Spahn et al, 2010).

Renal dietitians are essential specialized members of the healthcare team, responsible for providing adequate nutrition care and monitoring of HD patients (Thelen et al., 2009). Full implementation of evidence based guidelines (EBG) for CKD by dietitians and adequate dietitian- to- CKD patient time has shown to effectively decrease patient hospitalization, mortality and thus health care cost (Wolfe, 2012; Campbell et al., 2009).

Barriers to full implementation of EBG for CKD among dietitians have been recognized to be mainly: lack of specialized dietitians in renal care (Beto \& Bansal, 2004), lack of time and lack of the support system by the health care organizations (Wolfe, 2012). As a result, dietitians of various backgrounds are filling the increasing need for specialized nutrition professionals in HD centers. Wolfe (2011, p: 170) stated "even the most qualified and organized dietitian will be unable to provide quality nutrition care to dialysis patients when the time allotment is inadequate or patient load is too great". The situation is not different in Lebanon, but there are no publications on the topic.

The present thesis aims primarily to examine the effect of self management dietary counseling of CKD-MBD among Lebanese HD patients in an attempt to identify the cultural specific strategies needed to optimize the nutritional care in national HD units. The project followed the steps of intervention mapping (Figure 1). 
Figure 1: Intervention mapping (simplified model)

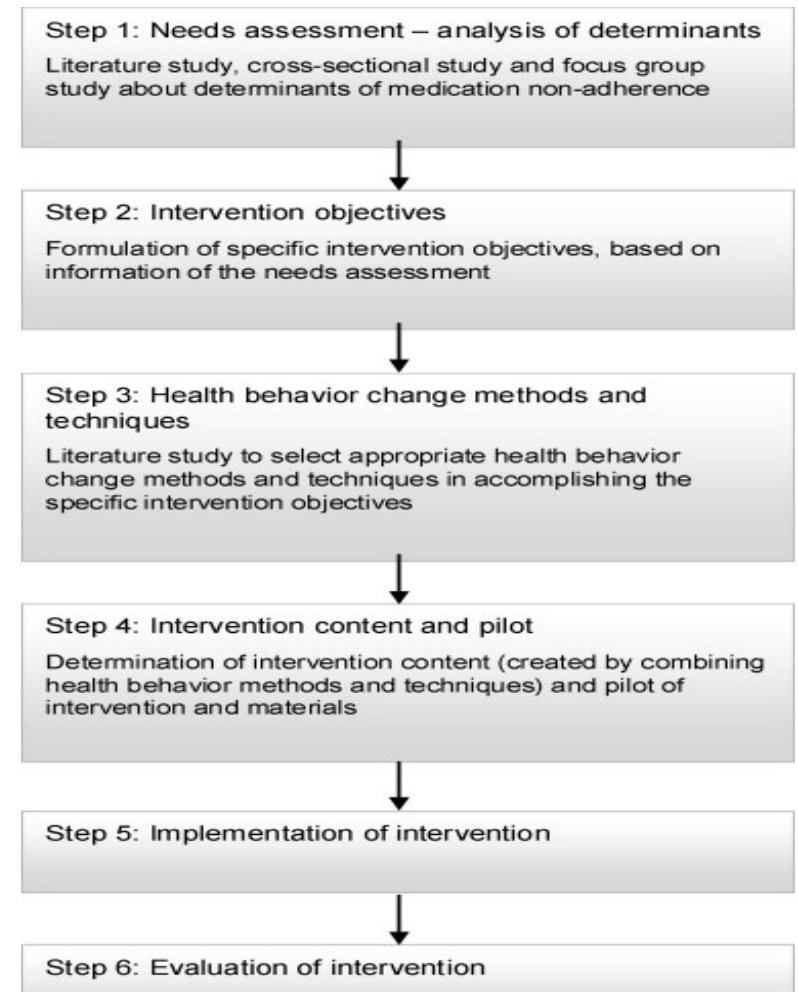

Adapted from Zwikker $\mathrm{H}$ et al, 2012

\section{Step 1: Needs assessment:}

Evaluation of dietetic practices in Lebanese HD units was conducted. Gap analysis of practice patterns was done by comparing the current status to EPG (KDOQI; 2000). Moreover barriers to full implementation were identified, detailed in chapter 2 .

Furthermore, focus group discussions were done with 3 dietitians working with HD patients and with $15 \mathrm{HD}$ patients. The aim of this was to explore their perspectives on facilitators and barriers towards optimal adherence to $P$ restricted diet. Findings are detailed in Chapter 4.

\section{Step 2: Intervention objectives:}

According to the findings of the needs assessment, study objectives were set to be the following:

- Develop and provide a dietetic training module that helps empower clinical dietitians on the EBG of renal MNT. 
- Develop a patient educational module that helps patients achieve self management in dietary management of hyperphosphatemia. The aim of this was to make easy to use ready-made educational material fit to the Lebanese language and culture, and effective in changing dietary behavior available.

- Study the effectiveness of the dietitian and patient educational module on the adherence of HD patients to the P restricted diet; specifically on the following clinical and nonclinical outcomes:

- Serum P ( primary outcome variable of the study)

- Knowledge in dietary restrictions

- Behavioral readiness to adapt the new dietary lifestyle

- Dietary intake

- Malnutrition inflammation scores (MIS)

- QoL scores

- Rates of hospitalization, length of stay and need for emergency HD

\section{Step 3: Health behavior change methods and techniques:}

A systematic review with meta-analysis was conducted in Pubmed, Medline and Embase databases and detailed in chapter 3. The review targeted all published articles in the past decade on educational dietary interventions focusing on hyperphosphatemia management among HD patients with serum phosphorus (P) as the main outcome variable. After full evaluations by 2 independent reviewers, 18 articles met the inclusion criteria. Table 1 shows the key strategies retrieved from the review.

Moreover, the transtheoretical model (TTM) or the stages of behavioral change model created by Prochaska was chosen to be the basis of the patient educational material/intervention. This model considers behavioral change as a dynamic process whereby people move from one stage to another over time. There are 5 stages in this model: 1) Pre-contemplation, 2) contemplation, 3) preparation, 4) action, 5) maintenance. To create movement through the stages, an appropriate, stage-based intervention is planned (Prochaska et al, 2008). Recent literature is leaning towards the effectiveness of staged-matched nutritional education (Molaison et al, 2001; MochariGreenberger et al, 2010) and in health promotion (Whitelaw et al, 2000). 
Table 1: The formula for effective dietary education to manage hyperphosphatemia in HD patients

\begin{tabular}{|c|c|c|c|c|c|c|}
\hline $\begin{array}{l}\text { Patients in- } \\
\text { volved in prepa- } \\
\text { ration of the } \\
\text { intervention } \\
+ \\
\text { Multidiscipli- } \\
\text { nary team } \\
\text { approach where } \\
\text { depression is } \\
\text { also treated }\end{array}$ & $\begin{array}{l}\text { Educational material to } \\
\text { be used } \\
\text { 1. Colorful informational } \\
\text { booklet } \\
\text { 2. Handouts } \\
\text { 3. Booklet on P rich and } \\
\text { poor food items } \\
\text { 4. Games and puzzles } \\
\text { 5. Posters } \\
\text { 6. Involving relatives } \\
\text { 7. Recipes adapted to } \\
\text { the patients' taste } \\
\text { and culture }\end{array}$ & $\begin{array}{l}\text { Education } \\
\text { must be } \\
\text { done before } \\
\text { the HD } \\
\text { sessions and } \\
\text { individual- } \\
\text { ized }\end{array}$ & 1. & $\begin{array}{l}\text { Hyperphosphatemia, } \\
\text { its complications, and } \\
\text { diet control with a } \\
\text { complete list of P } \\
\text { content in daily food; } \\
\text { Restricted/non- } \\
\text { restricted foods for } \\
\text { low P diet, P/protein } \\
\text { ratio of foods; } \\
\text { Avoiding foods with P } \\
\text { additives; } \\
\text { P binders, their } \\
\text { benefit and mode of } \\
\text { action, } \\
\text { Information on rele- } \\
\text { vant blood tests; in } \\
\text { addition to behavioral } \\
\text { change methods like } \\
\text { self-evaluation and } \\
\text { self- regulation }\end{array}$ & $\begin{array}{l}\text { Use of } \\
\text { behavioral } \\
\text { theories }\end{array}$ & $\begin{array}{l}\text { Not less } \\
\text { than } 6 \\
\text { month } \\
\text { duration for } \\
\text { education, } \\
\text { and not less } \\
\text { than } \\
\text { monthly }\end{array}$ \\
\hline
\end{tabular}

\section{Step 4: Intervention content and pilot:}

Prior to the design of this thesis, a small scale study with similar objective and patient population was conducted by the study team (Karavetian \& Ghaddar, 2012). It was a randomized controlled trial on 122 patients divided into 3 groups that examined the effect of self-management dietary counseling (SMDC) on adherence to dietary management of hyperphosphatemia among HD patients. The intervention duration was 8 weeks during which the full intervention group received a two 20-minute sessions each week. Outcome variables were: serum P, Ca, patient knowledge on the P restricted diet and dietary adherence. The full intervention group experienced a significant improvement in all study parameters. Thus this study was considered the pilot of the current thesis. Sample size was calculated based on the pilot; all questionnaires that needed to be translated to Arabic were used form the study where they were already translated and validated. The patient education concepts used in the pilot were elaborated and expanded into the patient education material of the current thesis. This is detailed in chapter 4.

Based on the preceding steps and the pilot study, the protocol of the study was developed, shown in Figure 2 and detailed in chapter 5. Subsequently the dietitian and patient education modules were developed; detailed in chapter 6 . 


\section{Step 5 and Step 6: Implementation and Evaluation of Intervention:}

The full implementation of the study was explained in chapter 6 and 7. Chapter 4 concentrated on the change in knowledge and behavioral stage of the patient as per the TTM model, and chapter 5 concentrate on the change in QOL, nutritional status and hospitalization. Outcome evaluation was done for all study outcome variable to study the efficacy of the study.

Figure 2: Flow Chart of Study Design

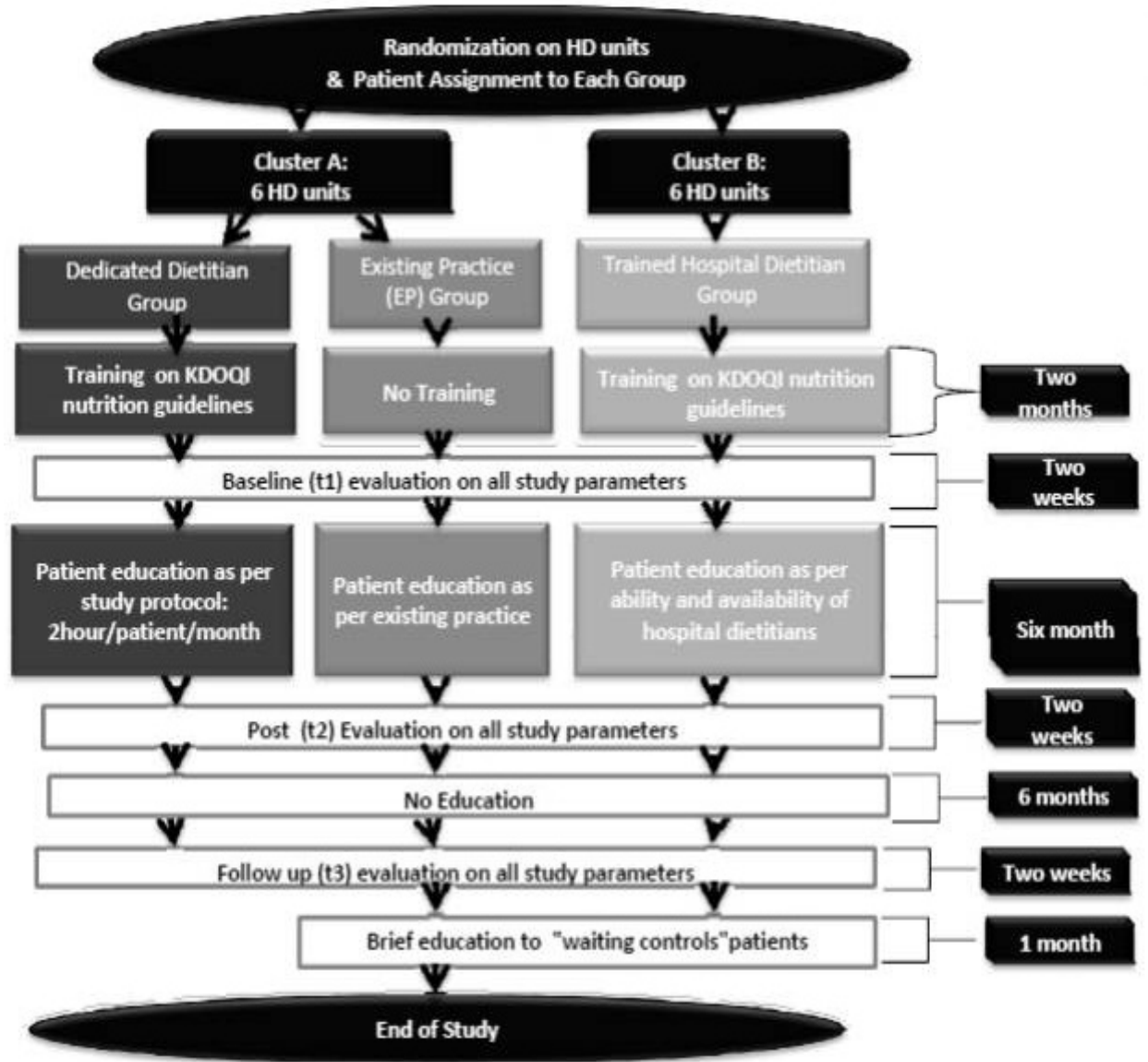




\section{REFERENCES}

Afifi, A., El-Sayed, H., El-Setouhi, M., Ahmed, H. and Khalifa, N. (2005). Hyperphosphatemia among end-stage renal disease patients in developing countries: A forgotten issue? Hemodialysis International, 9(4), 409415.

Amann, K., Gross, M. L., London, G. M., and Ritz, E. (1999). Hyperphosphataemia-a silent killer of patients with renal failure?. Nephrology Dialysis Transplantation, 14(9), 2085-2087.

Ammar, W. (2009). Health beyond politics. Beirut. World Health Organization/Ministry of Public Health.

de Brito Ashurst, I. and Dobbie, H. (2003). A randomized controlled trial of an educational intervention to improve phosphate levels in hemodialysis patients. Journal of Renal Nutrition, 13(4), 267-274.

Baker, D. W., Asch, S. M., Keesey, J. W., Brown, J. A., Chan, K. S., Joyce, G., and Keeler, E. B. (2005). Differences in education, knowledge, self-management activities, and health outcomes for patients with heart failure cared for under the chronic disease model: the improving chronic illness care evaluation. Journal of Cardiac Failure, 11(6), 405-413.

Beto, J.A. and Bansal, V.K. (2004). Medical nutrition therapy in chronic kidney failure: integrating clinical practice guidelines. Journal of the American Dietetic Association, 104(3), 404-409.

Bodenheimer, T., Lorig, K., Holman, H., and Grumbach, K. (2002). Patient self-management of chronic disease in primary care. Journal of the American Medical Association, 288(19), 2469-2475.

Caldeira, D., Amaral, T., David, C., and Sampaio, C. (2011). Educational strategies to reduce serum phosphorus in hyperphosphatemic patients with chronic kidney disease: systematic review with metaanalysis. Journal of Renal Nutrition, 21(4), 285-294.

Campbell, K.L., Ash, S., Zabel, R., Mcfarlane, C., Juffs, P. and Bauer, J.D. (2009). Implementation of standardized nutrition guidelines by renal dietitians is associated with improved nutrition status. Journal of Renal Nutrition, 19(2), 136-144.

Denhaerynck, K, Manhaeve, D., Dobbels, F., Garzoni, D., Nolte, C. and De Geest, S. (2007). Prevalence and consequences of nonadherence to hemodialysis regimens. American Journal of Critical Care, 16(3), 222235.

Durose, C.L., Holdsworth, M., Watson, V. and Przygrodzka, F. (2004). Knowledge of dietary restrictions and the medical consequences of noncompliance by patients on hemodialysis are not predictive of dietary compliance. Journal of the American Dietetic Association, 104(1), 35-41.

National Kidney Foundation Kidney Disease Outcomes Quality Initiative (NKF KDOQI) (2000) Clinical Practice Guidelines for Nutrition in Chronic Renal Failure https://www.kidney.org/professionals/kdoqi/guidelines_updates/doqi_nut.html. Accessed on January 20, 2011.

Levey, A. S., Coresh, J., Bolton, K., Culleton, B., Harvey, K. S., Ikizler, T. A., . . . and Witten, B. (2002). Initiative KDOQ: K/DOQI clinical practice guidelines for chronic kidney disease: evaluation, classification, and stratification. American Journal of Kidney Diseases, 39, S1-S266.

Elzein, H., Kabalan, S., Mallat, S., \& Abuzeinab, H. (2010). 85: Conception of a National Registry for Renal Replacement Therapy (RRT) in Lebanon. American Journal of Kidney Diseases, 55(4), B53.

Karavetian, M. and Ghaddar, S. (2012). Nutritional Education for the Management of Osteodystrophy (NEMO) in Patients on Haemodialysis: A Randomised Controlled Trial. Journal of Renal Care, 39(1), 19-30

Locatelli, F., Cannata-Andia, J.B., Drueke, T.B., Horl, W.H., Fouque, D., Heimburger, O. and Ritz, E. (2002). Management of disturbances of calcium and phosphate metabolism in chronic renal insufficiency, with emphasis on the control of hyperphosphataemia. Nephrology Dialysis Transplantation, 17(5), 723-731.

McCann, L. (2009). Pocket guide to nutrition assessment of the patient with chronic kidney disease. 4th ed. New York: National Kidney Foundation.

Mochari-Greenberger, H., Terry, M.B. and Mosca, L. (2010). Does stage of change modify the effectiveness of an educational intervention to improve diet among family members of hospitalized cardiovascular disease patients? Journal of the American Dietetic Association, 110(7), 1027-1035.

Molaison, E. F., and Yadrick, M. K. (2003). Stages of change and fluid intake in dialysis patients. Patient Education and Counseling, 49(1), 5-12. 
Prochaska, J. O. (2008). Decision making in the transtheoretical model of behavior change. Medical Decision Making, 28(6), 845-849.

Spahn, J. M., Reeves, R. S., Keim, K. S., Laquatra, I., Kellogg, M., Jortberg, B., and Clark, N. A. (2010). State of the evidence regarding behavior change theories and strategies in nutrition counseling to facilitate health and food behavior change. Journal of the American Dietetic Association, 110(6), 879

Thelen, B., Byham-gray, L., Touger-decker, R., O'sullivan Maillet, J. and Khan, H. (2009). Survey of current job functions of renal dietitians. Journal of Renal Nutrition, 19(6), 450-461.

Tsay, S. L., and Hung, L. O. (2004). Empowerment of patients with end-stage renal disease-a randomized controlled trial. International Journal of Nursing Studies, 41(1), 59-65.

Whitelaw, S., Baldwin, S., Bunton, R., and Flynn, D. (2000). The status of evidence and outcomes in Stages of Change research. Health Education Research, 15(6), 707-718.

Wish, J. B. (2001). Performance measures, accountability, and public policy. American Journal of Kidney Diseases, 37(2), 431-434.

Wolfe, W.A. (2011). Adequacy of dialysis clinic staffing and quality of care: a review of evidence and areas of needed research. American Journal of Kidney Diseases, 58(2),166-176.

Wolfe, W.A. (2012). Moving the issue of renal dietitian staffing forward. Journal of Renal Nutrition, 22(5), 515520.

Zwikker H, van den Bemt B, van den Ende C, van Lankveld W, den Broeder A, van den Hoogen F, van de Mosselaar B, van Dulmen S. (2012). Development and content of a group-based intervention to improve medication adherence in non-adherent patients with rheumatoid arthritis. Patient Education and Counseling, 89(1), 143-151 


\title{
CHAPTER 2
}

\section{Nutritional Education for the Management of Osteodystrophy (NEMO) in Patients on} Haemodialysis:

\author{
A Randomised Controlled Trial
}

Karavetian, M., Ghaddar, S. (2012). Nutritional Education for the Management of Osteodystrophy (NEMO) in Patients on Haemodialysis: A Randomised Controlled Trial.

Journal of Renal Care, 39(1): 19-30 


\section{ABSTRACT}

Objective: To examine the effect of self-management dietary counselling (SMDC) on adherence to dietary management of hyperphosphatemia among haemodialysis patients.

Design: An eight-week cluster based randomised control trial.

Participants: 122 stable adult patients were recruited from an HD unit in Sidon, Lebanon. Study groups were: full intervention $(A)(n=41)$, partial intervention $(B)(n=41)$, and control (C) $(n=40)$.

Intervention: Group (A) received SMDC, Group (B) received educational games only and Group $(C)$ did not receive any research intervention.

Main Outcome Measures: Serum Phosphorus (P), Calcium Phosphate product (Ca x P) and two questionnaires: patient knowledge (PK) and dietary non-adherence (PDnA) to $P$ reduced diet.

Results: Group A experienced a significant improvement in mean ( \pm SD) P $(6.54 \pm$ $2.05-5.4 \pm 1.97 \mathrm{mg} / \mathrm{dl})$, Ca $\times$ P $(58 \pm 17-49 \pm 12)$, PK scores (50 $\pm 17-69 \pm 25 \%)$, and PDnA scores (21.4 $\pm 4.0-18.3 \pm 2.0)$. Group B experienced a significant improvement in Ca x P (52 $\pm 14-45 \pm 16)$. Group C did not experience any significant change post intervention.

Conclusion: Our findings demonstrate the importance of patient-tailored counselling on serum $\mathrm{P}$ management. 


\section{INTRODUCTION}

Chronic Kidney disease (CKD) is a progressive disease. Patients with CKD often face many challenges, such as the complex regimen they have to follow and their low perception of the impact of the therapy on their clinical outcomes. As a result, it is common to see patients on haemodialysis having difficulty adhering to their P control recommendations (Breiterman, 2005). Studies have shown a very low adherence rate (36\%) to renal diet among patients on haemodialysis (HD), as measured by biochemical parameters (Lee \& Molassiotis, 2002), with dietary phosphorus (P) being the most challenging (Durose et al., 2004). A recently published meta-analysis showed that nonadherence with phosphate binder intake was reported to be as high as $74 \%$ (mean = 51\%; Karamanidou et al., 2008).

Non-adherence with dietary phosphate recommendations in patients on HD is associated with major medical problems, such as bone resorption (renal osteodystrophy), organ calcification and eventually chronic parathyroid hyperplasia and related cardiovascular complications (Block et al., 1998; Matteson \& Russell, 2010). There have been no available data showing the prevalence of hyperphosphataemia among those on HD in Lebanon. However, the prevalence of hyperphosphataemia in Cairo ( $P>5$ $\mathrm{mg} / \mathrm{dl}$ ) was 69.1\% (Afifi et al., 2005).

An innovative method to improve adherence to dietary therapy among patients on HD was sought. Behavioural modelling was identified as a framework with a focus on beliefs and self- efficacy (Ghaddar et al., 2009). Self-management counselling (SMC) is an individualised intervention that uses the cognitive behavioural therapy approach. It aims to increase patients' knowledge and their participation in health-related decisions to maximise adherence and improve clinical outcomes (Richard, 2006).

The current study examined the effect of self-management dietary counselling (SMDC) focusing on phosphate control in order to identify the culturally specific strategies needed to optimise nutritional care in HD units in Lebanon.

\section{MATERIALS AND METHODS}

The study was an eight-week nutritional cluster randomised trial (CRT) that utilised a double-blind design. It included 122 patients from a HD centre in the South of Lebanon (Sidon). This centre served $150 \mathrm{HD}$ patients and was the largest in the country at the time of the study (Lebanese $\mathrm{MPOH}, 2005)$. Participants were assigned into three groups: Full intervention (Group A) ( $n=41$ ), partial intervention (Group B) $(n=41)$ and control (Group C) $(n=40)$. A CRT design was carried out according to the shifts of the HD sessions, to minimise interaction among members of the study groups (Griva et al., 2011). 
Eligible participants were patients who were stable on HD and had been on HD therapy for at least three months. They were 18 years of age or older and of Lebanese origin. They had full cognitive, psychiatric and physical capability for self-care and communication. The study was approved by the American University of Beirut Institutional Review Board and by the participating hospital. Informed consent was secured from the participants prior to the initiation of the study.

Demographic data and medical histories were retrieved from patients' medical charts. Data included patients' age, gender, years on dialysis, educational level, primary diagnosis of kidney disease and co-morbidities. A three-month average of examined biochemical parameters were collected prior to the initiation of the study as baseline data and then monthly throughout the study. The parameters included serum calcium (Ca), serum $\mathrm{P}, \mathrm{Ca}$ and $\mathrm{P}$ product ( $\mathrm{Ca} \times \mathrm{P}$ ), intact parathyroid hormone (PTH), serum albumin and calculated urea reduction ratio (URR). At the time of the study, PTH was tested only twice per year and serum albumin only four times per year, based on governmental funding. Therefore, we were only able to record one value for baseline PTH and two values for baseline albumin albumin. Lack of monthly albumin assessment prevented us from evaluating serum corrected $\mathrm{Ca}$, thus we used serum $\mathrm{Ca}$.

A patient knowledge (PK) questionnaire was utilised to assess patients' knowledge of kidney disease, renal diet, phosphate binders and vitamin $D$ therapy. The questionnaire was adapted from Ford et al. (2004) and its total score was expressed in percentages. It was translated into Arabic (local language), back translated into English to make sure the meaning of the original questions stayed the same, after which the Arabic version was piloted in 10 patients (Gandek \& Ware 1998; Sabbah et al., 2003).

A patient dietary non-adherence (PDnA) to phosphate restricted diet questionnaire was also used in this study. It was developed utilising the same format of the School Physical Activity and Nutrition (SPAN) questionnaire (Hoelscher et al., 2003). The PDnA questionnaire consists of 13 items reflecting patients' dietary and phosphate binder intake during the day prior to the questionnaire administration. Three items assessed dairy intake, five assessed sweet intake, three assessed high P starch intake, one cluster assessed high P protein items, and one cluster assessed high P fatty food items commonly consumed in Lebanon (condensed whole milk items and sesame paste [Tahini]). The answers for each item were: none (0), once (1), twice (2) and three (3) or more times a week. A score ranging from 0 to 3 was given to each item, and a total score was calculated to each one of the five categories (meat, fat, starch, sweets and dairy products). The total score ranged from 0 to 39, with higher scores indicating higher $\mathrm{P}$ intake thus lower adherence to a $P$ reduced diet.

The questionnaire was piloted to 10 patients on HD. Furthermore, a questionnaire consisting of two questions was developed to assess the adherence of phosphate binder intake with meals and with snacks during the day prior to the questionnaire administration. The patients were asked about the number of phosphate binders they took per day, and the timing of their binder intake. The possible answers were: doctor 
stopped patient's binders (0), yes, patient takes binders as prescribed (1), or no, patient does not take binders as prescribed (2). Those answers were compared with physicians' prescriptions.

The type and quantity of phosphate binder intake at baseline were assessed for all patients in each group and elemental Ca content was calculated. All questionnaires were administered through the research dietitian. The dietitian then encircled the answer as per patient's response.

\section{Study Protocol}

All three study groups were assessed pre- and post-study to allow for within- and between-group comparisons. All study groups continued to receive their routine nutritional education from their hospital dietitian.

\section{Group A: Intervention}

Participants in Group A received two 20-minute sessions each week throughout the eight-week study period. Methods used during these sessions were SMDC and interactive games relevant to the weekly educational topic, the aim of which was to test participants' comprehension. The games were individually graded and results were discussed with each participant in that group. Additionally, after each monthly laboratory results, mineral bone disorder (MBD) related parameters were individually discussed for 10 minutes and relevant nutritional counselling was provided if required. Positive reinforcement was provided to all participants in that group regardless of their performance level, with the aim of improving participants' MBD parameters.

\section{Group B: Partial Intervention}

Group B received the study educational games; however, those participants were not provided with the correct answers. We included this group to assess the effect of the presence of a dietitian as an "authoritative figure" (Thomas et al., 2001; Ford et al., 2004).

\section{Group C: Control}

Group $\mathrm{C}$ did not receive any nutritional intervention.

At the end of the study, all participants received a folder that included the games and educational materials, all printed in low literary level, in bold and in illustrative photos. The educational materials included:

(1) General information about kidney disease,

(2) Hyperphosphataemia and its health-related complications,

(3) Importance of adherence to dietary recommendations and phosphate binder therapy on preventing associated comorbidities, 
(4) A list of food items high in P, accompanied with relevant culturally appropriate low $P$ alternatives.

\section{Data Analysis}

Analysis of variance (ANOVA) and Duncan's post hoc test were carried out to examine baseline differences among the three study groups. A chi-square test was applied to evaluate difference in frequency distribution of categorical variables. A paired sample ttest was used to examine within-group differences for the dependent variables. The Statistical Package for Social Sciences (SPSS) version 13 (0.05 significance, 95\% confidence level) was used to calculate the statistical analysis.

\section{RESULTS}

A total of 122 patients were enrolled, 87 completed the study and 35 (28\%) dropped out (Table 1). The observed high attrition rate was due to the transfer of 20 patients to another clinic ( $n=3,8$ and 9 from the Group A, B and C respectively). The remaining 15 who left the study were due to transplantation $(n=1)$, death $(n=10)$ and withdrawal $(n$ =4). That resulted in $n=37, n=26$ and $n-24$ for groups $A, B$ and C, respectively.

Table 1. Distribution of patients throughout the study and attrition rate

\begin{tabular}{lccc}
\hline & $\begin{array}{c}\text { Intervention } \\
\text { group (A) } \mathbf{n = 4 1}\end{array}$ & $\begin{array}{c}\text { Partial intervention } \\
\text { group (B) } \mathbf{n = 4 1}\end{array}$ & $\begin{array}{c}\text { Control } \\
\text { group (C) } \mathbf{n}=\mathbf{4 0}\end{array}$ \\
\hline Transfer to another dialysis unit & 3 & 8 & 9 \\
Transplantation & --- & 1 & --- \\
Death & 2 & 3 & 5 \\
Withdrawal & --- & 2 & 2 \\
Total & 5 & 14 & 16 \\
\hline
\end{tabular}

\section{Baseline Data}

At baseline, the study included $48.5 \%$ males and $51.5 \%$ females with a mean ( \pm SD) age of $58 \pm 16$ years and $56 \pm 14$ years, respectively. Mean years on dialysis were $5.07 \pm$ 5.12 years (median $=4$ years). $74.6 \%$ of the participants were on dialysis for less than five years. Mean URR was $68.19 \pm 12.97 \%$ (Min: 10\%, Max: $82.06 \%$ ) and mean PTH level was $710 \pm 571$ ( $\min 20$ and $\max 3000$ ). Mean albumin level was $38.5 \mathrm{~g} / \mathrm{l}$ ( $\min 14.5 \mathrm{~g} / \mathrm{l}$ and $\max 44 \mathrm{~g} / \mathrm{l})$. Eighty-nine percent of the participants at baseline had a phosphate binder prescription (Table 2). 
Table 2. Demographic characteristics of the study populations $(n=122)$

\begin{tabular}{|c|c|c|}
\hline Characteristic & Categories & Percent \\
\hline Gender & Male & 49 \\
\hline Age & Patients $\geq 65$ years & 36 \\
\hline \multicolumn{2}{|c|}{ Patients on dialysis $>5 y r$} & 25 \\
\hline \multicolumn{2}{|l|}{ Continue to work } & 15 \\
\hline \multirow[t]{3}{*}{ Co-morbidities } & Diabetes & 33 \\
\hline & Cardio vascular disease & 19 \\
\hline & Hypertention & 52 \\
\hline \multirow[t]{6}{*}{ Primary cause } & Diabetic nephropathy & 30 \\
\hline & Nephrosclerosis & 24 \\
\hline & Glomerulonephrosis & 11 \\
\hline & Hereditary & 16 \\
\hline & Polycystic Kidney & 13 \\
\hline & Other kidney disease & 6 \\
\hline \multirow[t]{5}{*}{ Education } & Illiterate & 32 \\
\hline & Read and write & 8 \\
\hline & Elementary & 43 \\
\hline & High school & 12 \\
\hline & University & 5 \\
\hline \multirow[t]{2}{*}{ Familial status } & Lives with family & 89 \\
\hline & Lives alone & 11 \\
\hline \multirow[t]{3}{*}{ BMI } & Normal: $18.5-24.9$ & 38 \\
\hline & Overweight: $25-29.9$ & 38 \\
\hline & Obese: $>30$ & 24 \\
\hline \multicolumn{2}{|l|}{ alb $(g / d l)>3.5$} & 92 \\
\hline \multicolumn{2}{|l|}{ URR >65\% } & 27 \\
\hline \multirow[t]{3}{*}{$P(\mathrm{mg} / \mathrm{dl})$} & Hypophosphatemia: $<3.49$ & 7 \\
\hline & Target level: $3.5-5.5$ & 37 \\
\hline & Hyperphosphatemia: >5.5 & 57 \\
\hline \multicolumn{2}{|c|}{$\mathrm{Ca}(\mathrm{mg} / \mathrm{dl}) \times \mathrm{P}(\mathrm{mg} / \mathrm{dl})>55$} & 52 \\
\hline \multirow[t]{5}{*}{ PTH mg/dl category } & $<100$ & 11 \\
\hline & $100-300$ & 15 \\
\hline & $301-800$ & 35 \\
\hline & $801-1500$ & 27 \\
\hline & $>1500$ & 13 \\
\hline \multicolumn{2}{|c|}{ Prescribed phosphate binders by physician } & 89 \\
\hline
\end{tabular}

The overall dietary PDnA score was significantly higher $(p<0.05)$ in Group A $(26.0 \pm$ $0.94)$, indicating lower adherence, compared with groups $B(23.5 \pm 0.50)$ and $C(23.0 \pm$ $0.63)$. Also, mean serum $P$ level was significantly higher $(p<0.05)$ in Group A $6.54 \pm$ 
2.05), also indicating lower adherence, compared to the groups $B(5.53 \pm 1.53)$ and $C$ $(6.31 \pm 1.8$; Table 3$)$. There were no significant differences for the rest of the study parameters among the three study groups at baseline. When an ANOVA test was conducted to detect possible correlation among study parameters, age was the only one with a significant negative correlation with PK $(p<0.05)$.

Table 3. Baseline profile of the three groups (mean \pm SD)

\begin{tabular}{|c|c|c|c|}
\hline & $\begin{array}{c}\text { Intervention } \\
\text { group }(A) n=41\end{array}$ & $\begin{array}{l}\text { Partial intervention } \\
\text { group (B) } n=41\end{array}$ & $\begin{array}{c}\text { Control } \\
\text { group }(C) n=40\end{array}$ \\
\hline Age (years) & $50.36 \pm 2.84^{\mathrm{a}}$ & $58.89 \pm 2.99^{b}$ & $59.63 \pm 2.89^{b}$ \\
\hline Year on dialysis (years) & $5.50 \pm 0.93$ & $3.93 \pm 0.63$ & $5.54 \pm 1.32$ \\
\hline PK (\%) & $53 \pm 3$ & $51 \pm 3$ & $48 \pm 4$ \\
\hline BMI & $25.9 \pm 5.57$ & $27.0 \pm 5.32$ & $26.3 \pm 5.22$ \\
\hline $\mathrm{Ca}(\mathrm{mg} / \mathrm{dl})$ & $8.69 \pm 1.06^{a}$ & $9.31 \pm 1.52^{b}$ & $8.47 \pm 1.65^{\mathrm{a}}$ \\
\hline$P(\mathrm{mg} / \mathrm{dl})$ & $6.54 \pm 2.05^{a}$ & $5.53 \pm 1.53^{b}$ & $6.31 \pm 1.8^{b}$ \\
\hline Ca $\times \mathrm{P}$ product & $57.62 \pm 17.19$ & $51.95 \pm 14.30$ & $53.41 \pm 23.39$ \\
\hline URR (\%) & $71.82 \pm 12.8$ & $72.37 \pm 15.9$ & $71 \pm 14.01$ \\
\hline PDnA & $26.0 \pm 0.94^{a}$ & $23.5 \pm 0.50^{b}$ & $23.0 \pm 0.63^{b}$ \\
\hline Average elemental Ca intake & $1400 \pm 1202.4$ & $1046.5 \pm 888.9$ & $1126.6 \pm 951.92$ \\
\hline $\begin{array}{l}\% \text { of patients taking binder with meals as } \\
\text { prescribed by physician/study group* }\end{array}$ & $77 \pm 10$ & $89 \pm 17$ & $68 \pm 14$ \\
\hline $\begin{array}{l}\% \text { of patients taking binder with snack as } \\
\text { prescribed by physician/study group* }\end{array}$ & $89 \pm 15$ & $83 \pm 9$ & $86 \pm 19$ \\
\hline PTH & $558.45 \pm 380.21$ & $737.68 \pm 199.86$ & $576.82 \pm 386.09$ \\
\hline
\end{tabular}

\section{Post-Intervention Data}

Post-test analysis showed a significant improvement in serum P levels $(p=0.01)$ (Table $4)$, and PK scores $(p=0.02$ ) only in Group A (Table 5). A significant improvement was observed in serum $C a \times P$ product in both groups $A(p=0.006)$ and $B(p=0.01)$, but not in Group C (Table 4). A significant improvement was noted in the overall PDnA score within the Group A ( $p=0.01$ ) but not in Group C. Participants in Group B showed a significant decrease in only one aspect of the PDnA questionnaire: intake of high $P$ sweet items $(p=0.01)$; however, their overall score did not reach statistical significance (Table 6). There was no significant improvement in any of the groups regarding phosphate binder intake with meals and snacks. 
Table 4. Effect on osteodystrophy biochemical parameters (mean \pm SD)

\begin{tabular}{lccc}
\hline & $\begin{array}{c}\text { Intervention } \\
\text { group (A) } \mathbf{n}=\mathbf{3 7}\end{array}$ & $\begin{array}{c}\text { Partial intervention } \\
\text { group (B) } \mathbf{n = 2 6}\end{array}$ & $\begin{array}{c}\text { Control } \\
\text { group (C) } \mathbf{n}=\mathbf{2 4}\end{array}$ \\
\hline P (mg) - Pre & $6.55 \pm 1.89$ & $6.71 \pm 1.46$ & $6.16 \pm 1.34$ \\
P (mg) - Post & $5.39 \pm 1.97^{*}$ & $5.08 \pm 1.65$ & $6.51 \pm 1.36$ \\
Ca x P - Pre & $57.62 \pm 17.19$ & $51.95 \pm 14.30$ & $53.41 \pm 23.39$ \\
Ca x P - Post & $49.46 \pm 11.63^{*}$ & $44.75 \pm 15.56^{*}$ & $52.50 \pm 13.59$ \\
\hline
\end{tabular}

${ }^{*} p \leq 0.05$ shows significance based on repeated ANOVA test.

Table 5. Effect of SMDC intervention on scores of knowledge in dietary phosphorus content, phosphate binder therapy and CKD (mean \pm SD)

\begin{tabular}{lccc}
\hline & $\begin{array}{c}\text { Intervention } \\
\text { group (A) } \mathbf{n}=\mathbf{3 7}\end{array}$ & $\begin{array}{c}\text { Partial intervention } \\
\text { group (B) } \mathbf{n}=\mathbf{2 6}\end{array}$ & $\begin{array}{c}\text { Control } \\
\text { group (C) } \mathbf{n}=\mathbf{2 4}\end{array}$ \\
\hline Pre - Knowledge & $50 \pm 17^{*}$ & $48 \pm 13$ & $49 \pm 18$ \\
Post - Knowledge & $69 \pm 25^{*}$ & $57 \pm 29$ & $61 \pm 29$ \\
\hline
\end{tabular}

*Demonstrates significance between pre and post at $p \leq 0.05$ based on repeated ANOVA test.

Table 6. Effect of SMDC intervention on dietary non-adherence questionnaire score (mean \pm SD)

\begin{tabular}{lcccccc}
\hline & \multicolumn{2}{c}{$\begin{array}{c}\text { Intervention } \\
\text { group }(\mathbf{A}) \mathbf{n}=\mathbf{3 7}\end{array}$} & \multicolumn{2}{c}{$\begin{array}{c}\text { Partial intervention } \\
\text { group (B) } \mathbf{n = 2 6}\end{array}$} & \multicolumn{2}{c}{$\begin{array}{c}\text { Control } \\
\text { group (C) } \mathbf{n}=\mathbf{2 4}\end{array}$} \\
\hline Sweets high in P & $8.3 \pm 1.8$ & $6.8 \pm 1.0^{*}$ & $7.8 \pm 1.8$ & $6.9 \pm 1.5^{*}$ & $7.3 \pm 1.4$ & $7.4 \pm 1.4$ \\
Starch high in P & $4.8 \pm 2.0$ & $3.5 \pm 0.9^{*}$ & $4.4 \pm 1.3$ & $3.7 \pm 1.0$ & $4.0 \pm 1.4$ & $3.8 \pm 1.2$ \\
Dairy high in P & $5.4 \pm 1.1$ & $5.5 \pm 0.8$ & $5.4 \pm 1.1$ & $5.7 \pm 0.8$ & $5.5 \pm 0.9$ & $5.9 \pm 1.0$ \\
Total score & $21.4 \pm 4.0$ & $18.3 \pm 2.0^{*}$ & $20.4 \pm 3.8$ & $18.9 \pm 2.7$ & $19.5 \pm 2.6$ & $19.8 \pm 3.0$ \\
\hline
\end{tabular}

${ }^{*} p \leq 0.01$ shows significance based on repeated ANOVA test.

\section{DISCUSSION}

This study was the first in Lebanon to examine the effect of a two-month nutritional education on serum $\mathrm{P}$ control in a sample of HD population. It showed that serum $\mathrm{P}$ level, as well as PDnA significantly improved only in Group A. Similar results were reported in studies utilising similar counselling approaches, and improvement in patient adherence was correlated to a diet restricted in $\mathrm{P}$ (Bodenheimer et al., 2002; de Brito Ashurst \& Dobbie, 2003; Cupisti et al., 2004; Ford et al., 2004; Tsay et al., 2005).

The SMDC approach encompasses a series of individualised educational sessions that aim at increasing patient involvement in their decision-making process to facilitate adherence to recommended therapy (Harum et al., 2003). 
Participants in Group A were provided with a list of culturally appropriate Lebanese low $P$ food items, a grocery shopping list, a list of healthier food selections when eating out to maximise the selection of low $P$ food items.

A positive rapport between the patients and the research dietitian was developed throughout the counselling process. That helped the participants share their concerns and needs, which might have contributed to the observed improvement in their PDnA scores.

We were able to show that dietitian involvement with patient care and the integration of innovative and positive patient-tailored counselling can have a positive outcome on serum $\mathrm{P}$, adherence to $\mathrm{P}$ control and PK scores. Similar studies that focused on SMFC and/or increased patient to dietitian interaction also reported similar results (Parmenter et al., 2000; de Brito Ashurst \& Dobbie, 2003; Cupisti et al., 2004; Ford et al., 2004; Tsay et al., 2005; Morey et al., 2008).

Demographic characteristics, such as age, gender and literacy levels have been controversially reported to affect PK (Wiser et al., 1997; Nissenson et al,. 2003; Poduval et al., 2003). In this study, no significant correlation was observed among any of the above listed variables. That might have been affected by the renal nutrition educational background of our patients who might have received a minimal renal nutritional education prior to the study. Parmenter et al. (2000) reported that if people of all backgrounds were given equal chances to information they would have reached the same results irrelevant of their educational background or gender. At the time of the study, Lebanon lacked dietitians trained in the renal field, since no specialty training for dietitians existed in universities or as part of an internship training. Additionally, dialysis clinics in Lebanon lack adequate dietetic coverage because the hospital dietitians (often only one is hired per hospital) cover the HD unit only based on nephrologists' consultation.

Patients in Group A showed a significant decrease in high P sweets $(p<0.01)$ and high $P$ starch $(p<0.01)$ intake. The decrease in high $P$ starch intake was due to a significant shift from eating whole-wheat starch (high in P) to processed ones (low in P). Group B reported a significant improvement in

adherence with high $\mathrm{P}$ sweet intake. It seems that even a simple interaction (game cards) had made a significant difference in adherence to low P sweet intake. Morey et al. (2008) reported that frequent interactions with the dietitian (once every month) lead to improved serum $P$ level.

No significant change was observed in the consumption of dairy products in any of the groups. In Lebanon, dairy products are considered one of the main items in the daily dietary intake. Patients' nephrologists reported that they encouraged their patients to consume dairy products as an affordable source of protein.

Literature has shown that patients on HD often have difficulty adhering to prescribed medication regimens due to increased prescriptions and related gastrointestinal side effects (Tonelli et al., 2010). At baseline, patients in our study took P binders spo- 
radically and inconsistently throughout the day. Patients sometimes reported they had mistakenly thought of them as recommended Ca supplements. After giving comprehensive and individualised education, we did not observe a significant improvement in phosphate binder intake with any of the groups. Elwyn et al. (2003) reported that patient adherence is strongly determined by personal beliefs and attitudes; therefore, therapy should be based on a mutual agreement between the healthcare professional and the patient.

\section{Limitations of The Study}

The study used a convenience sample of patients recruited from one dialysis centre in Lebanon; therefore, it may not represent the overall Lebanese HD population. Participants were randomised (based on dialysis shifts), which may have introduced group variations in our study. Moreover, the study used questionnaires, which are known to be subjective methods of assessment. The study was originally designed to be a threemonth prospective nutritional intervention, followed by a three- and six-month followup assessment to assess retention of PK and adherence, as well as control of MBD parameters. The planned timeline of the study was cut short and the follow-up period was cancelled due to the sudden war condition that broke out in the South of Lebanon at the time of the study, during summer 2006.

We recommend a three-month post-study follow-up to assess retention of PK provided to them. Morey et al. (2008) reported that the observed significant improvement in serum $P$ during the first three months of their nutritional intervention study was not retained at six months (Morey et al., 2008). We also recommend the development of a culturally appropriate renal nutrition education packet. We hope that future and larger studies focusing on this research area would eventually help in developing protocols to include dietitians in the dialysis centres in countries that lack such essential coverage. Renal dietitian involvement would be an essential component that aids in controlling patient MBD parameters, improving patient quality of life and decreasing cost related to morbidity and mortality.

\section{Implications for Practice}

Lebanon lacks the academic system to produce specialised dietitians, including renal dietitians. Moreover, the Lebanese accreditation standards for hospitals do not pose the need of employing dietitians solely for HD units. Epping-Jordan et al. (2004) stated that supporting resources and policies are needed in HD centres for staff to regularly apply SMDC. Our study may pave the way for large-scale studies to develop the cornerstones for possible improvement in all the abovementioned loopholes of the Lebanese system, and thus aim to improve patient clinical outcomes. 


\section{CONCLUSION}

Lack of adherence with one or more aspects of the dialysis treatment is a major health concern that can lead to increased risk of mortality and morbidity, and decreased patient quality of life. Dietitians can play an important role in the dialysis centres, especially when they are certified and/or licensed by an accredited programme that trains dietitians on providing patients with appropriate medical nutrition therapy and empowering them to participate in health-related decision making processes (EppingJordan et al., 2004). 


\section{REFERENCES}

Afifi, A., El-Sayed, H., El-Setouhi, M., Ahmed, H. and Khalifa, N. (2005). Hyperphosphatemia among end-stage renal disease patients in developing countries: A forgotten issue? Hemodialysis International, 9(4), 409415.

Bame, S., Petersen, N. and Wray, N.P. (1993). Variation in hemodialysis patient compliance according to demographic characteristics. Social Sciences \& Medicine, 37(8), 1035-1043.

Block, G.A., Hulbert-Shearon, T.E., Levin, N.W. and Port, F.K. (1998). Association of serum P and calcium $x$ phosphate product with mortality risk in chronic hemodialysis patients: a national study. American Journal of Kidney Diseases, 31(4), 607-617.

Bodenheimer, T., Lorig, K., Holman, H., and Grumbach, K. (2002). Patient self-management of chronic disease in primary care. Journal of the American Medical Association, 288(19), 2469-2475.

Breiterman, W.R. (2004). Adherence to the dialysis prescription: partnering with patients for improved outcomes. Nephrology Nursing Journal: Journal of the American Nephrology Nurses' Association, 31(4), 432436.

Chiu, Y.W., Teitelbaum, I., Misra, M., de Leon, E.M., Adzize, T., and Mehrotra, R. (2009). Pill Burden, Adherence, Hyperphosphatemia, and Quality of Life in Maintenance Dialysis Patients. Clinical Journal of the American Society of Nephrology, 4(6), 1089-1096.

Cupisti, A., D'Alessandro, C., Baldi, R., and Barsotti, G. (2004). Dietary habits and counseling focused on phosphate intake of hemodialysis patients with hyperphosphatemia. Journal of Renal Nutrition, 14(4), 220225.

de Brito Ashurst, I. and Dobbie, H. (2003). A randomized controlled trial of an educational intervention to improve phosphate levels in hemodialysis patients. Journal of Renal Nutrition, 13(4), 267-274.

Durose, C.L., Holdsworth, M., Watson, V. and Przygrodzka, F. (2004). Knowledge of dietary restrictions and the medical consequences of noncompliance by patients on hemodialysis are not predictive of dietary compliance. Journal of the American Dietetic Association, 104(1), 35-41.

Elwyn, G., Edwards, A. and Britten, N. (2003). "Doing prescribing": how might clinicians work differently for better, safer care. Quality and Safety in Health Care, 12(suppl 1), i33-i36.

Epping-Jordan, J.E., Pruitt, S.D., Bengoa, R. and Wagner, E.H. (2004). Improving the quality of health care for chronic conditions. Quality \& Safety in Health Care, 13(4), 299-305.

Ford, J.C., Pope, J.F., Hunt, A.E. and Gerald, B. (2004). The effect of diet education on the laboratory values and knowledge of hemodialysis patients with hyperphosphatemia. Journal of Renal Nutrition, 14(1), 3644.

Gandek, B. and Ware Jr, J.E. (1998). Methods for validating and norming translations of health status questionnaires: the IQOLA project approach. Journal of Clinical Epidemiology, 51(11), 953-959.

Ghaddar, S., Shamseddeen, W. and Elzein, H. (2009). Behavioral modeling to guide adherence to fluid control in hemodialysis patients. Journal of Renal Nutrition, 19(2), 153-160.

Griva, K., Mooppil, N., Seet, P., Krishnan, D.S., James, H. and Newman, S.P. (2011). The NKF-NUS hemodialysis trial protocol- a randomized controlled trial to determine the effectiveness of a self management intervention for hemodialysis patients. BMC Nephrology, 12(1), 4.

Harum, P., Galves, O., Mayol, L. and Blanchard, R. (2003). Immediate and delayed memory recall patterns of chronic hemodialysis adult Hispanic patients. Journal of Renal Nutrition,13(2), 98-104.

Hoelscher, D.M., Day, R.S., Kelder, S.H. and Ward, J.L. (2003). Reproducibility and validity of the secondary level School-Based Nutrition Monitoring student questionnaire. Journal of the American Dietetic Association, 103(2), 186-194.

Jaoude, D.A., Olabi, A., Najm, N.E.O., Malek, A., Saadeh, C., Baydoun, E. and Toufeili, I. (2010). Chemical composition, mineral content and cholesterol levels of some regular and reduced-fat white brined cheeses and strained yogurt (Labneh). Dairy Sciences \& Technology, 90(6), 699-706.

Karamanidou, C., Clatworthy, J., Weinman, J., and Horne, R. (2008). A systematic review of the prevalence and determinants of nonadherence to phosphate binding medication in patients with end-stage renal disease. BMC Nephrology, 9(1), 2 
Lebanese Ministry of Public Health. (2005), "Office of the Minister of State for Administrative Reform", available at: http://cms1.omsar.gov.lb/en/ (accessed 19 January, 2006).

Lee, S.H. and Molassiotis, A. (2002). Dietary and fluid compliance in Chinese hemodialysis patients. International Journal of Nursing Studies, 39(7), 695-704.

Locatelli, F., Cannata-Andia, J.B., Drueke, T.B., Horl, W.H., Fouque, D., Heimburger, O. and Ritz, E. (2002). Management of disturbances of calcium and phosphate metabolism in chronic renal insufficiency, with emphasis on the control of hyperphosphataemia. Nephrology Dialysis Transplantation, 17(5), 723-731.

Matteson, M.L. and Russell, C. (2010). Interventions to improve hemodialysis adherence: a systematic review of randomized-controlled trials. Hemodialysis International, 14(4), 370-382.

Morey, B., Walker, R. and Davenport, A. (2008). More dietetic time, better outcome? A randomized prospective study investigating the effect of more dietetic time on phosphate control in end-stage kidney failure haemodialysis patients. Nephron Clinical Practice, 109(3), c173-c180.

Nissenson, A.R., Berns, J.S., Sakiewicz, P., Ghaddar, S., Moore, G.M., Schleicher, R.B. and Seligman, P.A. (2003). Clinical evaluation of heme iron polypeptide: sustaining a response to rHuEPO in hemodialysis patients. American Journal of Kidney Diseases, 42(2), 325-330.

Parmenter, K., Wardle, J.K. and Waller, J. (2000). Demographic variation in nutrition knowledge in England. Health Education Research, 15(2), 163-174.

Poduval, R., Wolgemuth, C., Ferrell, J. and Hammes, M.S. (2003). Hyperphosphatemia in dialysis patients: Is there a role for focused counseling? Journal of Renal Nutrition, 13(3), 219-223.

Richard, C.J. (2006). Self-Care Management in adults undergoing hemodialysis. Nephrology Nursing Journal: Journal of the American Nephrology Nurses' Association, 33(4), 387-394.

Sabbah, I., Drouby, N., Sabbah, S., Retel-Rude, N. and Mercier, M. (2003). Quality of Life in rural and urban populations in Lebanon using SF-36 health survey. Health and Quality of Life Outcomes, 1(1), 30.

Thomas, L.K., Sargent, R.G., Michels, P.C., Richter, D.L., Valois, R.F. and Moore, C.G. (2001). Identification of the factors associated with compliance to therapeutic diets in older adults with end stage renal disease. Journal of Renal Nutrition, 11(2), 80-89.

Tonelli, M., Pannu, N. and Manns, B. (2010). Oral phosphate binders in patients with kidney failure. New England Journal of Medicine, 362(14), 1312-1324.

Tsay, S.L., Yuh-Chain, L., Yueh-Ching, L. (2005). Effects of an adaptation training program for patients with end-stage renal disease. Journal of Advanced Nursing, 50(1), 39-46.

Wiser, N.A., Shame, J.M., McGuigan, A.T. Memken, J.A. and Olsson, P.J. (1997). The effect of a group nutrition education program on nutrition knowledge, nutrition status and quality of life in hemodialysis patients. Journal of Renal Nutrition, 7(4), 187-193.

Zrinyi, M., Juhasz, M., Balla, J., Katona, E., Ben, T., Kakuk, G., and Pall, D. (2003). Dietary self-efficacy: determinant of compliance behaviors and biochemical outcomes in hemodialysis patients. Nephrology Dialysis Transplantation, 18(9), 1869-1873. 


\section{CHAPTER 3}

\section{Dietetic Practices in Hemodialysis Units in Lebanon and Their Conformity with KDOQI Nutrition Guidelines}

Karavetian, M., Elzein, H., Hwalla, N., de Vries, N. (2013). Dietetic Practices in Hemodialysis Units in Lebanon and Their Conformity with KDOQI Nutrition Guidelines.

International Journal of Health \& Nutrition, 4(2): 1-8 


\section{ABSTRACT}

In Lebanon, HD units are exclusively hospital based, and most hospitals have only one dietitian performing all nutrition related activities in the hospital. This study investigated current dietetic practices and their conformity with Kidney Disease Quality Outcomes Initiative (KDOQI) nutrition guidelines in HD units, Lebanon. National crosssectional survey, using an anonymous 36 item, self-administered questionnaire, collected from all dietary departments of hospital based HD units in Lebanon ( $n=55)$. The questionnaire included: 1) demographics and professional characteristics; 2 ) knowledge of KDOQI nutrition guidelines; 3 ) level of implementation of KDOQI guidelines in assessing and estimating nutritional needs. Descriptive statistics was used. The response rate was $71 \%, 97 \%$ were female, $82 \%$ were within the age of $21-34,67 \%$ were full timers in the hospitals and $85 \%$ worked $\leq 10$ hours per week in HD units. Minimum educational level was Bachelor of Science yet none had a specialty. Almost $50 \%$ had $<$ five years experience in general clinical or renal practice setting. Half of the dietitians worked in hospitals where their clinical workload ranged from 100 to 200 patients, including HD patients. Overall, dietitian knowledge of KDOQI nutrition guidelines was $35.45 \% \pm 16.9 \%$. Most dietitians (97\%) implemented at least 1 guideline, and only $5 \%$ applied all guidelines. The study identified a low conformity with KDOQI guidelines among dietitians managing HD patients in Lebanon. HD units in Lebanon can possibly improve their patients' outcomes by providing dietitians with sufficient time, knowledge, empowerment and training based on the KDOQI nutrition guidelines. 


\section{INTRODUCTION}

Chronic kidney disease (CKD) has emerged as a public health problem worldwide. In Lebanon, a continued increase in the prevalence of hemodialysis (HD) patients among the Lebanese population has been observed by the National Kidney Registry (www.kidneyregistrylb.com). Preliminary unpublished registry data of March 2012 indicate the presence of over $3000 \mathrm{HD}$ patients in 60 hospital based dialysis centers in Lebanon, compared to an estimated 2600 cases in 55 centers in 2010 (Mallat et al., 2011). Renal dietitians are essential specialized members of the healthcare team, responsible for providing adequate nutrition care process and monitoring of HD patients (Thelen et al., 2009). Full implementation of evidence based guidelines (EBG) for CKD by dietitians and adequate dietitian- to- CKD patient time has shown to effectively decrease patient hospitalization, mortality and thus health care cost (Wolfe, 2012; Campbell et al., 2009). Two hours per month was identified as the adequate dietitian-to- CKD patient time (EAL, 2010). Barriers to full implementation of EBG for CKD have been recognized to be mainly: lack of specialized dietitians in renal care (Beto \& Bansal, 2004), lack of time and lack of the support system by the health care organizations (Wolfe, 2012). As a result, dietitians of various backgrounds are filling the increasing need for specialized nutrition professionals in HD centers.

Renal dietitians utilize a number of professionally recognized resources to assess and provide care to HD patients (Vergili \& Wolf, 2010). The most professionally recognized guideline is the Kidney Disease Quality Outcomes Initiative (KDOQI), developed by the National Kidney Foundation (NKF-KDOQI; 2000). However, Thelen et al. (2009) stated that the implementation of these guidelines by renal dietitians has been proven to be difficult, due to the unclear scope of practice for renal dietitians, the insufficient education and training given and the lack of clear standards of practice to follow.

The extent of implementation of EBG-s in dietetic care of HD patients is not clear worldwide. A 2001 survey of renal dietitians in the US found significant nationwide variability in the reference norms used for laboratory values and medications prescribed in the management of hyperphosphatemia among HD patients in addition to variations in patient education patterns which was related to dietitian workload (Martin \& Reams, 2003). Another nationwide survey in the US described dietitians' practices in terms of KDOQI nutritional guidelines and indicated that only $5 \%$ implemented all of the guidelines (Burrowes et al., 2005). Vergili \& Wolf (2010) queried 688 dietitians regarding a broad range of nutrition practices, such as energy requirements, metabolic parameters among others for management of patients on maintenance HD therapy. They found that the dietitians follow different standards of practice and few implement KDOQI.

HD units in Lebanon are exclusively hospital based. Hospitals employ all-purpose dietitian(s) to conduct food service, administrative, internship and clinical tasks including the care of HD unit patients. No data in the literature exists on the dietetic practices 
provided by dietitians in these hospital based HD units. This study, through a cross sectional nationwide survey, aimed to explore the knowledge of dietitians responsible for managing HD patients in Lebanon and to assess the conformity of their practice with KDOQI nutrition guidelines ( NKF-KDQOI, 2000), the "Practice-to-EBG gap".

\section{MATERIALS AND METHODS}

\section{Study Design}

National cross-sectional survey on dietary departments in hospitals, using an anonymous self-administered questionnaire.

\section{Setting:}

All hospital based HD units $(n=55)$ in Lebanon as per the 2010 MOPH database.

\section{Survey Design and Analysis:}

A validated 36 item questionnaire was adapted from Vergili \& Wolf (2010) and modified with minor changes for cultural specificity. The questionnaire was not translated, since all dietitians in Lebanon can read and write in English. The draft of the modified questionnaire was evaluated by the author before finalization. The draft was piloted on three Lebanese dietitians involved with HD patients' dietary care. Feedback from the pilot was incorporated to produce the final working version.

The questionnaire included three sections to assess: 1) dietitians' demographics and professional characteristics (gender, age, years of clinical experience, years of renal dietetic experience, patient load, number of hours at work, credentials, etc); 2) knowledge and compliance to KDOQI nutrition and diabetes guidelines during routine practice (body weight for nutrient calculation, fluid need, sodium, phosphorus, potassium restrictions, energy needs, glucose, bicarbonate and vitamin supplementations) where the possible answers choices were listed; and 3) compliance to using patient parameters used for dietary assessment of HD patients conforming to KDOQI nutrition guidelines at every relevant occasion, whether it was the first time or a follow up.

All questions were closed-ended with multiple categories where answers were either at nominal or interval level. To identify strength and weaknesses among the Lebanese dietetic practices in HD units the following computations were done : 1) Knowledge of the nutritional guidelines was measured by the following formula: [(total score of each dietitian on knowledge questions * 100)/ total score of correct answers]; where each question was given a 1 or 0 score indicating correct or wrong answers respectively. The average overall knowledge score was computed and $60 \%$ cut-off point 
was used to define success (this cut off point was inspired from academia where it's used to indicate the minimum score for success. 2) The percentage of guidelines implemented by each dietitian was calculated. 3) The percentage of dietitians implementing each guideline was computed (\% of Implementation); relevant guidelines were grouped into subgroups and a subgroup score was calculated from the average score of its components (e.g., all guidelines related to management of kalemia were grouped into the "Potassium" subgroup), and finally the scores of subgroups were arranged in a descending order. This calculation was also conducted for KDOQI nutritional assessment parameters.

\section{Implementation of Survey:}

Due to lack of a registry for dietitians in Lebanon, the Ministry of Public Health (MOPH) oversaw the distribution of the survey to the head nephrologist of each HD unit $(n=55)$ for data collection. Two letters accompanied the survey. The first letter was directed to the nephrologist asking to refer the survey to the dietitian and send it back to the MOPH within a month of receiving it. The second letter was directed to the dietitian explaining the study and requesting that the survey be completed by the dietitian responsible for the MNT of HD patients. If the hospital dietitian was not responsible for the HD patients, they were asked to return the questionnaire with a "not responsible" note. The survey was anonymous for dietitians' names but the hospital's name was evident. Hospitals that failed to respond within the specified time frame, received the survey for a second time, but this time it was sent directly to the dietary department in the hospital. After completion of each questionnaire, a certificate of participation to the study was provided to the dietitians by the MOPH. The whole process of sending and receiving the survey took place between January 2011 and March 2012. Due to lack of a central ethical board, each participating hospital approved through their institutional review board (IRB).

\section{Statistical Analysis:}

All statistical analyses were conducted using the Statistical Package for the Social Sciences (SPSS) (version 16.0.2, 2008, IBM inc., Armonk, New York, United States). Descriptive analysis was conducted, categorical data were reported as frequencies and percentage counts; continuous data as means \pm standard deviation.

\section{RESULTS}

Fifty five dietitians were contacted, 43 (78\%) responded, four (7\%) of whom stated "not responsible for HD patients". Final sample size consisted of 39 dietitians (71\%). 
Description of sample: All respondents were female with the exception of one male, $82 \%$ were within the age of $21-34$ years, $60 \%$ worked in hospitals outside metropolitan Beirut, $67 \%$ were full timers ( $\geq 36$ hours/week) and only $7 \%$ were trained in a dietetic specialty. None of the dietitians was certified for renal nutrition, since such a program and certificate does not exist in the country. The minimum educational level of all dietitians was bachelor in science and license to practice (Licensed dietitian - LD) as per national standards. The vast majority $(80 \%)$ of the dietitians reported to have prepared their patient educational material either alone or with a multidisciplinary team. Almost half had worked in their current job for a maximum of two years, had up to only five years experience in clinical practice and up to two years in renal practice. Almost half of the dietitians worked in institutions where their clinical workload covered $50-100$ inpatients and between 50 - 100 HD patients (Table 1). The majority (85\%) worked 10 hours or less per week in the HD unit. The rest of the working hours were distributed over administrative and food service tasks in addition to counseling other inpatients and outpatients (Table 2).

Table 1. Study Dietitian Characteristics from Various HD units in Lebanon

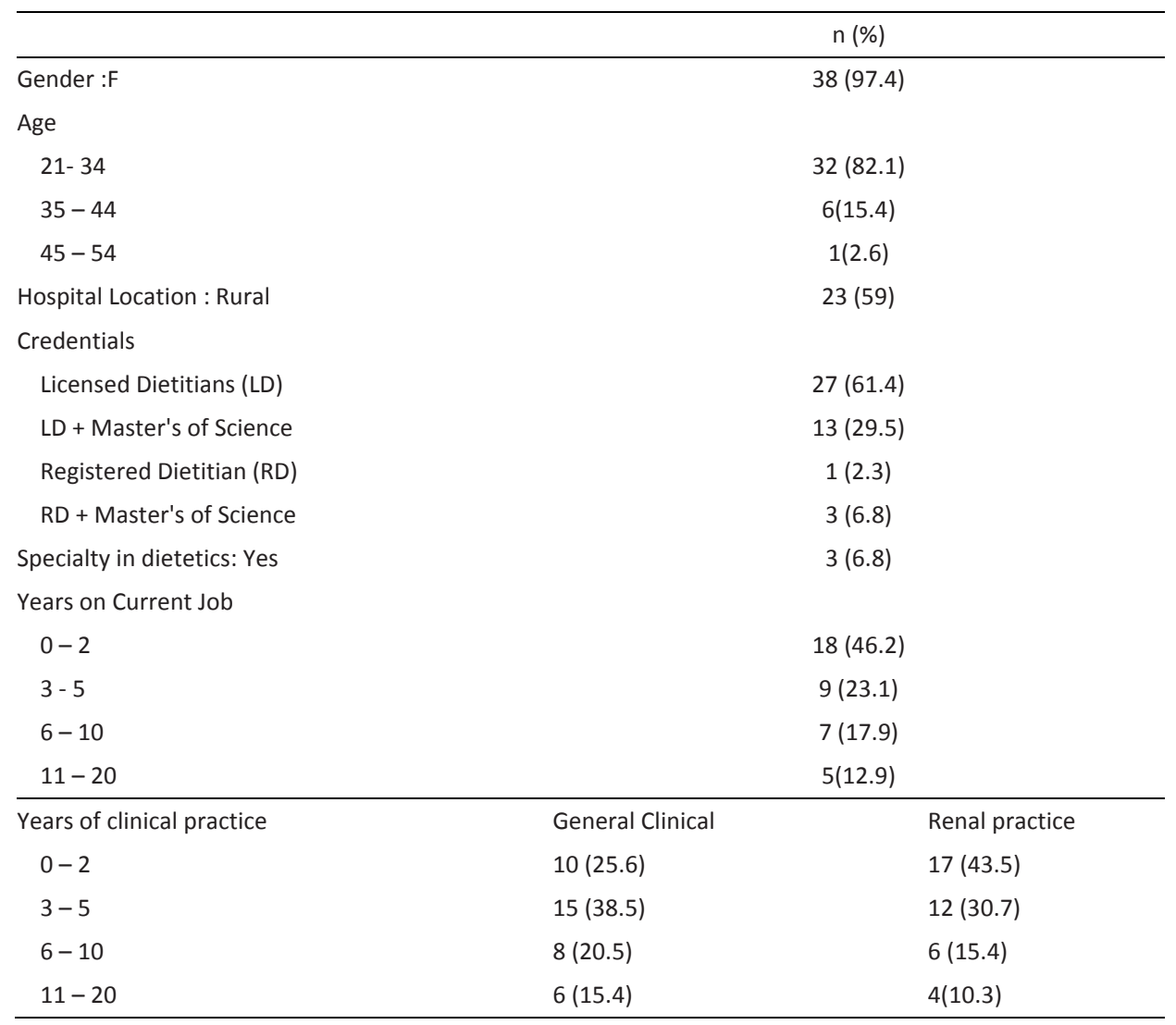




\begin{tabular}{llc}
\hline Dietitians-to-patient load as per capacity & In-patient & HD unit \\
$1:<50$ & $4(10.8)$ & $20(52.6)$ \\
$1: 51-100$ & $15(40.6)$ & $15(39.5)$ \\
$1: 101-149$ & $9(24.3)$ & $1(2.6)$ \\
$1: 150$ and more & $9(24.3)$ & $2(5.3)$ \\
\hline & & $n(\%)$ \\
\hline Working hours by Hospital Dietitians & $5(12.8)$ \\
$11-20 \approx 1 / 2$ FTE & $8(20)$ \\
$21-35 \approx 3 / 4$ FTE & $26(66.7)$ \\
$\geq 36-42=1$ FTE & \\
Source of patient education material used & $4(10.3)$ \\
International association & $32(79.2)$ \\
Dietitian prepared it with colleagues & $3(7.6)$ \\
No tool & \\
\hline
\end{tabular}

FTE: full time equivalent

Table 2. Workload: Distribution of Dietitians by number of hours spent per task

\begin{tabular}{lccccccc}
\hline $\begin{array}{l}\text { Hours spent } \\
\text { /week }\end{array}$ & $\begin{array}{c}\text { Clinical } \\
\text { Wards }\end{array}$ & HD Unit & $\begin{array}{c}\text { Administrative } \\
\text { tasks }\end{array}$ & $\begin{array}{c}\text { Food } \\
\text { service }\end{array}$ & $\begin{array}{c}\text { Community } \\
\text { nutrition }\end{array}$ & $\begin{array}{c}\text { Out -patient } \\
\text { Clinic }\end{array}$ & Research \\
\hline & $\mathrm{n}(\%)$ & $\mathrm{n}(\%)$ & $\mathrm{n}(\%)$ & $\mathrm{n}(\%)$ & $\mathrm{n}(\%)$ & $\mathrm{n}(\%)$ & $\mathrm{n}(\%)$ \\
$1-10$ & $3(8)$ & $33(85)$ & $19(50)$ & $18(46)$ & $7(18)$ & $17(44)$ & $7(18)$ \\
$11-20$ & $3(8)$ & $5(12)$ & $11(28)$ & $13(33)$ & $3(8)$ & $6(15)$ & $1(3)$ \\
$21-35$ & - & $1(3)$ & $9(22)$ & $3(8)$ & - & - & - \\
$>35$ & - & - & - & $1(3)$ & - & - & - \\
\hline
\end{tabular}

Sum of percentages may be less than $100 \%$, there are tasks that some dietitians don't practice at all and the list may not be exhaustive.

\section{Description of Nutrition Practices}

Overall dietitian knowledge score showed a mean of $35.45 \% \pm 16$. Figure 1, shows that $97 \%$ of study participants implemented at least one KDOQI guideline for estimating nutritional needs in routine practice, 64\%, 36\% and 23\% used five, 10 and 15 guidelines respectively, and $5 \%$ applied all guidelines. Barriers identified were lack of time and lack of integration into the medical team. 
Figure 1: Percentage of KDOQI guidelines for nutrition need estimation implemented by dietitians in HD units in Lebanon

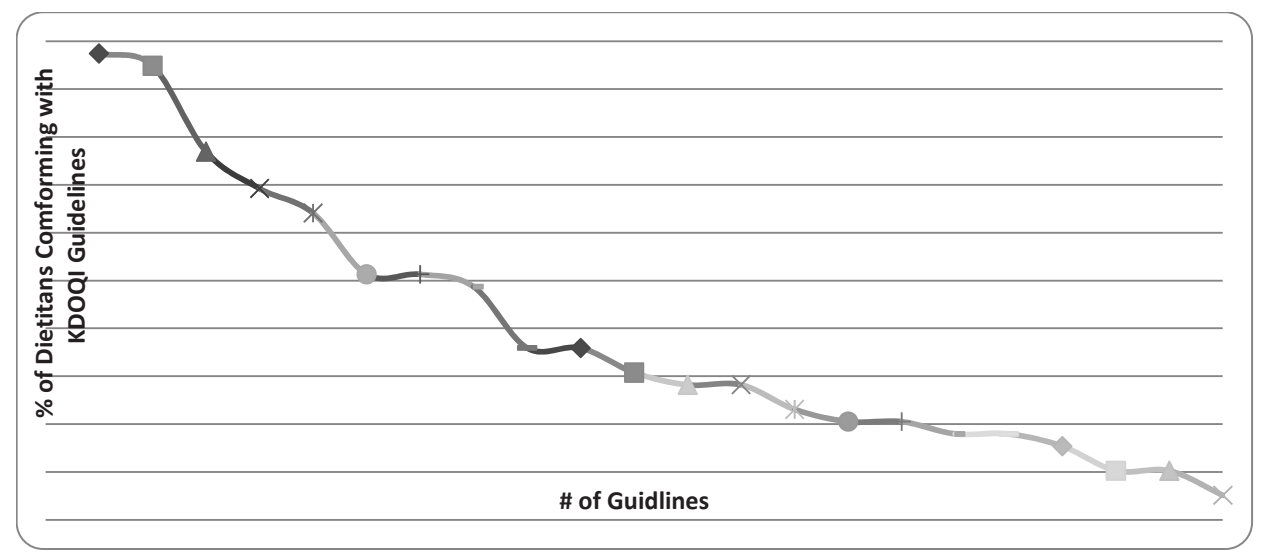

Percent implementation of KDOQI guidelines for estimating patient nutritional needs showed (Table 3) that implementation of potassium related guidelines was the highest $(59 \%)$ and acid base balance management in routine practice was the lowest (10\%).

Moreover, the \% implementation of KDOQI patient assessment parameters showed (Table 4 ) that creatinin and potassium were used by most dietitians $(82 \%)$ in routine HD patient assessment and CRP was used the least (21\%).

Reasons why certain blood tests were not taken into consideration during assessment (not shown in this paper), were reported to be either lack of availability of blood tests on routine basis or the limited access of dietitians to these blood tests or lack of time. 
Table 3. Percentage Implementation of KDOQI Guidelines for Assessment of Nutritional Needs of HD Patients among Dietitians in Lebanon.

\begin{tabular}{|c|c|c|c|}
\hline Item & Subgroups of Guidelines & $\begin{array}{c}\mathrm{n}(\%) \\
\text { Implementers } \\
\text { of each } \\
\text { guideline }\end{array}$ & $\begin{array}{c}\mathrm{n}(\%) \\
\text { Implementers } \\
\text { of each } \\
\text { group }\end{array}$ \\
\hline \multirow{2}{*}{$\begin{array}{l}\text { Potassium } \\
\text { (K) }\end{array}$} & Upper limit of K (5.5 meq/L) & $27(69)$ & $23(59)$ \\
\hline & $\begin{array}{l}\mathrm{K} \text { daily needs for HD patients }(30-50 \mathrm{mg} / \mathrm{kg} \text { of } \mathrm{SBW} / \mathrm{d} \text { or } 2- \\
3 \mathrm{~g} / \mathrm{d})\end{array}$ & $19(48)$ & \\
\hline \multirow{3}{*}{$\begin{array}{l}\text { Phosphorus } \\
\text { (P) }\end{array}$} & Upper limit of $P(5.5 \mathrm{mg} / \mathrm{dl})$ & $20(51)$ & $18(45)$ \\
\hline & Upper limit of Ca*P byproduct ( $55 \mathrm{mg} / \mathrm{dl})$ & $19(49)$ & \\
\hline & $\begin{array}{l}\text { Dietary } \mathrm{P} \text { daily needs: } \\
<17 \mathrm{mg} / \mathrm{d} \text { or } 800-1000 \mathrm{mg} / \mathrm{d} \\
\mathrm{P} / \text { protein ratio } 10-12\end{array}$ & $11(28)$ & \\
\hline \multirow[t]{3}{*}{ Energy $(E)$} & E for normal weight $(30-35 \mathrm{kcal} / \mathrm{kg} / \mathrm{d})$ & $20(51)$ & $15(38)$ \\
\hline & E for underweight $(40-45 \mathrm{kcal} / \mathrm{kg} / \mathrm{d})$ & $14(36)$ & \\
\hline & E for overweight $(20-25 \mathrm{kcal} / \mathrm{kg} / \mathrm{d})$ & $11(28)$ & \\
\hline \multirow{9}{*}{$\begin{array}{l}\text { Weight used } \\
\text { for nutrient } \\
\text { calculations }\end{array}$} & aBWef used for protein calculation for overweight (Yes) & $30(77)$ & $11(28)$ \\
\hline & $\begin{array}{l}\text { Degree of overweight the patient should be so to use } \\
\text { aBWef (>115\% of IBW or SBW) }\end{array}$ & $12(31)$ & \\
\hline & $\begin{array}{l}\text { Formula to use for aBWef for the underweight (KQODI } \\
\text { formula) }\end{array}$ & $11(28)$ & \\
\hline & $\begin{array}{l}\text { Formula to use for aBWef for the overweight (KQODI } \\
\text { formula) }\end{array}$ & $10(26)$ & \\
\hline & Weight to use for under-weight if not aBWef (IBW or SBW) & $9(23)$ & \\
\hline & $\begin{array}{l}\text { Degree of underweight the patient should be so to use } \\
\text { aBWef }(<95 \% \text { of IBW or SBW) }\end{array}$ & $8(21)$ & \\
\hline & Formula for edema free Weight (sodium equation) & $8(21)$ & \\
\hline & Determine healthy (IBW or SBW) & $6(15)$ & \\
\hline & $\begin{array}{l}\text { Weight to use for over-weight HD patients if not aBWef } \\
\text { (IBW / SBW) }\end{array}$ & $4(10)$ & \\
\hline \multirow[t]{2}{*}{ Diabetes } & Random Blood Glucose target (< or equal 180mg/dl) & $7(18)$ & $11(27)$ \\
\hline & Goal $\%$ of $\mathrm{Hba} 1 \mathrm{C}$ (< or equal to $6.5 \%)$ & $14(36)$ & \\
\hline \multirow[t]{2}{*}{ Fluid } & Inter-dialytic weight gain (up to $4 \%$ of dry weight) & $7(18)$ & $5(12)$ \\
\hline & Fluid recommendation (1000ml + urine output) & $2(5)$ & \\
\hline Acid Base & Goal of bicarbonate (> or equal to $22 \mathrm{meq} / \mathrm{L}$ ) & $4(10)$ & $4(10)$ \\
\hline
\end{tabular}

KDOQI formula: aBWef (edema-free adjusted body weight) = edema free BW + [(SBW - edema BW) x 0.25] Sodium Formula: $142 \mathrm{mEq} / \mathrm{L}$ * Normal Total Body Water (L)/ Pre Dialysis Serum sodium (mEq/L) HbA1c: glycated haemoglobin, IBW: ideal body weight, SBW: Standard Body Weight, d:day 
Table 4. Percentage Implementation of KDOQI guidelines of Assessing HD patients in Routine Dietetic Practices

\begin{tabular}{|c|c|c|c|}
\hline & & $\%(n)$ Implementers & $\%$ (n) Implementers of each \\
\hline Creatinin & $\mathrm{Cr}$ & $32(82)$ & $32(82)$ \\
\hline Potassium & $\mathrm{K}$ & $32(82)$ & $32(82)$ \\
\hline Dyslipidemia & Lipid profile & $31(79)$ & 31 (79) \\
\hline \multirow[t]{3}{*}{ Fluid } & Sodium (Na) & $30(77)$ & $24(62)$ \\
\hline & Fluid & $23(59)$ & \\
\hline & Interdialytic Weight Gain (IDWG) & $20(51)$ & \\
\hline Diabetes & $\mathrm{HbA1c}$ & $24(62)$ & $24(62)$ \\
\hline \multirow[t]{5}{*}{ Nutritional Status } & Body Mass Index (BMI) & $28(72)$ & $20(50)$ \\
\hline & Albumin (Alb) & $27(69)$ & \\
\hline & Malnutrition & $22(56)$ & \\
\hline & Subjective Global Assessment (SGA)† & $13(33)$ & \\
\hline & Pre-albumin & $8(21)$ & \\
\hline Quality of Life & Quality of Life (QOL) & $19(49)$ & $19(49)$ \\
\hline \multirow[t]{4}{*}{ Osteodystrophy } & Phosphorus & $25(64)$ & $14(37)$ \\
\hline & Vitamin D (Vit D) & $12(31)$ & \\
\hline & Phosphate Binders & $11(28)$ & \\
\hline & Parathyroid Hormone (PTH) & $9(23)$ & \\
\hline Anemia & Iron (Fe) & $15(38)$ & $15(38)$ \\
\hline Acid Base & Bicarbonate & $14(36)$ & $14(36)$ \\
\hline Inflammation & C-Reactive Protein (CRP) & $8(21)$ & $8(21)$ \\
\hline
\end{tabular}

+SGA: malnutrition assessment tool with subjective observations

Sum of percentages exceeds $100 \%$, because respondents may have chosen more than one response.

\section{DISCUSSION}

This study is the first to address practice patterns and knowledge of KDOQI nutrition guidelines in the management of HD patients by dietitians in Lebanon. A high response rate $(71 \%)$ was received, thus the sample was representative. Results show that the dietitians responsible for management of HD patients were quite young in Lebanon compared to $>45$ years of age reported in the literature (Vergili \& Wolf, 2010; Burrowes et al., 2005). Also the majority had very few years of experience either in general clinical or in renal care compared to $>10$ years reported in the literature (Vergili \& Wolf, 2010; Burrowes et al., 2005). Moreover, almost 50\% of the dietitians had been in their current job for up to two years only, which may be due the young nature of the profession emerging to the medical health care in the country, empowered by the national hospital accreditation standards in 2001 . One could speculate that the above described situation might be a result of high turnover due to work overload, exhaustion and thus 
job dissatisfaction; a scenario very similar to the one described in the literature (Wolfe, 2012).

The study did not determine a dietitian-to-CKD patient ratio, since the care of HD patients generally constituted a small portion of the responsibility of the hospital dietitian. In most hospitals in Lebanon, dietitians are mainly responsible for the foodservice aspects of the institution and consulted upon need to see patients. For these reasons, it was not possible to conduct a comparison with the established dietitians-to-CKD patient ratio of 1:100 - 150 in HD units published in the literature (Vergili \& Wolf, 2010; Burrowes et al., 2005); but surely current study data show that the participants are overloaded.

Even though the surveyed dietitians seemed to have adequate university education in general dietetics, when it came to knowledge and competencies in care of renal patients they had a low overall score. This can be explained by the lack of advanced trainings for dietitians to specialize in renal dietetic care as part of their general internship. A certifying body for such specialization is non-existent in the country.

An evaluation of study participants' implementation level of KDOQI nutrition guidelines for estimating nutritional needs compared to that of the literature showed that $97 \%$ applied at least one guideline compared to that of earlier US reports of 91\% (Burrowes et al., 2005), 64\% and $36 \%$ used five and 10 guidelines respectively compared to somewhat higher numbers of $72 \%$ and $55 \%$ in Burrowes et al. (2005). Five percent applied all guidelines, similar to the number reported by Burrowes et al. (2005). This may indicate that in face of all the limitations imposed on Lebanese hospital dietitians, they are still trying to update themselves with their own resources and in their own time.

Barriers to compliance in the study sample were identified as lack of time, lack of integration in the health care system and lack of support from the physician (data from unpublished results of the current survey). Participants reported that the lack of readymade culturally sensitive patient educational material in Arabic adds to the burden of following KDOQI standards in routine nutrition care process of HD patients, in the midst of overwhelming responsibilities in the hospital. This has been reported before in the literature. Wolfe (2011, p:170) stated "even the most qualified and organized dietitian will be unable to provide quality nutrition care to dialysis patients when the time allotment is inadequate or patient load is too great". Literature emphasized the need of organization wide supporting policies and resources for the improvement of health care professionals' practice standards and thus clinical patient outcome. (Epping-Jordan et al., 2004; Wolfe, 2012).

In conclusion, dietetic services in HD units in Lebanon are lagging behind although professionals involved do their very best. Hospitals that operate a HD unit do not seem to equip their dietitians with sufficient time, training, or empowerment to follow KDOQI standards of care in the management of HD patients. The supply of dietetic services and demand of renal patients is not in balance; due to the lack of specialized renal dietitians in the face of the ever-rising numbers of renal failure and HD patients in 
Lebanon. The MOPH is encouraged to promote the integration of renal dietitians as a core member of the health care team for the optimal cost effective management of HD patients in Lebanon. This can be done by: the following steps: 1 ) hospitals provide specialized training to hospital dietitians on KDOQI standards, 2) reinforce their implementation, 3) continuously audit and assess compliance to KDOQI nutrition guidelines in routine practice, 4) allocate extra time for management of HD patients either by decreasing responsibilities of already existing dietitians or recruiting new ones to be fully dedicated to the HD unit and finally 5) consider renal dietitians as key health care professionals in the management of HD patients. 


\section{REFERENCES}

Academy of Nutrition and Dietetics Evidence Analysis Library. (2010), "Is MNT provided by a Registered Dietitian for chronic kidney disease (CKD) in adults effective?", available at: http://andevidencelibrary.com/template.cfm?key=2407 (accessed 25 February, 2013).

Beto, J.A. and Bansal, V.K. (2004). Medical nutrition therapy in chronic kidney failure: integrating clinical practice guidelines. Journal of the American Dietetic Association, 104(3), 404-409.

Burrowes, J.D., Russell, G.B. and Rocco, M.V. (2005). Multiple factors affect renal dietitians' use of the NKFK/DOQI Adult Nutrition Guidelines. Journal of Renal Nutrition, 15(4), 407-426.

Campbell, K.L., Ash, S., Zabel, R., Mcfarlane, C., Juffs, P. and Bauer, J.D. (2009). Implementation of standardized nutrition guidelines by renal dietitians is associated with improved nutrition status. Journal of Renal Nutrition, 19(2), 136-144.

Epping-Jordan, J.E., Pruitt, S.D., Bengoa, R. and Wagner, E.H. (2004). Improving the quality of health care for chronic conditions. Quality \& Safety in Health Care, 13(4), 299-305.

Mallat, S., Hatoum, A., Kabalan, S., Elzein, H., and Abdallah, A. (2011). Demographic and Clinical profile of patients initiated on hemodialysis in Lebanon. American Journal of Kidney Diseases, 57(4), B62.

Martin, C.J. and Reams, S.M. (2003). The renal dietitian's role in managing hyperphosphatemia and secondary hyperparathyroidism in dialysis patients: a national survey. Journal of Renal Nutrition, 13(2), 133-136.

National Kidney Foundation -Kidney Disease Outcomes Quality Initiative (NKF- KDOQI) (2000) Clinical Practice Guidelines for Nutrition in Chronic Renal Failure http://www.kidney.org/professionals/kdoqi/guidelines_updates/doqi_nut.html Accessed on 3 February 2014.

National Kidney Registry. (2012) http://www.kidneyregistrylb.com (accessed 29 June, 2012).

Thelen, B., Byham-gray, L., Touger-decker, R., O'sullivan Maillet, J. and Khan, H. (2009). Survey of current job functions of renal dietitians. Journal of Renal Nutrition, 19(6), 450-461.

Vergili, J.M. and Wolf, R. L. (2010). Nutrition practices of renal dietitians in hemodialysis centers throughout the United States: a descriptive study. Journal of Renal Nutrition, 20(1), 8-e1.

Wolfe, W.A. (2011). Adequacy of dialysis clinic staffing and quality of care: a review of evidence and areas of needed research. American Journal of Kidney Diseases, 58(2),166-176.

Wolfe, W.A. (2012). Moving the issue of renal dietitian staffing forward. Journal of Renal Nutrition, 22(5), 515-520. 



\title{
CHAPTER 4
}

\section{Dietary Educational Interventions for Hyperphosphatemia Management in Hemodialysis (HD) Patients:}

\author{
A Systematic Review and Meta-Analysis
}

Karavetian, M., de Vries, N., Rizk, R., El Zein, H. (2014). Dietary Counseling Interventions for Hyperphosphatemia Management in Hemodialysis (HD) Patients: A Systematic Review and Meta-Analysis.

Accepted in Nutrition Reviews. 


\section{ABSTRACT}

Strategies to enhance knowledge and adherence to dietary management of hyperphosphatemia among hemodialysis (HD) patients, has been vastly studied in the last decade. However, this review is the first to compile all of them (2003-2013) and conduct a meta-analysis through effect size calculation, with the aim of identifying the optimal methods needed for an effective nutritional education management of hyperphosphatemia among HD patients. The identified strategies were: 1) use of selfevaluation and self-regulation techniques within the educational tools with easy to apply skills; 2) use of individualized counseling by a renal dietitian provided just before the HD session; 3) high intensity of education; 4) long duration of interventions. Future studies should focus on conducting randomized controlled trials with powered samples to help generate stronger evidence. 


\section{INTRODUCTION}

Hyperphosphatemia is the leading cause of mineral bone disorder in chronic kidney disease (Martin \& Gonzalez, 2011) and cardiovascular mortality risk among hemodialysis (HD) patients (Danese et al., 2008; Tentori et al., 2008; Floege et al., 2011; Petrovic et al., 2012). Achieving optimal serum phosphorus (P) through P restricted diets (800$1000 \mathrm{mg} /$ day) remains the cornerstone of treating chronic kidney disease- mineral bone disorder (K/DOQI, 2003; KDIGO, 2009): yet adhering to these levels has been reported by HD patients to be the most complicated among all dietary restrictions (Denhaerynck et al., 2007; Kugler et al., 2011).

Research about effective strategies to achieve optimal dietary adherence to $\mathrm{p}$ restricted diet among hd patients is explored in numerous articles in the last decade and many have published evidence based guidelines. k/doqi (2003) and kdigo (2009) recommend providing patients with consistent and frequent dietary consultations by experts coupled with regular follow-ups (fu) in the context of an education program. moreover, 2 hours per patient per month for 12 months has been shown to be effective dietitian-to-renal patient consultation time to achieve adherence (eal, 2010). however, none of the guidelines prescribed explained the educational strategies needed to achieve optimal adherence.

The objective of this review is to examine published nutritional educational interventions that enhance HD patient's knowledge and adherence to dietary instructions related to dietary $\mathrm{P}$ restrictions; in the aim of improving serum $\mathrm{P}$ levels.

\section{METHODS}

\section{Search Methodology}

The search methodology for this paper was developed to retrieve educational dietary interventions focusing on hyperphosphatemia (chronic kidney disease- mineral bone disorder) management among HD patients.

A search was conducted using the Pubmed, Medline and Embase databases on June 23,2013 . Only articles published in the past 10 years were included, thus searching for the most recent findings in this topic. The search strategy included selected Medical Subject Heading terms and keywords. The search used the following terms: Phosphates/blood, Phosphorous/blood, Counseling, Education, Intervention, Diet, Nutrition, and Hemodialysis. The following keywords were also used: Phosphate, Phosphorous, Osteodystrophy, Counsel*, Educat*, Intervention, Diet*, and Renal Dialysis*, whereby asterisk $\left(^{*}\right)$ indicated that the word before it will be searched in all its versions. The search string used is found in the Appendix 1. 
The search was run using different Boolean operators (AND, OR) and a total of 106 articles were retrieved from Pubmed, 81 articles from Medline, and 53 articles from Embase. Two more articles were identified through reference lists of retrieved articles. This resulted in 138 unique references out of which 18 were included in the analysis (Figure 1).

Figure 1: Flow diagram of study selection.
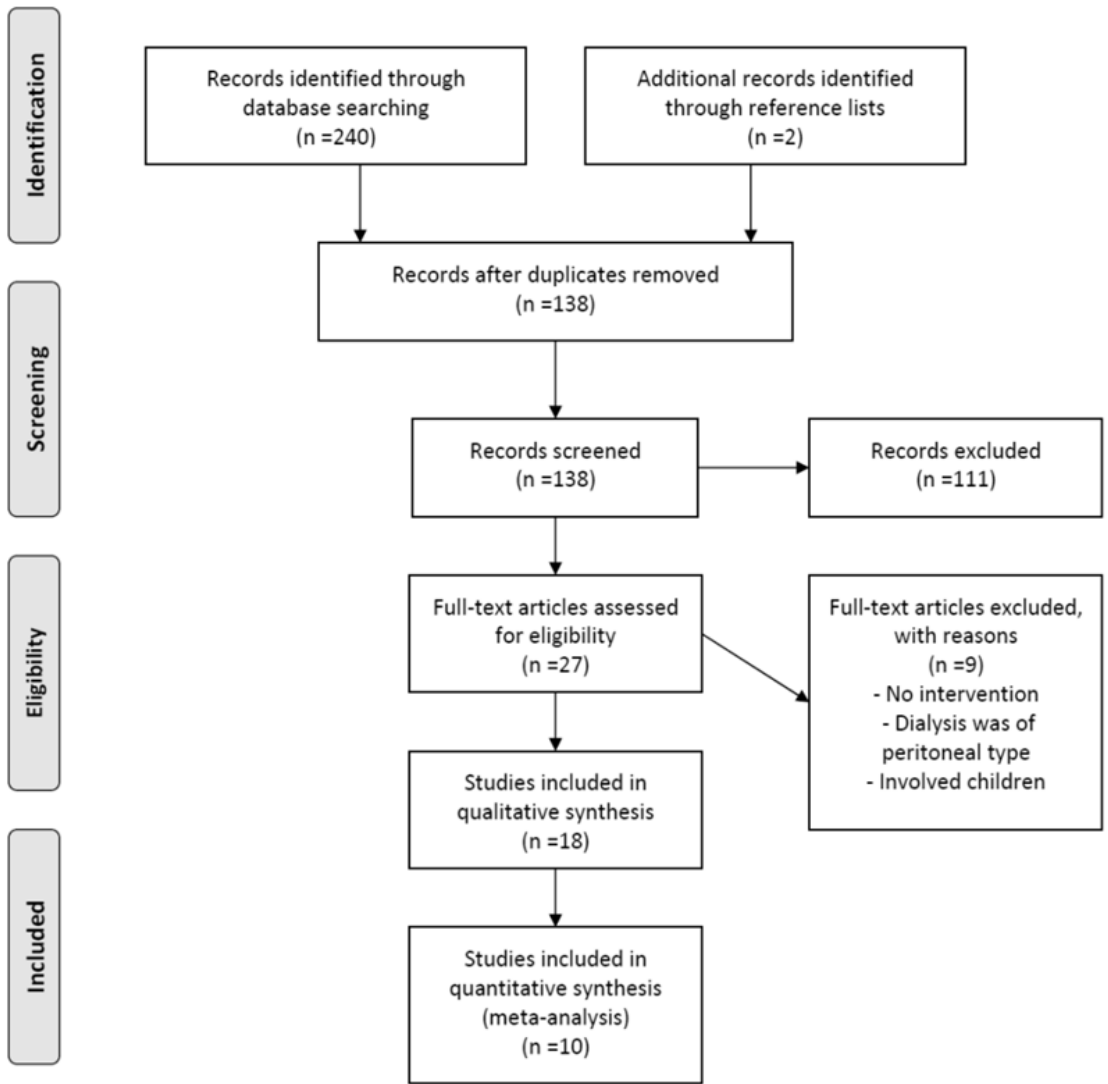

Abstract evaluations were carried out for all articles by 2 reviewers following the same criteria for article selection, including: (1) HD as the stage of renal disease among participants, (2) serum $P$ as primary outcome, (3) focused on serum P management, (4) with an educational component, (5) including any kind of educational or counseling intervention related to diet for the interventional group, (6) age of patients $\geq 18$ years, (7) comparators that were passive (standard practice) or active or studies that had no comparator.

Data extraction included sample size, study design, educational techniques and results extracted. This was conducted by two reviewers, separately, and unified 
through discussion. Moreover, serum $\mathrm{P}$ was chosen as the main indicator of achieved dietary adherence to be extracted for this review, since it is the key outcome measure in managing hyperphoshatemia and osteodystrophy among HD patients as per KDIGO (2009) guidelines.

\section{Data Analysis}

To enable comparison, all serum $\mathrm{P}$ values were converted to $\mathrm{mg} / \mathrm{dL}$ (conversion ratio: 1 $\mathrm{mmol} / \mathrm{L}=3.095 \mathrm{mg} / \mathrm{dL}$ ) (Shils \& Shike, 2006) thus showing the results of all of the reviewed studies in the international system of units. Effect size (ES) for each study was calculated to evaluate the effectiveness of the deployed strategy. ES calculation was done based on Thalheimer \& Cook (2003), where relative size of Cohen's d was defined according to 4 levels: $d$ of less than 0.2 as negligible effect, over 0.2 as small, over 0.5 as medium, and over 0.8 as large; studies were sorted in descending order of ES in Table 1.

\section{RESULTS}

Based on the-above mentioned criteria, 27 articles were selected from the 138 reviewed; of which 9 were excluded based on full-text assessment. As such, 18 studies with a structured educational intervention met the inclusion criteria (Table 1). 
Table 1. Main characteristics of reviewed articles (in descending order of ES, the dark line separates the articles with no ES, the order is descending in years).

\begin{tabular}{|c|c|c|c|c|}
\hline Author & Sample & Design & Educational technique & Results \\
\hline $\begin{array}{l}\text { Ashurst and } \\
\text { Dobbie (2003) }\end{array}$ & $\begin{array}{l}\text { I }(n=29) \text {, } \\
C(n=29) \text { both } \\
\text { hyper- } \\
\text { phosphatemics } \\
\text { Age: } \\
\text { I (54.2: range } \\
\text { 22- } 77) \text {, } \\
\text { C: }(53: \text { range } \\
23-88) \\
\text { Gender: } \\
\text { I: } 66 \% \mathrm{M} \\
\text { C: } 56 \% \mathrm{M}\end{array}$ & $\begin{array}{l}\text { RCT } \\
\text { Intervention: } 1 \text { time; } 40- \\
\text { minute individualized } \\
\text { education by renal dietitian } \\
\text { FU: at 12th week post- } \\
\text { intervention } \\
\text { Setting: } 1 \text { HD unit (educa- } \\
\text { tion just before HD ses- } \\
\text { sion) }\end{array}$ & $\begin{array}{l}\text { I: education aimed to empower } \\
\text { patients to get involved in their } \\
\text { health care, using educational color- } \\
\text { ful booklet with cartoon models } \\
\text { explaining importance of lifestyle } \\
\text { change and health, dietary re- } \\
\text { striction, medication and relevant } \\
\text { blood tests, plus a medication record } \\
\text { chart and a refrigerator magnet } \\
\text { (used as a reminder). } \\
\text { C: provided with medication record } \\
\text { chart only. } \\
\text { Theory: none }\end{array}$ & $\begin{array}{l}\text { - I: } \downarrow \text { sig. }[\mathrm{P}]: \\
\text { Pre : } 6.07 \pm 0.01 \\
\text { Post: } 4.96 \pm 0.12 \\
\mathrm{mg} / \mathrm{dL} \\
\text { - C: } \downarrow \mathrm{NS}[\mathrm{P}]: \\
\text { Pre : } 6.13 \pm 0.15 \\
\text { Post: } 5.92 \pm 0.12 \\
\mathrm{mg} / \mathrm{dL} \\
\text { (data extracted } \\
\text { from graph) } \\
\text { Results sustained } \\
\text { over } 3 \text { months }\end{array}$ \\
\hline $\begin{array}{l}\text { Ford et al. } \\
(2004)\end{array}$ & $\begin{array}{l}\text { I }(n=32) \text {, } \\
C(n=31) \text { both } \\
\text { hyper- } \\
\text { phosphatemics } \\
\text { Age: range } \\
\text { 18-76+ } \\
\text { Gender: } \\
\text { I: } 34.37 \% \mathrm{M} \\
\text { C: } 41.93 \% \mathrm{M}\end{array}$ & $\begin{array}{l}\text { Quasi-experimental } \\
\text { Intervention: } 24 \text { weeks; } \\
\text { monthly } 20 \text { to } 30 \text {-minute } \\
\text { individualized education by } \\
\text { research renal dietitian } \\
\text { FU: no } \\
\text { Setting: } 3 \text { HD units (educa- } \\
\text { tion during HD session) }\end{array}$ & $\begin{array}{l}\text { I: education aimed to empower } \\
\text { patients for self-evaluation and self- } \\
\text { regulation, to control dietary P } \\
\text { (prevention of renal bone disease; } \\
\text { high P foods; medications), using } \\
\text { educational posters, handouts, } \\
\text { puzzles, and an individualized P } \\
\text { tracking tool and laboratory results } \\
\text { review. Dietitians demonstrated } \\
\text { renal meals preparation. } \\
\text { C: routine care including laboratory } \\
\text { results review with the same dieti- } \\
\text { tian. } \\
\text { Theory: none }\end{array}$ & $\begin{array}{l}\text { I: } \downarrow \text { sig. }[\mathrm{P}]: \\
\text { Pre : } 6.8 \pm 0.72 \\
\text { Post: } 5.2 \pm 1.2 \\
\mathrm{mg} / \mathrm{dL} \\
\text { C: } \downarrow \text { NS }[\mathrm{P}]: \\
\text { Pre }: 7.2 \pm 1.3 \\
\text { Post: } 6.7 \pm 1.7 \\
\mathrm{mg} / \mathrm{dL}\end{array}$ \\
\hline $\begin{array}{l}\text { Karavetian } \\
\text { and Ghaddar } \\
(2012)\end{array}$ & $\begin{array}{l}\text { I }(n=41), \\
C(n=40) \\
\text { Age } \pm S D: \\
\text { I }(50.36 \pm 2.84), \\
\text { C }(59.63 \pm 2.89) \\
\text { Gender: } 48.5 \% \\
\text { M }\end{array}$ & $\begin{array}{l}\text { Cluster RCT } \\
\text { Intervention: } 8 \text { weeks; } 2 \\
\text { weekly individual 20- } \\
\text { minutes educational ses- } \\
\text { sions by research renal } \\
\text { dietitian } \\
\text { FU: no } \\
\text { Setting: } 1 \text { HD unit (ses- } \\
\text { sions) }\end{array}$ & $\begin{array}{l}\text { I: individualized counseling, interac- } \\
\text { tive educational games and discus- } \\
\text { sion, in addition to individual labora- } \\
\text { tory results review and relevant } \\
\text { nutritional counseling if required. All } \\
\text { education was summarized into } \\
\text { handouts and given to patients in } \\
\text { addition to posters of high and low P } \\
\text { food items posted in the HD waiting } \\
\text { room, and small booklets of high P } \\
\text { food items and their low P alterna- } \\
\text { tives. } \\
\text { C: no nutritional intervention. } \\
\text { Theory: self-management dietary } \\
\text { counseling positive reinforcement } \\
\text { (self-regulatory theory) }\end{array}$ & $\begin{array}{l}\text { - I: } \downarrow \text { sig }[\mathrm{P}]: \\
\text { Pre }: 6.55 \pm 1.89 \\
\text { Post: } 5.39 \pm 1.97 \\
\text { mg/dL } \\
\text { - C: } \uparrow \text { NS [P]: } \\
\text { Pre: } 6.16 \pm 1.34 \\
\text { Post: } 6.51 \pm 1.36 \\
\text { mg/dL }\end{array}$ \\
\hline $\begin{array}{l}\text { Shi et al. } \\
\text { (2013) }\end{array}$ & $\begin{array}{l}\text { I }(n=40) \\
C(n=40) \\
\text { both hyper- } \\
\text { phosphatemics }\end{array}$ & $\begin{array}{l}\text { RCT } \\
\text { Intervention: } 24 \text { weeks 20- } \\
30 \text { minutes, 2-3 times a } \\
\text { week of nurse-led inten- }\end{array}$ & $\begin{array}{l}\text { I: use of educational booklet, dia- } \\
\text { logue with participants or their } \\
\text { relatives who were invited to the } \\
\text { session and } 1 \text { PowerPoint lecture }\end{array}$ & $\begin{array}{l}- \text { I: } \downarrow \text { sig. }[\mathrm{P}]: \\
\text { Pre }: 6.66 \pm 1.17 \\
\text { Post: } 5.51 \pm 1.20 \\
\mathrm{mg} / \mathrm{dL}\end{array}$ \\
\hline
\end{tabular}




\begin{tabular}{|c|c|c|c|c|}
\hline Author & Sample & Design & Educational technique & Results \\
\hline & $\begin{array}{l}\text { Age } \pm \text { SD: } \\
\text { I : } 54.75 \pm 11.86 \\
\text { C: } 51.85 \pm 13.51 \\
\text { Gender: } \\
\text { I: } 52.5 \% \mathrm{M} \\
\text { C: } 57.5 \% \mathrm{M}\end{array}$ & $\begin{array}{l}\text { sive individualized educa- } \\
\text { tion by trained and experi- } \\
\text { enced nephrology nurse } \\
\text { FU: No } \\
\text { Setting: } 2 \text { hospital-based } \\
\text { HD units }\end{array}$ & $\begin{array}{l}\text { (including colorful pictures of high-P } \\
\text { foods) about general P knowledge } \\
\text { and P binders, method to maintain P } \\
\text { balance. } \\
\text { C: standard medical and social care, } \\
\text { but no educational materials. } \\
\text { Theory: none }\end{array}$ & $\begin{array}{l}\text { - C: } \downarrow \text { NS [P]: } \\
\text { Pre : } 6.51 \pm 1.45 \\
\text { Post: } 6.38 \pm 1.48 \\
\text { mg/dL }\end{array}$ \\
\hline $\begin{array}{l}\text { Yokum et al. } \\
\text { (2008) }\end{array}$ & $\begin{array}{l}\text { I }(n=17), C \\
(n=17) \\
\text { both hyper- } \\
\text { phosphatemics } \\
\text { Age } \pm S D \text { : } \\
\text { I }(51.1 \pm 12.7) \\
\text { C: }(47.6 \pm 14.4) \\
\text { Gender: } \\
\text { I: } 55 \% M \text {; } \\
\text { C: } 60 \% M\end{array}$ & $\begin{array}{l}\text { RCT } \\
\text { Intervention: } 16 \text { weeks; } \\
\text { monthly individualized } \\
\text { consultations by research } \\
\text { renal pharmacist and } \\
\text { dietitian } \\
\text { FU: no } \\
\text { Setting: HD and satellite } \\
\text { units (education during HD } \\
\text { session) }\end{array}$ & $\begin{array}{l}\text { I: management according to a de- } \\
\text { fined P management protocol deci- } \\
\text { sion tree. } \\
\text { C: patients managed without a } \\
\text { decision tree, educated only by the } \\
\text { dietitian. } \\
\text { Theory: none }\end{array}$ & $\begin{array}{l}\text { I: } \downarrow \text { NS. }[\mathrm{P}]: \\
\text { Pre }: 6.29 \pm 0.86 \\
\text { Post: } 5.61 \pm 1.67 \\
\text { mg/dL } \\
\text { - C: } \uparrow \text { sig. }[\mathrm{P}]: \\
\text { Pre }: 5.82 \pm 0.99 \\
\text { Post: } 6.41 \pm 0.77 \\
\text { mg/dL }\end{array}$ \\
\hline $\begin{array}{l}\text { Lou et al. } \\
\text { (2012) }\end{array}$ & $\begin{array}{l}\text { I }(n=41) \\
\text { C }(n=39) \\
\text { both hyper- } \\
\text { phosphatemics } \\
\text { Age: } \\
\text { I }(61.3 \pm 15), \\
\text { C }(63 \pm 16) \\
\text { Gender: } 52.5 \% \\
\text { M }\end{array}$ & $\begin{array}{l}\text { Cluster RCT } \\
\text { Intervention: } 24 \text { weeks; } \\
\text { Initial individualized dietary } \\
\text { counseling, followed by } \\
\text { monthly reinforcement } \\
\text { sessions ( } 30 \text { minutes) by } \\
\text { registered dietitian } \\
\text { FU: no } \\
\text { Setting: } 5 \text { HD units }\end{array}$ & $\begin{array}{l}\text { I: instructions on low } \mathrm{P} \text { and } \\
\mathrm{P} / \text { protein ratio menus adapted to } \\
\text { the patients' dialysis shift and to } \\
\text { Mediterranean diet characteristics } \\
\text { with indications about the quantities } \\
\text { of food and preparation methods. } \\
\text { C: received usual dietary recom- } \\
\text { mendations. } \\
\text { Theory: none }\end{array}$ & $\begin{array}{l}\text { I: } \downarrow \text { sig. }[\mathrm{P}]: \\
\text { Pre }: 7.1 \pm 1.5 \\
\text { Post: } 5.5 \pm 1.4 \\
\text { mg/dL } \\
\text { C: } \downarrow \text { NS [P]: } \\
\text { Pre :6.8 } 0.8 \\
\text { Post: } 6.2 \pm 1.3 \\
\text { mg/dL }\end{array}$ \\
\hline $\begin{array}{l}\text { de Araujo et } \\
\text { al. (2010) }\end{array}$ & $\begin{array}{l}\text { I }(n=16) \text {, } \\
C(n=17) \text { both } \\
\text { hyper- } \\
\text { phosphatemics } \\
\text { Age: } 52.5 \pm 14.2 \\
\text { Gender: } \\
\text { I: } 62.50 \% \mathrm{M} \\
\text { C: } 47.05 \% \mathrm{M}\end{array}$ & $\begin{array}{l}\text { RCT } \\
\text { Intervention: } 6 \text { times, 30- } \\
\text { minute group education } \\
\text { (type of educator \& inter- } \\
\text { vention duration : unclear) } \\
\text { FU: } 13 \text { weeks } \\
\text { Setting: } 2 \text { HD units (educa- } \\
\text { tion immediately before } \\
\text { HD session) }\end{array}$ & $\begin{array}{l}\text { I: education on avoiding food rich in } \\
\mathrm{P} \text {, the correct use of binders, the } \\
\text { importance of biochemical parame- } \\
\text { ters and manifestations of bone } \\
\text { diseases using visual educational } \\
\text { tools (images, drawings... ), ana- } \\
\text { tomic models and simulator manne- } \\
\text { quins. } \\
\text { C: information on vascular access, } \\
\text { types of catheters and arteriovenous } \\
\text { graft. } \\
\text { Theory: none }\end{array}$ & $\begin{array}{l}\text { I: } \downarrow \text { sig. }[\mathrm{P}]: \\
\text { Pre: } 7.3 \pm 0.8 \\
\text { Post: } 6.5 \pm 1.5 \\
\text { mg/dL } \\
\text { C: } \downarrow \text { sig. }[\mathrm{P}]: \\
\text { Pre: } 7.4 \pm 1.9 \\
\text { Post: } 6.9 \pm 1.3 \\
\text { mg/dL }\end{array}$ \\
\hline $\begin{array}{l}\text { Sullivan et al. } \\
\text { (2009) }\end{array}$ & $\begin{array}{l}\text { I }(n=145), C \\
\text { ( } n=134) \text { both } \\
\text { hyper- } \\
\text { phosphatemics } \\
\text { Age: } \\
\text { I: }(54 \pm 13) \text {, } \\
\text { C: }(52 \pm 13) \\
\text { Gender: } \\
\text { I: } 57 \% \% \mathrm{M} \\
\text { C: } 66 \% \mathrm{M}\end{array}$ & $\begin{array}{l}\text { RCT } \\
\text { Intervention: } 8 \text { weeks; a } \\
\text { 30-minute one time indi- } \\
\text { vidualized education and a } \\
\text { reinforcement session by } \\
\text { telephone at FU by study } \\
\text { coordinator (dietitian) } \\
\text { FU: at 4th week post } \\
\text { intervention } \\
\text { Setting: } 14 \text { HD units (edu- } \\
\text { cation during HD session) }\end{array}$ & $\begin{array}{l}\text { I : Teaching patients to read food } \\
\text { labels. Use of handouts on avoiding } \\
\text { foods with P additives and conse- } \\
\text { quences for health. Patients were } \\
\text { provided with the menus of the } \\
\text { restaurants they usually go to and } \\
\text { the high and low P meals were } \\
\text { marked to help patients chose them. } \\
\text { Reinforcement session conducted } \\
\text { via telephone. Material was pre- } \\
\text { pared by dietitians. }\end{array}$ & $\begin{array}{l}\text { I: } \downarrow \text { sig. }[\mathrm{P}]: \\
\text { Pre : } 7.2 \pm 1.2 \\
\text { Post: } 6.2 \pm 1.7 \\
\text { mg/dL } \\
\text { C: } \downarrow \text { sig. }[\mathrm{P}]: \\
\text { Pre : } 7.1 \pm 1.00 \\
\text { Post: } 6.7 \pm 1.9 \\
\text { mg/dL }\end{array}$ \\
\hline
\end{tabular}




\begin{tabular}{|c|c|c|c|c|}
\hline Author & Sample & Design & Educational technique & Results \\
\hline & & & $\begin{array}{l}\text { C: study coordinator telephoned } \\
\text { patients at FU and inquired on how } \\
\text { often they read nutrition facts } \\
\text { labels, eat at fast-food restaurants, } \\
\text { and receive P related recommenda- } \\
\text { tions from their facility dietitian, } \\
\text { without giving them education or } \\
\text { feedback. } \\
\text { Theory: none }\end{array}$ & \\
\hline $\begin{array}{l}\text { Morey et al. } \\
\text { (2008) }\end{array}$ & $\begin{array}{l}\text { I }(\mathrm{n}=34), \mathrm{C} \\
\text { ( } \mathrm{n}=33) \text { both } \\
\text { hyper- } \\
\text { phosphatemics } \\
\text { Age } \pm S D \\
\text { I: }(60.4 \pm 15.6) \\
\text { C:(54.9 } \pm 15.9) \\
\text { Gender: } \\
\text { I: } 73.5 \% \mathrm{M} \\
\text { C: } 52.5 \% \mathrm{M}\end{array}$ & $\begin{array}{l}\text { RCT } \\
\text { Intervention: } \\
24 \text { weeks; individualized } \\
\text { monthly education by } \\
\text { study dietitian } \\
\text { FU: at 24th week post } \\
\text { intervention } \\
\text { Setting: N/A (education } \\
\text { during HD session) }\end{array}$ & $\begin{array}{l}\text { I: advanced dietetic verbal and } \\
\text { written counseling aiming at limiting } \\
\text { dietary P and improving compliance } \\
\text { with P binders. } \\
\text { C: standard care with in service } \\
\text { dietetic consultations at baseline } \\
\text { and month } 6 . \\
\text { Theory: motivational counseling, } \\
\text { negotiation, behavior modification } \\
\text { therapy, reminders, reinforcement, } \\
\text { supportive care }\end{array}$ & $\begin{array}{l}\text { - I: } \downarrow N S[P] \\
\text { Pre: } 6.35 \pm 1.48 \\
\text { Post: } 5.89 \pm 1.33 \\
\text { mg/dL } \\
\text { - C: } \downarrow \text { NS [P] } \\
\text { Pre: } 6.94 \pm 1 . \\
\text { Post: } 6.2 \pm 1.55 \\
\text { mg/dL } \\
\text { Data derived from } \\
\text { graph. }\end{array}$ \\
\hline $\begin{array}{l}\text { Baraz et al. } \\
\text { (2010) }\end{array}$ & $\begin{array}{l}I_{0}(n=32) \\
\text { Iv }(n=31) \\
I_{0} \& \text { IV } \\
\text { Age } \pm \text { SD: } \\
38.5 \pm 9.5 \\
I_{0} \& \text { IV } \\
\text { Gender: } 52.4 \% \\
\text { M }\end{array}$ & $\begin{array}{l}\text { Randomized trial- no } \\
\text { control } \\
\text { Intervention: } 2 \text { times; 30- } \\
\text { minute education by } \\
\text { expert renal nurse } \\
\text { FU: at 8th week post } \\
\text { intervention } \\
\text { Setting: } 3 \text { HD units }\end{array}$ & $\begin{array}{l}\text { I॰: didactic and interactive oral group } \\
\text { sessions the day after HD session. A } \\
\text { teaching booklet was also provided. } \\
\text { IV: individual video education during } \\
\text { HD sessions. } \\
\text { Both educations included infor- } \\
\text { mation on dietary management, } \\
\text { restricted/non-restricted foods, } \\
\text { reasons for compliance and possible } \\
\text { consequences of non-compliance. } \\
\text { Theory: none }\end{array}$ & $\begin{array}{l}\text { - } \mathrm{I}_{\mathrm{o}}: \downarrow \text { sig. }[\mathrm{P}]: \\
\text { Pre: } 6.16 \pm 1.52 \\
\text { Post: } 5.02 \pm 0.9 \\
\mathrm{mg} / \mathrm{dL} \\
\text { - Iv: } \downarrow \text { sig. }[\mathrm{P}]: \\
\text { Pre: } 6.25 \pm 1.47 \\
\text { Post: } 5.16 \pm 1.21 \\
\text { mg/dL }\end{array}$ \\
\hline $\begin{array}{l}\text { Mayne et al. } \\
\text { (2012) }\end{array}$ & $\begin{array}{l}\mathrm{n}=702 \\
\text { Age } \pm \text { SD: } 61 \pm 15 \\
\text { Gender: } 56 \% \mathrm{M}\end{array}$ & $\begin{array}{l}\text { Prospective, multi-center, } \\
\text { single-arm trial- no control } \\
\text { Intervention: } 24 \text { weeks; a } 1 \\
\text { time individualized dietary } \\
\text { education by renal dietitian } \\
\text { and an individualized } \\
\text { regular monitoring for [P] } \\
\text { by facility staff. In addition } \\
\text { to } 5 \text { different educational } \\
\text { material mailed to the } \\
\text { patient during the course } \\
\text { of the study. } \\
\text { FU: no } \\
\text { Setting: } 8 \text { HD units }\end{array}$ & $\begin{array}{l}5 \text { communications were mailed to } \\
\text { patients on: portion size, following a } \\
\text { renal diet at home and while eating } \\
\text { out, function of different members } \\
\text { of the renal care team, simple but } \\
\text { specific ways for involving patients } \\
\text { and caregivers with the patient's } \\
\text { care. In center education was on } \\
\text { diet, P management, and adherence } \\
\text { support for P binders. } \\
\text { Theory: none }\end{array}$ & $\begin{array}{l}\uparrow \text { sig. percentage of } \\
\text { patients achieving } \\
{[\mathrm{P}]<5.5 \mathrm{mg} / \mathrm{dL} / \text { facility: }} \\
\text { Pre : } 61.6 \pm 5.2 \% \\
\text { Post: } 71.3 \pm 9.0 \%\end{array}$ \\
\hline Reddy et al. & $\mathrm{n}=115$ & No control trial & Use of booklets written by a dietitian & $\downarrow$ sig. $[P]:$ only \\
\hline
\end{tabular}




\begin{tabular}{|c|c|c|c|c|}
\hline Author & Sample & Design & Educational technique & Results \\
\hline (2009) & $\begin{array}{l}\text { Age: } 61.1 \\
\text { Gender: } 54.8 \% \\
M\end{array}$ & $\begin{array}{l}\text { Intervention: } \\
\text { Duration :unclear; } \\
\text { group }(n=6-8) \text { education } \\
\text { by research dietitian } \\
\text { FU: no } \\
\text { Setting: } 2 \text { satellite HD units } \\
\text { (education during HD } \\
\text { session) }\end{array}$ & $\begin{array}{l}\text { and a local audio cassette on all } \\
\text { relevant information. } \\
\text { Theory: none }\end{array}$ & $\begin{array}{l}\text { among the hyper- } \\
\text { phosphatemics } \\
\text { ( } n=30): \\
\text { Pre : } 6.35 \pm 0.12 \\
\text { Post: } 5.95 \pm 0.24 \\
\mathrm{mg} / \mathrm{dL}\end{array}$ \\
\hline $\begin{array}{l}\text { Campbell et } \\
\text { al. (2009) }\end{array}$ & $\begin{array}{l}\mathrm{n}=65 \\
\text { Age: } 64.3 \pm 14.8 \\
\text { Gender: } 58 \% \mathrm{M}\end{array}$ & $\begin{array}{l}\text { Retrospective observation- } \\
\text { al study- no control } \\
2 \text { year study: education at } \\
\text { start of study and FU } \\
\text { afterward, with reinforce- } \\
\text { ment upon need at least } \\
\text { every } 6 \text { months via individ- } \\
\text { ualized structured nutri- } \\
\text { tional care by research } \\
\text { renal dietitian, and FU on } \\
\text { blood tests. } \\
\text { Setting: } 2 \text { HD units }\end{array}$ & $\begin{array}{l}\text { Systematic education regarding } \\
\text { binder usage and general P man- } \\
\text { agement. Educational material used } \\
\text { is not mentioned } \\
\text { Theory: none }\end{array}$ & $\begin{array}{l}\downarrow \text { sig. }[\mathrm{P}]: \\
\text { Pre : } 5.58 \pm 1.55 \\
\text { Post: } 4.56 \pm 1.55 \\
\mathrm{mg} / \mathrm{dL}\end{array}$ \\
\hline $\begin{array}{l}\text { Karamanidou } \\
\text { et al. (2008) }\end{array}$ & $\begin{array}{l}\text { I }(n=19), C \\
(n=20) \\
\text { Age } \pm S D: \\
\text { I: }(57.7 \pm \\
14.86), \\
\text { C: }(59.2 \pm 16.92) \\
\text { Gender: } \\
\text { I: } 52.6 \% M \\
\text { C: } 50.0 \% \mathrm{M}\end{array}$ & $\begin{array}{l}\text { RCT } \\
\text { Intervention: } \\
1 \text { time individual } \\
\text { Specialty of educator: } \\
\text { unclear } \\
\text { FU: at 4th and 16th weeks } \\
\text { post-intervention } \\
\text { Setting: } 3 \text { satellite HD units }\end{array}$ & $\begin{array}{l}\text { I: leaflet provided to improve pa- } \\
\text { tients' understanding of hyperphos- } \\
\text { phatemia, rationale for using P } \\
\text { binders and their mode of action. } \\
\text { Plus, a live demonstration on P } \\
\text { binding in the stomach. } \\
\text { C: received usual care } \\
\text { Theory: self-regulatory theory }\end{array}$ & $\begin{array}{l}\text { - I: No Change for } \\
\text { both groups in }[\mathrm{P}] \\
\text { Pre: } 4.96 \pm 0.93 \\
\text { Post: } 4.96 \pm 1.24 \\
\text { mg/dL } \\
\text { - C: NS. [P]: } \\
\text { Pre: } 4.34 \pm 1.24 \\
\text { Post: } 4.34 \pm 1.55 \\
\text { mg/dL }\end{array}$ \\
\hline $\begin{array}{l}\text { Sun et al. } \\
(2008)\end{array}$ & $\begin{array}{l}\mathrm{n}=50 \text { hyper- } \\
\text { phosphatemics } \\
\text { Age } \pm S D: \\
53.8 \pm 14.0 \\
\text { Gender: } 42 \% \mathrm{M}\end{array}$ & $\begin{array}{l}\text { Prospective self control } \\
\text { study } \\
\text { Intervention: individualized } \\
4 \text { weeks; a } 30 \text {-minute/ } \\
\text { patient education by a } \\
\text { single well-trained neph- } \\
\text { rology nurse } \\
\text { Education was repeated } \\
\text { until the patient passed } \\
\text { post-education evaluation. } \\
\text { FU: at } 12 \text { th week post } \\
\text { intervention } \\
\text { Setting: } 1 \text { HD unit }\end{array}$ & $\begin{array}{l}\text { A program to improve basic } \\
\text { knowledge of hyperphosphatemia, } \\
\text { its complications, and diet control } \\
\text { with a complete list of P content in } \\
\text { daily foods, using a standard booklet } \\
\text { with figures } \\
\text { Theory: none }\end{array}$ & $\begin{array}{l}\downarrow \text { sig }[\mathrm{P}] \\
\text { Pre : } 7.38 \pm 1.21 \\
\text { Post: } 6.68 \pm 1.97 \\
\mathrm{mg} / \mathrm{dL}\end{array}$ \\
\hline $\begin{array}{l}\text { Nisio et al. } \\
\text { (2007) }\end{array}$ & $\begin{array}{l}\mathrm{n}=147 \\
\text { Age: } 50.5 \pm 15.7 \\
\text { Gender: } \\
57.82 \% \mathrm{M}\end{array}$ & $\begin{array}{l}\text { No control trial } \\
\text { Intervention: } 40-\text { minute } \\
\text { group education ( } 6-9 \\
\text { patients/group) by renal } \\
\text { dietitians followed by } \\
\text { educational games } 1 \text { week }\end{array}$ & $\begin{array}{l}\text { I: educational presentation using an } \\
\text { illustrative booklet on the conse- } \\
\text { quences of hyperphosphataemia, } \\
\text { foods high in P, the correct use of } \\
\text { binders and measures for reduction } \\
\text { of serum P and educational games. } \\
\text { Theory: none }\end{array}$ & $\begin{array}{l}\text { In total sample } \\
\downarrow \text { sig. }[\mathrm{P}]: \\
\text { Pre: } 5.5 \pm 1.6 \\
\text { Post: } 5.2 \pm 1.6 \mathrm{mg} / \mathrm{dL} \\
\text { In hyperphos- } \\
\text { phatemics: }\end{array}$ \\
\hline
\end{tabular}




\begin{tabular}{|c|c|c|c|c|}
\hline Author & Sample & Design & Educational technique & Results \\
\hline & & $\begin{array}{l}\text { after } \\
\text { FU: unclear ( } 5 \text { months for } \\
\text { intervention and FU) } \\
\text { Setting: } 1 \text { HD unit } \\
\text { (education during HD } \\
\text { session) }\end{array}$ & & $\begin{array}{l}\downarrow \text { sig. }[\mathrm{P}]: \\
\text { Pre: } 6.9 \pm 1.2 \\
\text { Post: } 5.8 \pm 1.6 \mathrm{mg} / \mathrm{dL}\end{array}$ \\
\hline $\begin{array}{l}\text { Sevick et al. } \\
\text { (2005) }\end{array}$ & $\begin{array}{l}\mathrm{n}=5 \\
\text { Age: range } 63- \\
70 \text { years } \\
\text { Gender: } 20 \% \mathrm{M}\end{array}$ & $\begin{array}{l}\text { Quasi-experimental single- } \\
\text { case } \\
\text { Intervention: } 16 \text { weeks } \\
\text { individualized education; } \\
\text { 1st } 6 \text { weeks: } 2 \text { ses- } \\
\text { sions/week by a } \\
\text { nurse/information special- } \\
\text { ist; } \\
\text { 2nd } 6 \text { weeks: weekly } \\
\text { sessions; } \\
\text { final } 4 \text { weeks: biweekly } \\
\text { sessions in addition to 1:1 } \\
\text { counseling by renal dieti- } \\
\text { tian when necessary } \\
\text { FU: no } \\
\text { Setting: } 1 \text { HD center (edu- } \\
\text { cation during HD sessions) }\end{array}$ & $\begin{array}{l}\text { Intensive dietary self-monitoring } \\
\text { using the Personal Digital Assistant- } \\
\text { based } \\
\text { program (BalanceLog); participants } \\
\text { were also provided with a manual } \\
\text { pertaining to the behavioral inter- } \\
\text { vention. In addition to intervention } \\
\text { sessions using strategies based on } \\
\text { self-efficacy and finally homework } \\
\text { assignments that participants were } \\
\text { asked to complete between inter- } \\
\text { vention contacts. } \\
\text { Theory: social cognitive theory }\end{array}$ & $\begin{array}{l}\text { Serum P levels of all } \\
\text { participants (hyper, } \\
\text { normo and hypo- } \\
\text { phosphatemics) } \\
\text { approached accepta- } \\
\text { ble levels (as per the } \\
\text { graph) }\end{array}$ \\
\hline $\begin{array}{l}\text { Cupisti et al. } \\
(2004)\end{array}$ & $\begin{array}{l}n=20 \text { hyper- } \\
\text { phosphatemics } \\
\text { Age } \pm S D \text { : } \\
47.6 \pm 10.9 \\
\text { Gender: } 65 \% \mathrm{M}\end{array}$ & $\begin{array}{l}\text { Prospective interventional } \\
\text { study- no control } \\
\text { Intervention: } 1 \text { time; } \\
\text { individualized counseling } \\
\text { session by a research renal } \\
\text { dietitian } \\
\text { FU: } \\
\text { at 8th wk post intervention } \\
\text { Setting: } 1 \text { HD unit (educa- } \\
\text { tion during HD session) }\end{array}$ & $\begin{array}{l}\text { Education on low P/protein ratio } \\
\text { foods and recipes, based on pa- } \\
\text { tient's dietary habits and lifestyle. } \\
\text { Information provided in printed } \\
\text { materials. Advice given orally and } \\
\text { summarized on a simple sheet at the } \\
\text { end of the session. } \\
\text { Theory: none }\end{array}$ & $\begin{array}{l}\downarrow \mathrm{NS}[\mathrm{P}] \\
\text { Pre: } 7.1 \pm 1.1 \\
\text { Post: } 6.6 \pm 1.6 \mathrm{mg} / \mathrm{dL}\end{array}$ \\
\hline
\end{tabular}

I- intervention, C- control, M- male, RCT- randomized controlled trial, FU- follow-up, HD- hemodialysis, sigsignificant, NS- non significant, SD- standard deviation

Except for Karamanidou et al.(2008), the rest of the studies achieved a reduction in serum $\mathrm{P}$ of which $13 \mathrm{had}$ a significant improvement. The change varied from $0.3 \mathrm{mg} / \mathrm{dL}$ to $1.6 \mathrm{mg} / \mathrm{dL}$ (average: $1 \mathrm{mg} / \mathrm{dL}$ ). Eight (Ashurst \& Bobbie, 2003; Ford et al., 2004; Karavetian \& Ghaddar, 2013; Shi et al., 2013; Lou et al., 2012; Baraz et al., 2010; Campbell et al., 2009; Nisio et al., 2007) of the studies achieved the K/DOQI target level of $\leq$ $5.5 \mathrm{mg} / \mathrm{dL}$ serum $\mathrm{P}$ post intervention.

Nine of the studies were randomized controlled trials (RCT) (Karamanidou et al., 2008; Ashurst \& Dobbie, 2003; Karavetian \& Ghaddar, 2013; Shi et al., 2013; Lou et al., 2012; Morey et al., 2008; Sullivan et al., 2009; Yokum et al., 2008; de Araujo et al., 2010), 2 were quasi-experimental (Ford et al., 2004; Sevick et al., 2005), 6 were inter- 
ventional studies without control (Baraz et al., 2010; Nisio et al., 2007; Sun et al., 2008; Mayne et al., 2012; Reddy et al., 2009; Cupisti et al., 2004) and 1 was a retrospective observational study without control (Campbell et al., 2009).

The average age of participants was 55 years (minimum: 18; maximum: 88). In most studies, there was roughly an equal distribution over gender groups, except in the following studies: males were $20 \%$ of participants in Sevick et al. (2005), $73 \%$ in Morey et al. (2008) and 35\% in Ford et al. (2004). Ten (Ashurst \& Dobbie, 2003; Ford et al., 2004; Shi et al., 2013; Lou et al., 2012; Morey et al., 2008; Sullivan et al., 2009; Yokum et al., 2008; de Araujo et al., 2010; Sun et al., 2008; Cupisti et al., 2004) of the studies included only hyperphosphatemics in their sample; as for the rest, the sample was randomly chosen form all patients found in the HD unit. Most studies had a small sample size, ranging from 17 to 45 patients per group; except for Sullivan et al. (2009) with a sample size of around 140 per group and 3 other studies (Nisio et al., 2007; Mayne et al., 2012; Reddy et al., 2009) with sample sizes ranging from 115 to 702 patients, but lacked a control group.

Behavioral theories used as a basis for intervention modeling were: 1) Leventhal's self-regulatory theory (Karamanidou et al., 2008; Karavetian \& Ghaddar, 2013); 2) motivational counseling (Morey et al., 2008) and 3) social cognitive theory (Sevick et al., 2005). Among these, only Karavetian \& Ghaddar (2013) reported a significant decrease in patients' serum P. Morey et al. (2008) showed beneficial effect on the short term (month 3), however, the significant decrease resolved at the end of the intervention (month 6).

The duration of each educational session used was 20 - 40 minutes, and the number of those sessions varied from 1 time in total to 8 times per month. The duration of the full intervention varied from 1 - 6 months where 4 of the studies (Ford et al., 2004; Lou et al., 2012; Morey et al., 2008; Yokum et al., 2008) educated the patient on a monthly basis for 6 months and 3 others (Karavetian \& Ghaddar, 2013; Shi et al., 2013; Sevick et al., 2005) adopted weekly education for 1 - 4 months. Eleven (Ashurst \& Dobbie, 2003; Ford et al., 2004; Karavetian \& Ghaddar, 2013; Campbell et al., 2009; Nisio et al., 2007; Morey et al., 2008; Sullivan et al., 2009; Mayne et al., 2012; Reddy et al., 2009; Cupisti et al., 2004) of the 18 studies had a renal dietitian only educating the patients; otherwise it was either a renal nurse and a renal dietitian (Sevick et al., 2005), a renal nurse only (Shi et al., 2013; Baraz et al., 2010; Sun et al., 2008) or a renal dietitian and a pharmacist (Yokum et al., 2008). In two studies (Karamanidou et al., 2008; de Araujo et al., 2010), the type of the educator was unclear. There was no specific trend in the reviewed articles regarding the intensity of the education given nor the type of the educator (renal dietitian, nurse or pharmacist) in terms of the effect on serum $\mathrm{P}$.

Sixteen (Karamanidou et al., 2008; Ford et al., 2004; Karavetian \& Ghaddar, 2013; Shi et al., 2-13; Lou et al., 2012; Baraz et al., 2010; Campbell et al., 2009; Nisio et al., 200; Morey et al., 2008; Sullivan et al., 2009; Yokum et al., 2008; Sevick et al., 2005; Sun et al., 2008; Mayne et al., 2012; Reddy et al., 2009; Cupisti et al., 2004) out of 18 studies 
educated their patients during the HD session itself. The study with the strongest improvement in serum P (Ashurst \& Dobbie, 2003) was unique in the timing of the education provided to their patients: just before their HD session. de Araujo et al. (2010) was the only other study that shared this timing protocol. The findings of de Araujo et al. (2010) showed significant improvement of serum P, but patients were educated on 6 different times, so the improvement may have been the result of the high intensity of the education. Further confirmation to the timing was the study protocol of Baraz et al. (2010) where 2 different education timings were tested: one during the session and another on the next day of the HD session; results showed no advantage of one over the other.

Individualized education was used by 14 studies (Karamanidou et al., 2008; Ashurst \& Dobbie, 2003; Ford et al., 2004; Karavetian \& Ghaddar, 2013; Shi et al., 2013; Lou et al., 2012; Campbell et al., 2009; Morey et al., 2008; Sullivan et al., 2009; Yokum et al., 2008; Sevick et al., 2005; Sun et al., 2008; Mayne et al., 2012; Cupisti et al., 2004) and all except 1 (Karamanidou et al., 2008) achieved improvement in serum P.

Group education was used by 4 studies and all resulted in significant improvement in serum P, and they were: 1) Reddy et al. (2009) used a one-time educational radio cassette and booklet ; 2) Nisio et al. (2207) used a 1 time educational booklet; 3) de Araujo et al. (2010) organized a relatively intense group education (frequency of meetings and various methods of educational material); 4) Baraz et al. (2010) compared the effect of a group education on the next day of HD session to individualized education during the HD session; both methods ended up with similar results, showing no advantage of one over the other.

Various educational tools were used (Table 2). Information given to patients focused on 1) hyperphosphatemia, its complications, and diet control with a list of $\mathrm{P}$ content in daily food; 2 ) restricted/non-restricted foods for low P diet, P/protein ratio of foods, reasons for compliance and possible consequences of non-compliance; 3) avoiding foods with $\mathrm{P}$ additives; 4) $\mathrm{P}$ binders, their benefit and mode of action, 5) information on relevant blood tests; in addition to behavioral change methods like selfevaluation and self-regulation. 
Table 2. Educational tools used to empower patients.

\begin{tabular}{l}
\hline Educational tools \\
$\begin{array}{l}\text { 1. Colorful informational booklet } \\
\text { 2. Handouts educational tool }\end{array}$ \\
3. Booklet on P-rich and poor food items \\
4. Games and puzzles \\
5. Posters \\
6. Involving relatives \\
7. Recipes adapted to the patients' taste and culture \\
8. Demonstration of renal meals. \\
9. Phosphate binder medication record chart and refrigerator magnet \\
10. Individualized P tracking tool \\
11. Laboratory results review \\
12. PowerPoint lecture \\
13. Reinforcement session conducted via telephone \\
14. Video education during HD sessions \\
15. Audio cassette on all relevant information to take home \\
16. Personal Digital Assistant- based program (BalanceLog) that helps dietary \\
self-management at home
\end{tabular}

ES analysis was conducted (Table 3): only 10 studies (Ashurst \& Dobbie, 2003; Ford et al., 2004; Karavetian \& Ghaddar, 2013; Shi et al., 2013; Lou et al., 2012; Morey et al., 2008; Sullivan et al., 2009; Yokim et al., 2008; de Araujo et al., 2010) were included in this analysis since the rest did not have a control and one of the studies (Karamanidou et al., 2008) had a control but no change was reported post intervention in any of the study groups. The negative ES in the results represents superiority of the intervention over the control group since having a high serum $\mathrm{P}$ is a negative outcome. Thus a negative ES indicates better improvement. 
Table 3. Effect Size of Studies.

\begin{tabular}{lllll}
\hline Author & ES & Lower Cl & Upper Cl & Effect Size \\
\hline 1. Ashurst and Dobbie (2003) & -8 & -9.5 & -6.45 & Large \\
2. Ford et al. (2004) & -1.02 & -1.54 & -0.49 & Large \\
3. Karavetian and Ghaddar (2012) & -0.66 & -1.1 & -0.21 & Medium \\
4. Shi et al.(2013) & -0.64 & -1.09 & -0.19 & Medium \\
5. Yokum et al. (2008) & -0.61 & -1.3 & 0.07 & Medium \\
6. Lou et al. (2012) & -0.51 & -0.96 & -0.07 & Medium \\
7. de Araujo (2010) & -0.36 & -1.05 & 0.32 & Small \\
8. Sullivan et al. (2009) & -0.27 & -0.51 & -0.04 & Small \\
9. Morey et al. (2008) & -0.21 & -0.72 & 0.29 & Small \\
10. Baraz et al. (2010) & -0.13 & -0.62 & 0.36 & Negligible \\
\hline
\end{tabular}

ES- effect size, $\mathrm{Cl}$ - confidence interval at $95 \%$

ES varied widely between studies; which may have been due to the major differences between study protocols. The ones with ES not indicative of their results are elaborated below. Yokum et al. (2008) generated a medium ES whereby the intervention group experienced a non significant improvement in serum $\mathrm{P}$ approaching K/DOQI optimal level; as for the control, there was a significant deterioration of the serum P. The authors considered the intervention a success, since they considered that the fate of the intervention patients without the intervention would have been like the control patients. Morey et al. (2008) had a small ES which was due to the non significant improvement in both study groups at the end of the study period (at month 6); but the intervention at month 3 resulted in a significant improvement, whereby serum $P$ dropped to $5.57 \pm 0.5 \mathrm{mg} / \mathrm{dL}$. The serum $\mathrm{P}$ of their control group stayed in $6.51 \pm 0.8$ $\mathrm{mg} / \mathrm{dL}$ (ES: -1.14 , Confidence Interval (CI): $-1.94 ;-0.87$ ). The authors explained that the level of lifestyle changes needed by the $\mathrm{P}$ restricted diet is complicated, thus a barrier to long term adherence. They pushed the topic even further and pointed out that a long term dietary restriction can result in mild depression which may lead to a relapse in the new behavioral change. They urged the need for group therapy, psychological help and proactive counseling prior to incidence of hyperphosphatemia, to effectively maintain long term adherence. As for the mild improvement of the control group at month 6 , they explained it by contamination of information between the 2 groups, pointing out that it is always difficult to separate the 2 groups of HD patients when they dialyze in the same unit. This problem also contributed to lowering the ES in de Araujo et al. (2010) where patients in the intervention and control group had significant improvement in serum $P$, even though control were educated on a topic that was completely different from diet and phosphatemia management. Finally, Baraz et al. (2010) reported a negligible ES since the 2 study groups underwent an intervention but with a different protocol; thus this study's ES clarified the lack of superiority of one protocol 
over the other. Furthermore, the ES calculation differentiated the effective techniques used to enhance dietary behavioral change among the studies. The 2 studies (Ashurst \& Dobbie, 2003; Ford et al., 2004) with large ES were unique in integrating selfmanagement tools within the educational material and individualized counseling by a renal dietitian. Moreover, we speculate that the large ES found in Ford et al. (2004) was due to the unique combination of: 1 ) a renal dietitian educating patients; 2 ) integration of self-evaluation and self-regulation tools within the education; 3 ) intervention duration of 6 consecutive months. Karavetian \& Ghaddar (2012) had a protocol quite similar to Ford et al. (2004) except that the intervention lasted only 8 weeks; this may have been the reason of the lower ES when compared to Ford et al. (2004).

The relation between knowledge, as an education outcome, and serum $\mathrm{P}$, as a behavioral change outcome, was examined. None of the studies conducted a correlation between the 2 parameters, but reported on the change of each parameter separately. The 2 parameters were significantly improved in 5 studies (Ford et al., 2004; Karavetian \& Ghaddar, 2013; Shi et al., 2013; Nisio et al., 2007; Sullivan et al., 2009) in contrast to 3 other studies (Karamanidou et al., 2008; De Aroujo et al., 2010; Reddy et al., 2009) where patients' improved knowledge did not lead to an improvement in serum $P$ (behavior). The rest of the studies did not assess knowledge but depended only on serum $\mathrm{P}$ as their outcome measure. Most authors noted knowledge as a controversial pre-determinant to behavior and pointed out situations which enhance or hinder the positive effect of attained knowledge on behavior (noted with serum P). Nisio et al. (2007) attributed their positive results in both parameters to the following direct and indirect enhancers to dietary behavior change: 1) recruiting only hperphosphatemic patients (serum $P \geq 7 \mathrm{mg} / \mathrm{dL}$ ) helped the drop of serum $P$ to be robust enough to demonstrate a significant improvement in behavior, 2) only $26 \%$ of their patients had elementary or lower educational level, thus most patients had a good educational level making them more responsive to new education, and 3) the authors speculate that the change in behavior seen with the drop of serum $P$ may have been due to the attained knowledge on $\mathrm{P}$ chelators and not as much from dietary knowledge, where patients started taking more $\mathrm{P}$ chelators (a rather easier way of managing part of hyperphsophatemia), 4) low mean age (50 year) indicating a younger and probably more responsive sample to education; 5) normal average body mass index (24.5 kg/m2) for this patient population indicating that the patients were not over-eaters, thus making it easier to apply the knowledge change behavior regarding dietary restrictions. Shi et al. (2013) and Sullivan et al. (2009) explained the positive behavior change to the focus of their dietary education on one major skill: $\mathrm{P}$ additives restriction, which contributes critically to the diet (up to $1000 \mathrm{mg} / \mathrm{d}$ ) (Yokum et al., 2008). Ford et al. (2004) and Karavetian \& Ghaddar (2012) explained their positive results by the intensity and variety of educational methods used, focusing on self management information. These 2 studies also saw the benefit of empowering a patient with new skills, and thus the improved knowledge led to an easier change in behavior. Baraz et al. (2010) reported that educa- 
tional interventions would be more effective in changing dietary behavior among HD patients when they are coupled with the following demographics: higher educational level, unemployment and younger age. de Araujo et al. (2010) offered 2 possible explanations for the lack of change in serum $P$ despite an improvement in knowledge: 1 ) serum $P$ does not change immediately which may demotivate patents from applying the dietary knowledge gained and 2) lack of individualization of diet without integrating family, social support and dietary beliefs may lead to a failure to change behavior. Karamanidou et al. (2008) recognized their one time education as insufficient to achieve behavioral change but also commented that the small sample size and the high attrition rate might have masked the possible behavioral change. Reddy et al. (2009) related the baseline low serum $P$ to the lack of change in serum $P$ post intervention despite a gain in knowledge, and thus no indicative of possible behavioral change.

\section{DISCUSSION}

This review was able to build solid evidence on the positive effect of dietary education on serum P; it was the first to engulf all interventional studies on dietary management of hyperphosphatemia among HD patients in the past decade and finally it identified the main enhancers and barriers to educational methods needed to achieve optimal dietary P management among HD patients. Caldeira et al. (2011) conducted a similar review, where all articles focusing on educational strategies related to dietary management of serum $P$ among CKD patients were compiled on June 2011. Their search resulted in 7 articles unlike the 18 in the current review; thus revealing the uniqueness of the latter. The differences in the outcome parameters and inclusion criteria between Caldeira et al. (2011) and the current review were including all CKD patients and not focused on HD, had a secondary outcome parameter (Calcium Phosphorus product) in addition to the serum $\mathrm{P}$ and searched among unpublished articles in addition to the published ones. Their findings revealed that $50 \%$ of the patients that received education achieved K/DOQI target levels of serum $\mathrm{P}$ without compromising nutritional status; this was not seen in the controls. The review highlighted the importance of intervention using psycho-educational theories, individualized, focusing on $\mathrm{P} /$ protein ratio, with a minimum duration of 4 months and delivered through a multidisciplinary team.

The current review derived facilitators for the studied behavioral change from the protocols of the studies with high ES which included: 1) use of self-evaluation and selfregulation techniques within the educational tools with mainly easy to apply skills that do not need huge lifestyle modifications; 2 ) use of individualized counseling by a renal dietitian; 3 ) high intensity of the education; 4 ) long duration of interventions ( $\geq 6$ consecutive months); 5) the timing of the education provided to their patients which was just before their HD session. Harum et al. (2003) reported that that educating patients before an HD session is the optimal timing to achieve optimal recall, compared to dur- 
ing or after the HD session; we speculate that this better recall may be the main facilitator towards better dietary self-management and thus improvement in serum $\mathrm{P}$ in the studies that used this methods. The main barriers were noted as 1) low frequency of meetings between the patient and the dietitian or the health care provider, 2) older age, 3) low educational level of patients and 4) employed patients who juggle between jobs and HD session.

\section{Strengths in the studies}

The strength of the interventions in these studies is that they are effective, affordable, done when the patients are being dialyzed or right/after before the HD session and are non-invasive. Unlike medication therapies, education interventions do not cause any health related side effects, are very low risk and create a positive atmosphere in the dialysis room. When patients are educated, they feel empowered; they stop feeling the victims of their condition which improves their quality of life and willingness to adhere to any therapy for improvement (Campbell et al., 2008). Higher quality of life has been associated with higher survival rates among HD patients (Campbell et al., 2008).

The studies focused on a patient population well known for incompliance (Denhaerynck et al., 2007) yet achieved improvement, even though this might sometimes due to the unpublished null effects. A wide range of age categories were studied, covering all decades of adulthood, which make the results generalizable to most HD patients. Moreover, the studies in the review were done in various countries: 1 from Australia (Campbell et al., 2009), 2 from Asia (Shi et al., 2013; Sun et al.,2008), 7 from Europe (Karamanidou et al., 2008; Ashurst \& Dobbie, 2003; Lou et al., 2012; Morey et al., 2008; Yokum et al., 2008; Cupisti et al., 2004), 6 from America (North (Ford et al., 2004; Sullivan et al., 2009; Sevick et al., 2005; Mayne et al., 2012) and South (Nisio et al., 2007; de Araujo et al., 2010)), and 2 from the Middle East (Karavetian \& Ghaddar, 2013; Baraz et al., 2010); thus making it is easy to draw inferences to the general HD populations of the world.

Most studies used individualized education, which is line with the guidelines set by the Academy of Nutrition and Dietetics (EAL, 2010).

\section{Limitations in the studies}

Most studies in this review did not report on education level of their patients and the differences between groups on this aspect. Harum et al. (2003) reported that level of education is an important prerequisite for the comprehension level of nutrition education among HD patients. A difference in education level of patients in comparison groups may contribute to bias in the results.

In Morey et al. (2008), 6\% of intervention patients needed an interpreter as opposed to $21 \%$ in the control group, which may indicate failure of random allocation to 
the groups. Having a lower percentage of patients that need an interpreter may put the intervention group in a superior position compared to the control and thus bias the results.

Gender was not equally distributed in 3 studies, as mentioned earlier. This may have affected the validity of their results and may compromise the comparison with the rest of the studies, since throughout the literature; female gender has been shown to be a predictor of better adherence (Kugler et al., 2011; Zrinyi et al., 2003). Thus it may be that the high ES of Ford et al. (2004) could be due to the high percentage of female participants and the low ES of Morey et al. (2008) to the high percentage of males.

Of all studies for which we could calculate an ES, Baraz et al. (2010) and Karavetian \& Ghaddar (2012) were the only ones that included the general HD population; as for the rest, only hyperphosphatemics were chosen, which may have led to stronger results since improvement of serum $\mathrm{P}$ is easier to achieve among hyperphosphatemics than in normo-phosphatemics.

Only 9 (Karamanidou et al., 2008; Ashurst \& Dobbie, 2003; Karavetian \& Ghaddar, 2013; Shi et al., 2013; Lou et al., 2012; Morey et al., 2008; Sullivan et al., 2009; Yokum et al., 2008; de Araujo et al., 2010) out of 16 studies were RCTs; more studies should adopt RCT models to enable stronger conclusions on the optimal method to be used to educate patients. Moreover, only 4 (Karamanidou et al., 2008; Karavetian \& Ghaddar, 2013; Morey et al., 2008; Sevick et al., 2005) out of 18 studies based their education on behavioral theories. Evidence shows that using behavioral theories is of added value to the success of dietary education (Spahn et al., 2010). Most studies had small sample sizes, which may either exaggerate the outcome or bias it by the selection of patients. Larger sample size RCTs are needed in this field.

A major limitation was underreporting of details of the educational methods, vague timing of the intervention (before, during or after the HD session). When the exact timing was not clearly stated but the setting was described as HD, we assumed that the education was done during the HD session. Many indicated frequency of education but not the duration of each session, some studies even did not mention the frequency itself.

Most studies concentrated on one aspect of lifestyle change, which was knowledge, but none concentrated on all the other factors affecting the patient adherence. Chan et al. (2012) explored determinants of adherence to new behaviors among HD patients and reported that dietary change was one of the most difficult changes perceived by patients. They pointed out barriers to adherence among HD patients which were: old age, vintage dialysis years, low education level, financial constraints, food preferences, degree of lifestyle change required, complexity of diet, forgetfulness, side effects of the change required. Thus, the authors highlighted the need to look beyond knowledge in changing behavior.

Another limitation was the failure to include possible mediators and moderators of the effect of education on serum $\mathrm{P}$ improvement, which makes it hard to pinpoint the 
working mechanisms. We therefore suggest in future studies to also measure intermediary outcome variables.

Some studies did not use dietitians as the educator to HD patients. K/DOQI (2003) and KDIGO (2009) state a "clear need for more active involvement" of renal dietitians in the care of renal patients to provide appropriate and consistent education and counseling and regular FUs during prescription of dietary $\mathrm{P}$ restriction. Dietetic professionals can conduct nutrition counseling to facilitate patient's behavioral change, they have the ability to deal with patient non-adherence to recommended dietary regimens and optimal nutrition prescription (EAL, 2010; McCann, 2005).

No multidisciplinary approach was used in any of the studies. Krause et al. (2006) demonstrated the significant positive effect of a multidisciplinary team approach on patient's physical and psychological wellbeing among patients with multi chronic illness. The authors worked on increasing self-efficacy towards self-management among patients and involving family in the process. They highlighted the need to focus on increasing patient's internal self-control in order to achieve optimal adherence in new behaviors. Physicians, psychologists, educators, social worker and dietitians should be integrated in developing and providing the education to HD patients.

None of the studies conducted a focus group to understand the actual barriers to adherence among patients and accordingly build the educational material. Hollingdale et al. (2008) explored the HD patient's perspective towards the renal diet and revealed that patients see the renal diet as unpractical and difficult to integrate in regular life. Thus the authors concluded that patients should be involved in the development of their dietary plans so to understand the missing puzzle pieces of achieving full adherence.

At least half of the studies educated the patients only once and surprisingly achieved a significant improvement; this illustrates the high level of the absorptive capacity among these patients for information towards dietary behavioral change. Chan et al. (2012) highlighted that educational communication between health care professionals and patients should be "simple and practical" and interaction should be frequent to assure that patients are sufficiently reminded of all the details of their selfcare.

KDIGO (2009) guidelines stress the need to balance the low serum $\mathrm{P}$ intake with that of high protein to prevent malnutrition among HD patients. Cupitsi et al. (2004) was the only study that addressed this concept. Educating patients only on dietary $P$ restriction might lead them to protein deficiency related malnutrition (Guida et al., 2011). Studies targeting renal hyperphosphatemia should start focusing on this balance and not only on reinforcing dietary $\mathrm{P}$ restriction to prevent protein deficiency malnutrition.

Many of the studies had not checked for homogeneity of study groups at baseline which may have resulted into exaggerated or biased results. Finally, most studies em- 
ployed convenience samples and had not done power analysis for a sufficient sample size. This may have resulted in misleading results (Thomas \& Juanes, 1996).

\section{CONCLUSION}

This review extracted 18 studies, 1415-22,24,26-30 of which resulted in a significant drop in serum $\mathrm{P}$ among the intervention group, thus showing a positive relation between nutrition education and improvement of serum $\mathrm{P}$. The studies showed common patterns of educating patients and the road to effective diet related behavioral change interventions for hyperphosphatemia management among HD patients is elucidated (Table 4). Stronger evidence still lacks and it can be achieved by: involving patents in understanding what educational material is needed and how it needs to be administered through focus groups, multidisciplinary team integration into RCTs with larger samples, targeting males and females equally, with longer intervention and longer FUs, theory based and more frequent education to patients, more involvement of family and administration, and finally cost effective analysis to start integrating such interventions in daily routine practice of dietetic care of HD patients.

Table 4. The formula for effective dietary education to manage hyperphosphatemia in HD patients.

\begin{tabular}{|c|c|c|c|c|c|}
\hline $\begin{array}{l}\text { Human } \\
\text { component }\end{array}$ & $\begin{array}{l}\text { Logistical } \\
\text { component }\end{array}$ & $\begin{array}{l}\text { Timing } \\
\text { component }\end{array}$ & $\begin{array}{l}\text { Educational } \\
\text { component }\end{array}$ & $\begin{array}{l}\text { Theoretical } \\
\text { component }\end{array}$ & $\begin{array}{l}\text { Time } \\
\text { component }\end{array}$ \\
\hline $\begin{array}{l}\text { Patients in- } \\
\text { volved in prepa- } \\
\text { ration of the } \\
\text { intervention } \\
+ \\
\text { Multidisciplinary } \\
\text { team approach } \\
\text { where depres- } \\
\text { sion is also } \\
\text { treated }\end{array}$ & $\begin{array}{l}\text { Educational mate- } \\
\text { rial to be used } \\
\text { 8. Colorful infor- } \\
\text { mational book- } \\
\text { let } \\
\text { 9. Handouts } \\
\text { 10. Booklet on P } \\
\text { rich and poor } \\
\text { food items } \\
\text { 11. Games and } \\
\text { puzzles } \\
\text { 12. Posters } \\
\text { 13. Involving rela- } \\
\text { tives } \\
\text { 14. Recipes } \\
\text { adapted to the } \\
\text { patients' taste } \\
\text { and culture }\end{array}$ & $\begin{array}{l}\text { Education } \\
\text { must be done } \\
\text { before the HD } \\
\text { sessions and } \\
\text { individualized }\end{array}$ & $\begin{array}{l}\text { 6. Hyperphosphatemia, } \\
\text { its complications, and } \\
\text { diet control with a } \\
\text { complete list of P } \\
\text { content in daily food; } \\
\text { 7. Restricted/non- } \\
\text { restricted foods for } \\
\text { low P diet, P/protein } \\
\text { ratio of foods; } \\
\text { 8. Avoiding foods with P } \\
\text { additives; } \\
\text { 9. binders, their } \\
\text { benefit and mode of } \\
\text { action, } \\
\text { 10. Information on rele- } \\
\text { vant blood tests; in } \\
\text { addition to behavioral } \\
\text { change methods like } \\
\text { self-evaluation and } \\
\text { self- regulation }\end{array}$ & $\begin{array}{l}\text { Use of behav- } \\
\text { ioral theories }\end{array}$ & $\begin{array}{l}\text { Not less } \\
\text { than } 6 \\
\text { month } \\
\text { duration } \\
\text { for educa- } \\
\text { tion and } \\
\text { not less } \\
\text { than } \\
\text { monthly }\end{array}$ \\
\hline
\end{tabular}




\section{Appendix 1 : Search string used}

(renal dialysis.ab,ti. or exp Renal Dialysis/) AND (exp Diet/ or diet*.ab,ti.) AND ((exp Education/ or educat*.ab,ti.) OR (counsel*.ab,ti. or exp Counseling/) OR (intervention.ab,ti. or exp Intervention Studies/)) AND ((phosphate.ab,ti. or exp Phosphates/) OR (phosphorus.ab,ti. or exp Phosphorus/)). 


\section{REFERENCES}

Academy of Nutrition and Dietetics Evidence Analysis Library. (2010). "Is MNT provided by a Registered Dietitian for chronic kidney disease (CKD) in adults effective?", available at: http://andevidencelibrary.com/template.cfm?key=2407 (accessed 12 January, 2012).

Baraz, S., Parvardeh, S., Mohammadi, E. and Broumand, B. (2010). Dietary and fluid compliance: an educational intervention for patients having haemodialysis. Journal of Advanced Nursing, 66(1), 60-68.

Caldeira, D., Amaral, T., David, C. and Sampaio, C. (2011). Educational strategies to reduce serum phosphorus in hyperphosphatemic patients with chronic kidney disease: systematic review with metaanalysis. Journal of Renal Nutrition, 21(4), 285-294.

Campbell, K. L., Ash, S. and Bauer, J. D. (2008). The impact of nutrition intervention on quality of life in predialysis chronic kidney disease patients [abstract].Clinical Nutrition, 27(4), 537-544.

Campbell, K.L., Ash, S., Zabel, R., Mcfarlane, C., Juffs, P. and Bauer, J.D. (2009). Implementation of standardized nutrition guidelines by renal dietitians is associated with improved nutrition status. Journal of Renal Nutrition, 19(2), 136-144.

Chan, Y. M., Zalilah, M. S. and Hii, S. Z. (2012). Determinants of Compliance Behaviours among Patients Undergoing Hemodialysis in Malaysia. PloS One,7(8), e41362.

Cupisti, A., D'Alessandro, C., Baldi, R., and Barsotti, G. (2004). Dietary habits and counseling focused on phosphate intake of hemodialysis patients with hyperphosphatemia. Journal of Renal Nutrition, 14(4), 220225.

Danese, M. D., Belozeroff, V., Smirnakis, K. and Rothman, K. J. (2008). Consistent control of mineral and bone disorder in incident hemodialysis patients. Clinical Journal of the American Society of Nephrology, 3(5), 1423-1429

de Araujo, L. P. R. D., Figueiredo, A. E. P. L. and d'Avila, D. O. L. (2010). Evaluation of an educational program on calcium and phosphorus metabolism for patients on hemodialysis. Revista da Escola de Enfermagem da USP, 44(4), 928-932.

de Brito Ashurst, I. and Dobbie, H. (2003). A randomized controlled trial of an educational intervention to improve phosphate levels in hemodialysis patients. Journal of Renal Nutrition, 13(4), 267-274.

Denhaerynck, K., Manhaeve, D., Dobbels, F., Garzoni, D., Nolte, C. and De Geest, S. (2007). Prevalence and consequences of nonadherence to hemodialysis regimens. American Journal of Critical Care, 16(3), 222235.

Floege, J., Kim, J., Ireland, E., Chazot, C., Drueke, T., de Francisco, A., . . . and Wheeler, D. C. (2011). Serum iPTH, calcium and phosphate, and the risk of mortality in a European haemodialysis population. Nephrology Dialysis Transplantation, 26(6), 1948-1955.

Ford, J.C., Pope, J.F., Hunt, A.E. and Gerald, B. (2004). The effect of diet education on the laboratory values and knowledge of hemodialysis patients with hyperphosphatemia. Journal of Renal Nutrition, 14(1), 3644.

Guida, B., Piccoli, A., Trio, R., Laccetti, R., Nastasi, A., Paglione, A., . . and Memoli, B. (2011). Dietary phosphate restriction in dialysis patients: a new approach for the treatment of hyperphosphataemia. Nutrition, Metabolism and Cardiovascular Diseases, 21(11), 879-884.

Harum, P., Galves, O., Mayol, L. and Blanchard, R. (2003). Immediate and delayed memory recall patterns of chronic hemodialysis adult Hispanic patients. Journal of Renal Nutrition,13(2), 98-104.

Hollingdale, R., Sutton, D. and Hart, K. (2008). Facilitating Dietary Change in Renal Disease: Investigating Patients' Perspectives. Journal of Renal Care, 34(3), 136-142.

Karamanidou, C., Weinman, J. and Horne, R. (2008). Improving haemodialysis patients' understanding of phosphate-binding medication: a pilot study of a psycho-educational intervention designed to change patients' perceptions of the problem and treatment. British Journal of Health Psychology, 13(2), 205-214.

Karavetian M. and Ghaddar S. (2012). Nutritional education for the management of osteodystrophy (NEMO) in patients on haemodialysis: a randomised controlled trial. Journal of Renal Care, 39(1), 19-30.

Kidney Disease Improving Global Outcomes (KDIGO) CKD Work Group. (2013). KDIGO 2012 clinical practice guideline for the evaluation and management of chronic kidney disease. Kidney International, 3, S1-S150. 
Kidney Disease: Improving Global Outcomes (KDIGO) CKD-MBD Work Group. (2009). KDIGO clinical practice guideline for the diagnosis, evaluation, prevention, and treatment of chronic kidney disease-mineral and bone disorder (CKD-MBD). Kidney International, 113, S1-S130.

Krause, C. M., Joyce, S., Curtin, K., Krause, C. M., Jones, C. S., Kuhn, M. E., . . . and Lucas, D. R. (2006). The impact of a multidisciplinary, integrated approach on improving the health and quality of care for individuals dealing with multiple chronic conditions. American Journal of Orthopsychiatry, 76(1), 109-114.

Kugler, C., Maeding, I. and Russell, C. L. (2011). Non-adherence in patients on chronic hemodialysis: an international comparison study. Journal of nephrology, 24(3), 366.

Levey, A. S., Coresh, J., Balk, E., Kausz, A. T., Levin, A., Steffes, M. W., . . . and Eknoyan, G. (2003). National Kidney Foundation practice guidelines for chronic kidney disease: evaluation, classification, and stratification. Annals of internal medicine, 139(2), 137-147.

Lou, L.M. Caverni, A., Gimeno, J.A., Moreno, R., Perez,J., Alvarez, A., Campos, B., . . and Martin, F. on behalf the Aragon CKD Research Group. (2012). Dietary intervention focused on phosphate intake in hemodialysis patients with hyperphosphoremia. Clinical Nephrology, 77(6), 476-483.

Martin, K. J. and Gonzalez, E. A. (2011). Prevention and control of phosphate retention/hyperphosphatemia in CKD-MBD: what is normal, when to start, and how to treat?. Clinical Journal of the American Society of Nephrology, 6(2), 440-446

Mayne, T.J., Benner, D., Ricketts, K., Burgess, M., Wilson, S., Poole, L., . . . and Krishnan, M. (2012). Results of a pilot program to improve phosphorus outcomes in hemodialysis patients. Journal of Renal Nutrition, 22(5), 472-479

McCann, L. (2005). K/DOQI practice guidelines for bone metabolism and disease in chronic kidney disease: Another opportunity for renal dietitians to take a leadership role in improving outcomes for patients with chronic kidney disease. Journal of Renal Nutrition, 15(2), 265-274.

Morey, B., Walker, R. and Davenport, A. (2008). More dietetic time, better outcome? A randomized prospective study investigating the effect of more dietetic time on phosphate control in end-stage kidney failure haemodialysis patients. Nephron Clinical Practice, 109(3), c173-c180.

Nisio, J. M., Bazanelli, A. P., Kamimura, M. A., Lopes, M. G. G., Ribeiro, F. S. D. M., Vasselai, P., . . and Cuppari, L. (2007). Impacto de um programa de educação nutricional no controle da hiperfosfatemia de pacientes em hemodiálise. Jornal Brasileiro de Nefrologia, 29(3), 152-157.

Petrovic, D., Obrenovic, R., Trbojevic-Stankovic, J., Majkic-Singh, N. and Stojimirovic, B. (2012). Hyperphosphatemia-The Risk Factor for Adverse Outcome in Maintenance Hemodialysis Patients. Journal of Medical Biochemistry, 31(3), 239-245

Reddy V, Symes F, Sethi N, et al. (2009). Dietitian-led education program to improve phosphate control in a single-center hemodialysis population. J Ren Nutr.19:314-320.

Sevick, M. A., Piraino, B., Sereika, S., Starrett, T., Bender, C., Bernardini, J., . . . and Burke, L. E. (2005). A preliminary study of PDA-based dietary self-monitoring in hemodialysis patients. Journal of Renal Nutrition, 15(3), 304-311

Shi, Y. X., Fan, X. Y., Han, H. J., Wu, Q. X., Di, H. J., Hou, Y. H and Zhao, Y. (2013). Effectiveness of a nurse-led intensive educational programme on chronic kidney failure patients with hyperphosphataemia: randomised controlled trial. Journal of Cinical Nursing, 22(7-8), 1189-1197.

Shils, M. E. and Shike, M. (Eds.). (2006). Modern nutrition in health and disease. Lippincott Williams \& Wilkins.

Spahn, J. M., Reeves, R. S., Keim, K. S., Laquatra, I., Kellogg, M., Jortberg, B. and Clark, N. A. (2010). State of the evidence regarding behavior change theories and strategies in nutrition counseling to facilitate health and food behavior change. Journal of the American Dietetic Association, 110(6), 879-891.

Sullivan, S., Sayre, S. S., Leon, J. B., Machekano, R., Love, T. E.. Porter, D., . . . and Sehgal, A. R. (2009). Effect of food additives on hyperphosphatemia among patients with end-stage renal disease. A randomized controlled trial. Journal of the American Medical Association, 301(6), 629-635

Sun, C.Y., Chang, K.C., Chen, S.H., Chang, C.T. and Wu, M.S. (2008). Patient education: an efficient adjuvant therapy for hyperphosphatemia in hemodialysis patients. Renal Failure, 30(1), 57-62. 
Tentori, F., Blayney, M. J., Albert, J. M., Gillespie, B. W., Kerr, P. G., Bommer, J., . . . and Port, F. K. (2008). Mortality risk for dialysis patients with different levels of serum calcium, phosphorus, and PTH: the Dialysis Outcomes and Practice Patterns Study (DOPPS). American Journal of Kidney Diseases, 52(3), 519.

Thalheimer, W. and Cook, S (2003). How to calculate effect sizes from published research: A Simplified spreadsheet. Retrieved from: www.psyphz.psych.wisc.edu/ shackman/Effect_Sizes_Spreadsheet.xls. Accessed on January 12, 2012.

Thomas, I. and Juanes, F. (1996). The importance of statistical power analysis: an example from Animal Behavior. Animal Behavior, 52, 856-859.

Yokum, D., Glass, G., Fun Cheung, C., Cunningham, J., Fan, S. and Madden, A. M. (2008). Evaluation of a phosphate management protocol to achieve optimum serum phosphate levels in hemodialysis patients. Journal of Renal Nutrition, 18(6), 521-529.

Zrinyi, M., Juhasz, M., Balla, J., Katona, E., Ben, T., Kakuk, G., and Pall, D. (2003). Dietary self-efficacy: determinant of compliance behaviors and biochemical outcomes in hemodialysis patients. Nephrology Dialysis Transplantation, 18(9), 1869-1873. 


\section{CHAPTER 5}

\section{Nutritional Education for Management of Osteodystrophy (NEMO) Trial: Design and Patient Characteristics, Lebanon}

Karavetian, M., Abboud, S., Elzein, H., Haydar, S., de Vries, N. (2014). Nutritional education for management of osteodystrophy (NEMO) trial: Design and patient characteristics, Lebanon

Nutrition Research and Practice, February 8 (1): 103 - 111 


\section{ABSTRACT}

This study aims to determine the effect of a trained dedicated dietitian on clinical outcomes among Lebanese hemodialysis (HD) patients: and thus demonstrate a viable developing country model. This paper describes the study protocol and baseline data. The study was a multicenter randomized controlled trial with parallel-group design involving 12 HD units: assigned to cluster $A(n=6)$ or $B(n=6)$. A total of 570 patients met the inclusion criteria. Patients in cluster $A$ were randomly assigned as per dialysis shift to the following: Dedicated Dietitian (DD) $(n=133)$ and Existing Practice (EP) $(n=$ 138 ) protocols. Cluster B patients $(n=299)$ received Trained Hospital Dietitian (THD) protocol. Dietitians of the DD and THD groups were trained by the research team on Kidney Disease Outcomes Quality Initiative nutrition guidelines. DD protocol included: individualized nutrition education for 2 hours/month/HD patient for 6 months focusing on renal osteodystrophy and using the Trans-theoretical theory for behavioral change. EP protocol included nutrition education given to patients by hospital dietitians who were blinded to the study. The THD protocol included nutrition education to patients given by hospital dietitian as per the training received but within hospital responsibilities, with no set educational protocol or tools. Baseline data revealed that $40 \%$ of patients were hyperphosphatemics (> $5.5 \mathrm{mg} / \mathrm{dl}$ ) with low knowledge of dietary $\mathrm{P}$ restriction in addition to inadequate daily protein intake $(58.86 \% \pm 33.87 \%$ of needs) yet adequate dietary $\mathrm{P}$ intake (795.52 $\pm 366.94 \mathrm{mg} /$ day). Quality of life (QOL) ranged from $48-75 \%$ of full health. Baseline differences between the 3 groups revealed significant differences in serum $\mathrm{P}$, malnutrition status, adherence to diet and in 2 factors of the QOL: physical and social functioning. The data show room for improvement in the nutritional status of the patients. The NEMO trial may be able to demonstrate a better nutritional management of HD patients. 


\section{INTRODUCTION}

The prevalence of chronic kidney disease (CKD) is increasing worldwide (Lebanese National Kidney Registry 2012), and the situation is not different in Lebanon. The number of hemodialysis (HD) patients rose from 2500 in 2010 to 3000 in 2012 (Mallat et al., 2011), a considerable increase for a small population of 4.14 million (CIA, 2012).

The lack of adherence to medical nutrition therapy (MNT) among HD patients is related to a wide range of complications such as hyperphosphatemia, Chronic Kidney Disease- Mineral and Bone Disorder (CKD-MBD), cardiovascular disease, morbidity, and considerable loss of quality of life, just to name a few (Denhaerynck et al., 2007). This in turn produces increased health care costs (Denhaerynck et al., 2007). Literature shows that only $36 \%$ of the HD patients are able to adhere to the MNT guidelines (Lee \& Molassiotis, 2002) and as low as $43 \%$ in one important aspect: phosphorus (P) intake recommendations (Denhaerynck et al., 2007). A study conducted in Lebanon on 122 HD stable patients showed that $57 \%$ of them has a serum $P>5.5 \mathrm{mg} / \mathrm{dl}$ indicating the lack of adherence (Karavetian \& Ghaddar, 2013). Reported predictors of non-adherence were gender, age, years on dialysis, patient and staff education level, physical limitations, financial limitations, inadequate staffing, and the patient's willingness to cooperate with the staff (Richard, 2006).

Self-management focused counseling (SMFC), an individualized intervention based on the cognitive behavioral therapy approach, has been shown to increase patient adherence to nutritional and medical therapy (Richard, 2006). Success of such program depends on its integration in the usual practical care of the dialysis units and staff. Moreover, a recent evidence based guideline highlighted the necessity of "minimum dietitian-patient" time of two hours per month for up to one year to achieve adequate self-management for all aspects of MNT for HD (EAL, 2010).

HD units in Lebanon are exclusively hospital based, and the dietetic services in these units are provided by the general hospital dietitians who are overloaded with the hospital work and not trained for the specific needs of HD patients (Karavetian et al., 2013). Resource and compensation limitations inadvertently force the decision not to have a dedicated renal dietitian, a situation prevalent in most developing countries (Gregory, 2009).

The objective of the Nutritional Education for Management of Osteodystrophy (NEMO) trial was to determine the value of a trained dedicated dietitian in the HD unit on patient clinical outcomes and the quality of life parameters in Lebanon, compared to 3 situations: 1) existing practice; 2) the practice of trained hospital dietitian who are occupied with hospital duties, with the goal of providing a basis for national health care policy change in nutritional management of HD patients. In this paper, we will explain the study design, methodology and present baseline patient characteristics. 


\section{METHODS}

\section{Subjects and Methods}

The study was a multicenter randomized controlled trial with parallel-group interventions. Study implementation involved three steps: (1) Sample determination and randomization of HD units and patients; (2) Staff training and development of patient education material; (3) Conduct of study and data collection. This paper will elaborate on the first two steps and present baseline results from the third step. The study had 3 protocols applied in 2 clusters of dialysis units. Cluster A consisted of 2 protocols: Dedicated Dietitian (DD) management of Osteodystrophy compared to Existing Practice (EP). Cluster B consisted of Trained Hospital Dietitian (THD) Management of Osteodystrophy.

1. Cluster A: The aim of this cluster was to identify the effect of a dedicated competent dietitian, externally assigned to the study HD unit, on the dietary behaviour of HD patients related to CKD-MBD management. Patients in each HD unit of Cluster A were randomly divided as per their HD shifts and assigned to the DD or the EP group. This cluster based randomization method has been proven to be adequate for patient oriented education studies in HD centres, since it minimizes diffusion of information from one group to another and prevents contamination (Griva et al., 2011). Hospital staff (physicians, dietitians, nurses) were conveyed the general aim of the study protocol for ethical reasons, but they were blinded to the specific patient oriented dietary education, outcome assessors and data analysis. The EP group was considered as the waiting controls. The research team planned to provide them with the intervention educational material after the completion of all the phases of the study.

2. Cluster B: The aim of this cluster was to assess whether providing equal training on MNT standards of CKD-MBD to the hospital dietitian can be a viable low cost alternative for having a dedicated dietitian; thus, the study group was labelled as THD, bearing in mind that the hospital dietitian had many responsibilities set by the hospital other than the management of the HD patients. There was no control group in this cluster, as it is not ethical to expect the hospital dietitian to offer two different standards of care within the same institution.

Randomization of the HD units recruited to the study was done in a way to represent the situation of Lebanon. As per the ministry of public health in Lebanon, HD units are divided into 3 pools based on their size: small (30-49 patients), medium (50-99 patients) and large ( $\geq 100$ patients). Thus, units were randomly selected such that all 3 pools are represented in each of two clusters A and B: one large, two medium and three small. This step is intended to adjust for potential institutional, practice, logistic, staffing and economic issues that may differ by unit size. 


\section{Sample determination and randomization of HD units and patients:}

Sample size was determined according to change in serum $P$, the main objective outcome of this study. We based our calculations on the data retrieved from our pilot study (Karavetian \& Ghaddar, 2013) where serum P changed significantly from 6.54 to $5.39 \mathrm{mg} / \mathrm{dl}$ ( $\pm 2.0 \mathrm{mg}$ ) in the DD intervention group and from 6.16 to $6.51 \mathrm{mg} / \mathrm{dl}( \pm 1.5$ $\mathrm{mg}$ ) in the control group with no statistical significance. To generate a similar significant effect of the prior in Cluster A of this study, a sample size of 50 patients in each of the intervention and control groups was estimated to achieve $80 \%$ power at a $5 \%$ alpha. As for cluster B intervention group, we multiplied the number of patients in it by 2 , expecting a drop in effect size in this protocol.

Subsequently, the sample size for each group was multiplied by 3 to account for the 3 different sizes of the participant HD units, and by an additional $20 \%$ to compensate for refusals, loss to follow up, and drop-outs. This summed up to a sample of $\mathrm{n}=360$ for cluster A divided into (Dedicated Dietitian group: $\mathrm{n}=180$ and EP group: $\mathrm{n}=180$ ) and another 360 patients for THD intervention and thus, a theoretical total sample size of 720 patients.

Inclusion criteria: HD patient of Lebanese origin, free of life-threatening acute disease, with a life expectancy $>6$ months, on HD $\geq 3$ months, adult (age: $\geq 18$ years), at their full capacity of cognitive, psychiatric and physical ability for self-care and communication, capable to communicate either verbally or through writing, fully aware of the procedure of the study, and able to provide a consent form. Patients who did not meet all inclusion criteria were excluded.

The NEMO trial was conducted according to the guidelines laid down in the Declaration of Helsinki and all procedures involving human subjects were approved by the institutional review board approvals by each participating institution. The consent also included permission to review the medical chart for demographic information and current laboratory values. Confidentiality and anonymity were maintained by use of coding.

\section{Staff Training:}

- DD group: Five research dietitians of graduate level externally recruited and trained by the principal investigator (PI) during a 2 months period on MNT standards for HD patients according to KDOQI nutrition standards (NKF-KQODI, 2000). Details of the training will be described in future publications by our team.

- EP group: Hospital dietitians of the HD units assigned to this group blinded to the study continued to provide routine dietetic care.

- THD group: Hospital dietitians of HD units assigned to this group received the same 2 months training by the PI as that of the DD group. 


\section{Patient Education Material Development}

Patient education material was developed on the basis of the Trans-theoretical Model (TTM) (Prochaska, 2008) and designed as proposed in the study of Finckenor et al. (2000). It was divided into 3 sections: pre-action (pre-contemplation, contemplation, and preparation), action and maintenance. Each section included many lessons, which were repeated in each section with a different approach. Materials used were: pamphlets, posters, booklet of alternatives to high $\mathrm{P}$ foods and recipe books. Details of the educational material will be described in a different paper by the same authors in the near future.

\section{Conduct of study and data collection.}

- DD Group: Each patient in this group received an individualized, twice a week, 15 minute education for 6 months, to a total of 12 hours of education in accordance with the 2 hour per month recommendation by the Academy of Nutrition and Dietetics (EAL, 2010). The education was provided by the 5 research renal dietitians in 6 HD units. Two of the units had less than 30 patients for which 1 dietitian was sufficient to manage both units.

- EP Group: Patients of this group continued to receive education from hospital dietitians as per existing practice. These dietitians were blinded to the study.

- THD Group: Patients in this group received education by the hospital dietitian as per the latter's availability. The hospital dietitian, after being trained by the PI, was left free to provide education during the 6 months of the study on her own initiative and was informed that her visits documented in the patient files would be monitored by the PI.

The study had 3 phases: baseline (t1), intervention (t2) and follow-up (t3) where the each of the latter 2 had 6 months duration. The aim of the 6 months duration of the intervention was to facilitate behavioral change to take place as per the recommendation of Prochaska (2008) and the aim of the 6 months follow up post intervention was to determine whether the patients had maintained their stage of behavioral change or relapsed. The 6 months follow up period is the duration of follow up in most nutrition education intervention studies in CKD (medium term) and considered to be effective (Mason et al., 2008). During the follow up period the research team had no contact with any of the participants.

\section{Data collection:}

The study was evaluated using objective and subjective tools.

The objective ones included data from the medical chart: demographics, biochemical markers (calcium, phosphorus, parathyroid hormone) and the frequency of dieti- 
tian's visits per patient (Diet Consults). All of these parameters, except the demographics, were collected and monitored at 3 time points: Baseline (t1: average of 6 months preceding the education), post-intervention (t2: average of 5 months during the education and 1 month immediately after the education) and follow up (t3: average of 6 months after the education). The protocol of the study is illustrated in Figure 1.

Figure 1: Flow chart of study design

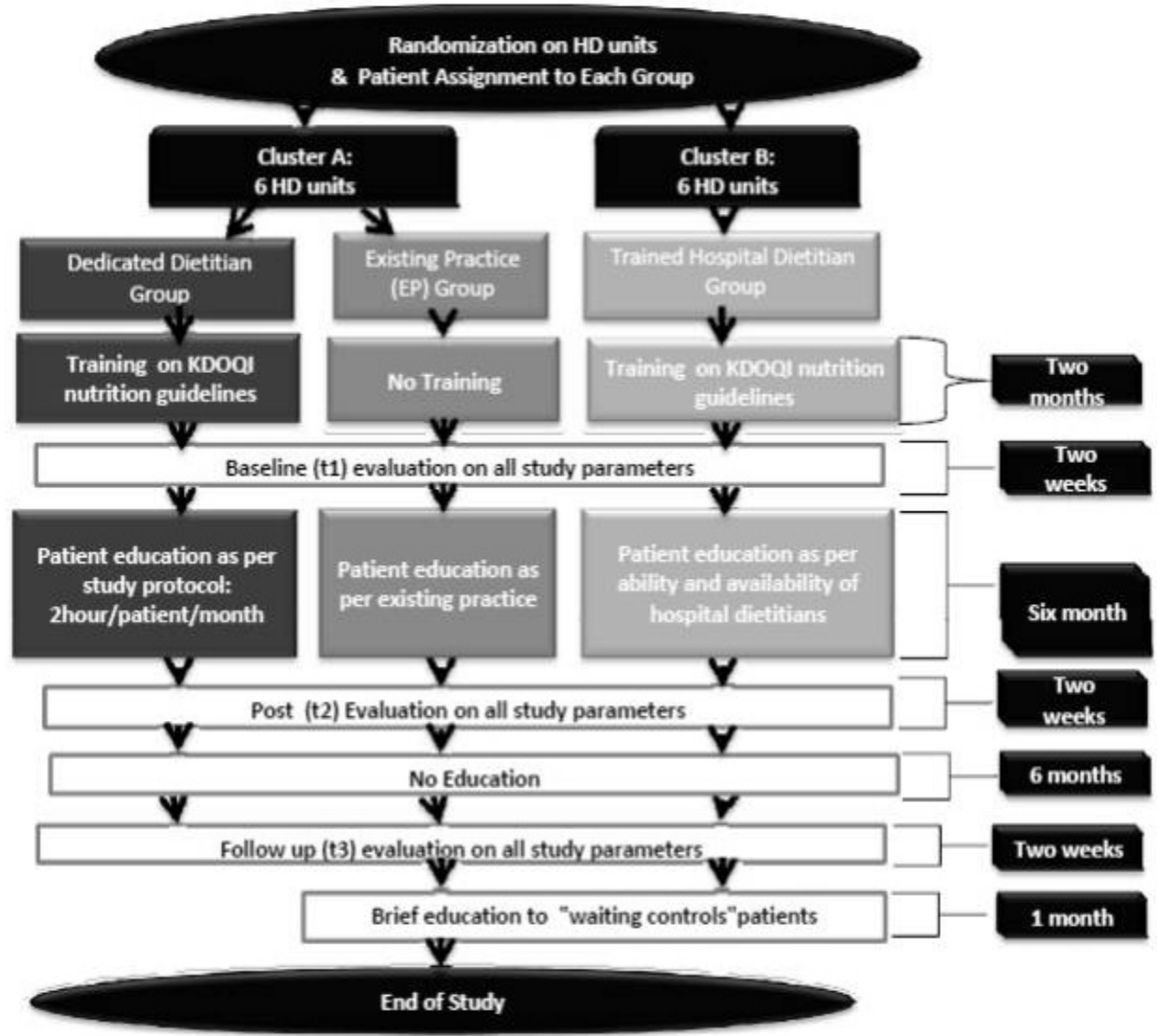

As for subjective tools, 5 questionnaires were used in this study. Each questionnaire was conducted for each patient at 3 different times during the study (t1, t2, t3). Only two questionnaires were administered per visit to each patient in order to prevent answering bias.

The Knowledge questionnaire (KnQ) was adapted from Ford et al. (2004). With 18 questions, it assessed the patient's knowledge about kidney disease, renal diet, phosphate binders, vitamin $D$ therapy and their perception of the importance of diet in their treatment. The total score ranged from 0-18 which was converted into a percentage, where a cut-off score of $60 \%$ indicated sufficient knowledge. 
Stages of Behavioral Change (SBehCh) towards $\mathrm{P}$ restricted diet (SBehCh-P) was assessed using the decision tree as described in the trans-theoretical model, adopted from Welch (2001) with no translation. Only the components were modified to address $\mathrm{P}$ issues; a dietary $\mathrm{P}$ intake between $800-1000 \mathrm{mg}$ and a $\mathrm{P} /$ protein ratio $<13$, in addition to having a serum $P$ between 3.5 and $5.49 \mathrm{mg} / \mathrm{dl}$, was set as the criterion of adherence. The tool assigned patients to one of the following stages with their respective scores: pre-contemplation (1), contemplation (2), preparation (3), action (4) or maintenance (5); the higher the score was for each patient, the more readiness to change on their part.

Dietary $\mathbf{P}$ and protein intake: The actual dietary phosphorus ( $\mathrm{mg}$ ) and the protein (g) intake was collected by a 3 time 24 hour recall and calculated using the renal exchange system and the USDA database. The mean of the 3 times was used to estimate the actual intake.

Daily Protein (\%) Consumed: The daily protein need was calculated (1.2 g/kg SBW) after which the \% protein intake was estimated (actual protein $(\mathrm{g})$ intake /daily protein (g) needs *100).

Malnutrition Inflammation Score (MIS): This is a comprehensive scoring system (Kalantar-Zadeh et al., 2001) with significant associations with prospective hospitalization and mortality as well as measures of nutrition, inflammation, and anemia in HD. MIS has 10 components, each with four levels of severity from 0 (normal) to 3 (severely abnormal). The sum of all 10 MIS components ranges from 0 (normal) to 30 (severely abnormal); a higher score reflects more severe degree of malnutrition and inflammation. The scoring sheet consists of four sections

Quality of life (QOL) was measured with the short-form health survey (SF-36) (Ware et al., 1992). It assessed 8 health concepts: physical functioning, usual role and social activities, bodily pain, general mental health and general health. Patients were presented Likert scale type items. The final score for each concept ranges between 0 (death) and 100 (full life).

The Arabic, culture specific, and validated version of KQ (Karavetian \& Ghaddar, 2013) and QOL (Sabbah et al., 2003) was used.

None of the authors had any relationship with private companies with financial interest in the information contained in the manuscript.

\section{Statistical analysis}

All statistical analyses were conducted using the Statistical Package for the Social Sciences (SPSS). A .05 significance level was utilized for strength of association to guarantee $95 \%$ confidence level. Descriptive analysis was conducted, categorical data were reported as frequencies and percentage counts: continuous data as means \pm standard deviation (SD). Pearson's Chi Square (X2) was used to show group differences for cate- 
gorical variables. ANOVA and Duncan's post hoc test was done to detect group differences for continuous data.

\section{RESULTS}

A total of 720 patients participated in the study; 570 of those met the inclusion criteria and were assigned to the 3 study groups: DD $(n=133)$, EP $(n=138)$ and THD $(n=299)$. The number of participants who completed the study was 435; this attrition rate was due to transfer of patients into another dialysis unit, transplantation, patient resistance, hospitalization, and death (Figure 2).

Figure 2: Attrition Data of the Study

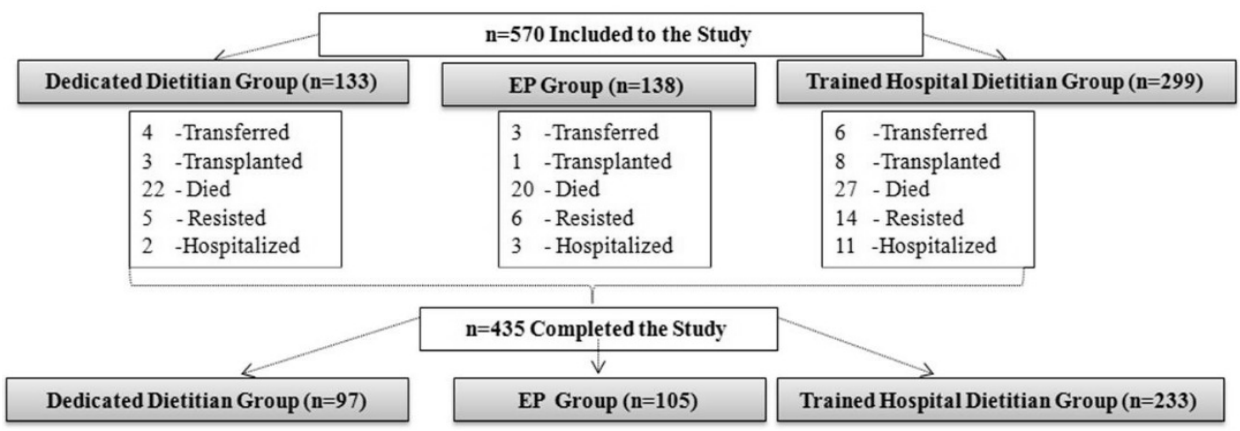

\section{Baseline Sample Characteristics:}

A descriptive analysis of baseline data (Tables 1 \& 2) showed that $57.8 \%$ of the population was male with a mean age of 59.28 and mean BMI of $25 \mathrm{~kg} / \mathrm{m} 2$. The majority of the patients were married $(77.4 \%)$, unemployed $(72.8 \%)$ with an elementary education level (33.5\%). Most of the patients had hypertension (67.7\%). Diabetes was the most common primary cause of HD initiation (24.4\%) followed by CVD and hypertension (18.25\%). The average frequency of hospital dietitian's visit was less than 1 time per patient within the 6 months prior to the study. The biochemical parameters showed that $40.4 \%$ of the population suffered from hyperphosphatemia and $26.1 \%$ had a Ca*P byproduct higher than $55 \mathrm{mg} 2 / \mathrm{dl} 2$. The mean value of PTH was also elevated. Our population consumed $58.9 \%$ of their daily protein needs and the mean dietary phosphorus intake was below the daily recommendations. 
Table 1. Baseline profile of study sample and groups

\begin{tabular}{|c|c|c|c|c|}
\hline & $\begin{array}{l}\text { DD group } \\
(n=133)\end{array}$ & $\begin{array}{l}\text { EP group } \\
(n=138)\end{array}$ & $\begin{array}{l}\text { THD group } \\
\text { (n=299) }\end{array}$ & $\begin{array}{c}\text { All } \\
(n=570)\end{array}$ \\
\hline & $\%(n)$ & $\%(n)$ & $\%(n)$ & $\%(n)$ \\
\hline Gender : Male & $55.0(73)$ & $56.9(79)$ & $58.3(174)$ & $57.8(329)$ \\
\hline \multicolumn{5}{|l|}{ Social status } \\
\hline Single & $14.4(19)$ & $22.4(31)$ & $17(51)$ & $17.1(98)$ \\
\hline Married & $78.0(104)$ & $71.6(99)$ & 77.7 (232) & $77.4(441)$ \\
\hline Other & $7.6(10)$ & $6.0(8)$ & $5.3(16)$ & $5.5(31)$ \\
\hline Work : No & $79.0(105)$ & $75.9(105)$ & 70.9 (212) & $72.8(415)$ \\
\hline \multicolumn{5}{|l|}{ Educational level } \\
\hline Illiterate & $19.8(26)$ & $21.4(30)$ & $26.40(79)$ & $24.08(137)$ \\
\hline Read \& Write & $14.7(19)$ & $16.8(23)$ & $11.0(33)$ & $12.91(74)$ \\
\hline Elementary & $32.8(44)$ & $28.20(39)$ & $36.1(108)$ & $33.51(191)$ \\
\hline High school & $20.7(28)$ & $18.3(25)$ & $14.4(43)$ & $16.58(94)$ \\
\hline University & $12.1(16)$ & $15.3(21)$ & $12.0(36)$ & $12.91(74)$ \\
\hline \multicolumn{5}{|l|}{ Primary cause of HD initiation } \\
\hline Diabetes & $26.7(35)$ & $19.6(27)$ & $24.4(73)$ & 24.33 (139) \\
\hline CVD and HTN & $13.3(18)$ & $8.0(11)$ & $24.9(75)$ & $18.25(104)$ \\
\hline Nephritis & $10.5(14)$ & $5.4(7)$ & $13.1(39)$ & $10.27(58)$ \\
\hline $\begin{array}{l}\text { Nephrosclerosis/obstructive } \\
\text { nephropathy }\end{array}$ & $2.1(3)$ & $8.1(11)$ & $5.7(17)$ & $4.94(28)$ \\
\hline PCKD & $1.0(1)$ & $2.7(4)$ & $2.8(8)$ & $2.09(12)$ \\
\hline Other & $46.4(62)$ & $56.2(78)$ & $29.1(87)$ & 40.1 (229) \\
\hline \multicolumn{5}{|l|}{ Co-morbidities } \\
\hline Diabetes & $38.9(36)$ & $36(34)$ & $34.2(77)$ & $35.7(143)$ \\
\hline HTN & $63.8(58)$ & $69.4(65)$ & $67.1(151)$ & $67.7(271)$ \\
\hline CVD & $20.8(19)$ & $27.8(26)$ & $22.9(52)$ & $23.6(94)$ \\
\hline Other diseases ${ }^{\dagger}$ & $22.5(20)$ & $14.4(13)$ & $8.6(19)$ & $15.6(62)$ \\
\hline Phosphatemia: $>5.5 \mathrm{mg} / \mathrm{dl}$ & $48.5(65)$ & $41.5(57)$ & $37.8(113)$ & $40.4(230)$ \\
\hline Ca*P Byproduct: > 55 & $28.5(38)$ & $23.2(32)$ & $25.6(77)$ & $26.1(149)$ \\
\hline \multicolumn{5}{|l|}{ SBehCh-Pt } \\
\hline Pre-Contemplation & $21.74(29)$ & $19.55(27)$ & $20.13(60)$ & $20.4(116)$ \\
\hline Contemplation & $33.91(45)$ & $22.56(31)$ & $24.50(73)$ & $26.99(154)$ \\
\hline Preparation & $4.35(6)$ & $10.53(14)$ & $10.40(31)$ & $8.43(48)$ \\
\hline Action & $24.35(32)$ & $33.83(47)$ & $21.14(63)$ & 26.44 (151) \\
\hline Maintenance & $15.65(21)$ & 13.53 (19) & $23.83(71)$ & $17.67(101)$ \\
\hline
\end{tabular}

Data are expressed in frequencies and percentages

†Indicates a difference between the groups.

HD, hemodialysis; CVD, cardiovascular disease; HTN, hypertension; PCKD, polycystic kidney disease; Ca * P, calcium - phosphorus product; SBehCh-P, stages of behavioral change towards phosphorus restricted diet. Pearson's chi-square was used to show between group differences of the categorical data. Significance taken at $\mathrm{p}<0.05$ 
Table 2. Study parameters of the 3 groups

\begin{tabular}{lcccc}
\hline & $\begin{array}{c}\text { DD group } \\
(\mathbf{n}=\mathbf{1 3 3})\end{array}$ & $\begin{array}{c}\text { Existing group } \\
(\mathbf{n = 1 3 8 )}\end{array}$ & $\begin{array}{c}\text { THD group } \\
(\mathbf{n = 2 9 9 )}\end{array}$ & $\begin{array}{c}\text { All } \\
(\mathbf{n}=\mathbf{5 7 0})\end{array}$ \\
\hline Age & $57.45 \pm 15.29$ & $60.09 \pm 15.63$ & $60.47 \pm 14.94$ & $59.28 \pm 15.09$ \\
BMI (kg/m2) & $25.10 \pm 5.77$ & $25.48 \pm 5.1$ & $24.17 \pm 4.4$ & $25 \pm 5$ \\
Serum P (mg/dl) & $5.57 \pm 1.53 \mathrm{a}$ & $5.39 \pm 1.48 \mathrm{bc}$ & $5.17 \pm 1.44 \mathrm{ab}$ & $5.31 \pm 1.48$ \\
PTH (pg/ml) & $400.86 \pm 457.6$ & $381.89 \pm 360.4$ & $344.9 \pm 338.5$ & $360.49 \pm 366.03$ \\
Diet Consults & $0.76 \pm 1.5$ & $0.93 \pm 1.6$ & $0.69 \pm 0.9$ & $0.77 \pm 1.3$ \\
KnQ (\%) & $40.02 \pm 12.75$ & $38.01 \pm 12.04$ & $38.89 \pm 12.78$ & $38.92 \pm 12.59$ \\
Dietary Phosphorus (mg/d) & $795.52 \pm 366.94$ & $785.79 \pm 365.99$ & $756.19 \pm 352.62$ & $795.52 \pm 366.94$ \\
Daily Protein (\%) & $64.66 \pm 54.07$ & $57.46 \pm 27.25$ & $57.03 \pm 23.91$ & $58.86 \pm 33.87$ \\
MIS & $7.26 \pm 3.51 \mathrm{a}$ & $6.62 \pm 3.16 \mathrm{ab}$ & $6.07 \pm 3.90 \mathrm{bc}$ & $6.45 \pm 3.62$ \\
QOL & & & & \\
Role-physical & $48.64 \pm 49.64$ & $52.89 \pm 48.6$ & $45.8 \pm 48.54$ & $48.39 \pm 48.83$ \\
Vitality & $50.91 \pm 18.10$ & $48.39 \pm 17.85$ & $49.28 \pm 17.46$ & $48.99 \pm 17.94$ \\
General Health & $55.08 \pm 24$ & $52.52 \pm 22.93$ & $55.82 \pm 22.65$ & $53.11 \pm 23.04$ \\
Physical Functioning & $52.32 \pm 34.59 \mathrm{a}$ & $64.47 \pm 32.25 \mathrm{~b}$ & $59.6 \pm 31.91 \mathrm{ab}$ & $59.38 \pm 33.31$ \\
Role-emotional & $64.55 \pm 47.63$ & $64.19 \pm 47.07$ & $68.8 \pm 45.54$ & $64.28 \pm 47.22$ \\
Bodily pain & $74.07 \pm 29.06$ & $77.23 \pm 28.8$ & $72.5 \pm 29.55$ & $73.95 \pm 30.24$ \\
Social functioning & $81.14 \pm 30.13 \mathrm{a}$ & $70.4 \pm 31.79 \mathrm{~b}$ & $81.6 \pm 29.21 \mathrm{a}$ & $75.43 \pm 31.52$ \\
Mental health & $56.71 \pm 16.51$ & $59.71 \pm 17.05$ & $58.45 \pm 19.06$ & $75.43 \pm 31.52$ \\
\hline
\end{tabular}

Data are expressed as mean \pm SD

abc Values in the same row with the different superscripts are significantly different at $p<0.05$ based on one way ANOVA and Duncan's post hoc test.

BMI, body mass index; PTH, parathyroid hormone; KnQ, knowledge questionnaire; MIS, malnutrition inflammation score.

\section{Baseline differences between the 3 study groups:}

A between group analysis showed a significant difference between the 3 groups at baseline (Tables $1 \& 2$ ) regarding the SBehCh-P scores X2 (8) = 19.56, $p<0.05$. A 2 by 2 group X2 comparison revealed that significant differences were caused by the THD. Among the comorbidities that the patients suffered from, there were no differences between the major categories (diabetes, hypertension, cardiovascular disease), but there was a significant difference in the "other disease" category, which were all the other infrequent conditions that the patients had, grouped into one group. Moreover, DD group had 3 significant differences compared to the other groups: serum $\mathrm{P}$ and MIS score was higher while QOL: Physical functioning (PF) was lower. The EP group had a significantly lower QOL: Social functioning (SF) score when compared to the rest of the study groups. 


\section{DISCUSSION}

The objective of the NEMO trial was to determine the role of a trained and dedicated dietitian in the HD unit on patient clinical outcomes and the quality of life parameters in Lebanon. Thus, it was important to know the patient characteristics of the main intervention group and its comparators selected for our study, in addition to the presence of baseline differences between the study groups.

According to the baseline characteristics, the mean age of the population was around 60 years reflecting the aging of the dialysis population in Lebanon; this was in line with the literature in other populations (Shaw-Stuart et al., 2000; Reddy et al., 2009; Rambod et al., 2010). The fact that almost $70 \%$ of our patients had a maximum of elementary level education could be a determinant of low adherence; this correlation was confirmed in Kugler et al. (2011) but not found by Lam et al. (2010). The majority of the population was married, which might have given a support system to facilitate adherence to the regimen. Kaveh \& Kimmel (2001) showed that married HD patients had improved adherence with protein restriction but not with a low potassium diet.

Unemployment rate was quite high (70\%) among our patients, for which the patients explained to be due to the lack of support from employers on work shifts that would include frequent absenteeism due to HD session; this was also reported in the literature (Muehrer et al., 2011). In addition to factors specific to the Lebanese culture, whereby the sick and the old are immediately considered the responsibility of the family; there is no health care system that covers their needs. Moreover Muehrer et al. (2011) reported that existing co-morbid conditions and symptoms associated with renal failure can negatively affect a person's ability to work.

The majority of our patients had a Ca*P byproduct higher than the normal range set by the KDOQI guideline. Even though this finding was in line with other studies (de Brito-Ashurst \& Dobbie, 2003; Sun et al., 2008), it was in contrast with a study done on a small sample of Asian population (Lim \& Gun, 2007) whereby the authors contributed the controlled serum Ca*P byproduct to the over suppression of PTH by the medical team. It is worth mentioning that elevated $\mathrm{Ca} * \mathrm{P}$ byproduct is associated with morbidities such as cardiovascular and systemic calcification (Qunibi, 2004; Block et al., 2004). Almost $40 \%$ of patients in all study groups suffered from hyperphosphatemia which can be considered an indicator of poor management of osteodystrophy, as suggested by Qunibi (2004). This poor management was even more evident with the elevated mean value of PTH of our sample when compared to the normal range $(150-300 \mathrm{pg} / \mathrm{ml})$ set by the KDOQI guidelines; this situation was in line with the literature (Sun et al., 2008; Reddy et al., 2009). The consequences of high PTH are bone demineralization, increasing risk of fractures and extra-skeletal calcification (Mayne et al., 2012). The fact that the DD group had a significantly higher serum $P$ than EP and THD group indicates that they could require more effort to normalize, hence a higher challenge to demonstrate the effectiveness of the intervention. This difference was not known by the study team 
until after the intervention period was over and half way through the follow up, so it should not impact any bias in the conduct of intervention.

The lack of sufficient dietetic counseling by the hospital dietitians for each patient was explained by Karavetian et al. (2013), where it was evident that dietetic services in all Lebanese HD units were provided by general hospital dietitians who were: 1) not trained to the specific needs of HD patients, 2) had inadequate knowledge of the nutrition management guidelines of HD patients, 3) were not required by their job description to be fully dedicated to these patients, 4) were understaffed and 5) had a high load of other nutritional and dietetic duties in the hospital.

The results of the KnQ showed that the 3 groups of the study had an insufficient knowledge which was in line with the findings of other studies (Cupisti et al., 2012; Durose et al., 2004). However, this was in contrast to the finding of a cross-sectional study in Portugal in which the patients' knowledge score was found to be adequate (79\%). The main difference of this group to the population of most studies was the relatively young age (mean 49 years) and higher education (mean 7 years of schooling) (Nerbass et al., 2010).

Our patients had trouble meeting their daily protein needs $(<60 \%$ of daily protein needs) and since $P$ is found in foods rich in protein, our patients unintentionally consumed a diet low in $\mathrm{P}$ (mean $<800 \mathrm{mg} / \mathrm{d}$ ). Inadequate protein intake among HD patients is directly correlated with malnutrition; a dangerous, yet highly prevalent condition among HD patients (Andrew et al., 2008; Locatelli et al., 2002; Morais et al., 2005). The ideal method of managing this protein to $P$ balance is choosing foods high in protein yet low in P (McCann, 2009), which can be achieved only by special education. In the literature, low adherence to diet restrictions, in particular to phosphorus, is prevalent (Denhaerynck et al., 2007; Lee \& Molassiotis, 2002).

As for SBehCh towards $\mathrm{P}$ restricted diet and for $\mathrm{P}$ binder intake, our patients were mainly in the pre-action stage which was in line with the findings of other studies (Finckenor et al., 2000; Mochari-Greenberger et al., 2010), whereby the majority of patients with a problem in health behavior were in the pre-action stage (precontemplation, contemplation, preparation). This may be explained by the fact that in traditional education programs, all patients are given instructions on how to change their lifestyle, without assessing whether they are ready to change, which results in resistance on part of the patient to the program and the lack of progress in the behavioral (Finckenor et al., 2000). Moreover, the analysis for between group differences revealed that the THD group was significantly different from the other 2 groups in SBehCH-P. This difference could be attributed to the higher percentage and frequency of patients in the "maintenance stage" in this group for both variables. Even though the selection of units was done through a randomization process, after entering the hospitals and meeting the staff, the research team noticed that out of the $6 \mathrm{HD}$ units in this cluster, 3 were much better managed by their medical team than all the other units in the study in both clusters; moreover, one of these 3 units had the highest rate of trans- 
plant in the country. One of the major eligibility criteria for renal transplant is for the patient to achieve optimal blood profile. The high rate of renal transplant of this unit may propose that 1 ) the patient management techniques of this one unit were significantly better, 2) thus the patients had higher compliance to therapy indicated by higher "maintenance stage". These 3 units may have pushed up the rates of "maintenance" patients in the cluster B.

The results of the MIS showed that the population was mildly malnourished. Our patients were not different from the ones reported in the literature, where it was evident that the malnutrition-inflammation syndrome is common among HD patients and may correlate with increased morbidity and mortality (Kalantar-Zadeh et al., 2001; Rambod et al., 2009). In cross-sectional study conducted in an HD unit in Jordan, $38.2 \%$ of patients were well nourished; the authors noted older age and HD vintage to be inversely correlated with nutritional status (Tayyem \& Mrayyan, 2008).

Globally, low QOL is prevalent among HD patients with a rate of $40-70 \%$ of full health (Kimmel et al., 2003) while a rate of 38-53\% is prevalent in Iran, a neighboring country (Aghakhani et al., 2012). Our patients' QOL ranged from $48-75 \%$, indicating similarity with the general population of the published studies, thus facilitating future comparisons. Multiple co-morbidities, polypharmacy and dialysis vintage have been shown to depress QOL (Covic et al., 2004; Han et al., 2012).

This study can serve as a developing country model. The baseline findings reveal a room for improvement among the Lebanese HD patients regarding osteodystrophy management and relevant biochemical, clinical and the quality of life outcomes, justifying an effort to improve nutritional advice. Moreover, differences among the 3 study groups at baseline were minimal, showing adequate randomization, low risk of bias between groups and homogenousity of medical management of these patients across different HD units. Finally, our patients' characteristics seem to be comparable to patients of the literature, which would facilitate evaluation of 18 months long full scale study, according to which a possible platform can be built for future improvement in policies governing dietetic management of HD patients in Lebanon. 


\section{REFERENCES}

Academy of Nutrition and Dietetics Evidence Analysis Library. (2010), "Is MNT provided by a Registered Dietitian for chronic kidney disease (CKD) in adults effective?", available at: http://andevidencelibrary.com/template.cfm?key=2407 (accessed 25 February, 2013).

Aghakhani, N., Samadzadeh, S., Mafi, T.M. and Rahbar, N. (2012). The impact of education on nutrition on the quality of life in patients on hemodialysis: a comparative study from teaching hospitals. Saudi Journal of Kidney Diseases and Transplantation, 23(1), 26-30.

Andrew, N.H., Engel, B., Hart, K., Passey, C. and Beaden, S. (2008). Micronutrient intake in haemodialysis patients. Journal of Human Nutrition and Dietetics, 21(4), 375-376.

Block, G.A., Klassen, P.S., Lazarus, J.M., Ofsthun, N., Lowrie, E.G. and Chertow, G.M. (2004). Mineral metabolism, mortality, and morbidity in maintenance hemodialysis. Journal of the American Society of Nephrology, 15(8), 2208-2218.

Central Intelligence Agency (US). (2012), "The World Factbook", available at: http://www.cia.gov/library/publications/the-world-factbook/geos/le.htm1 (accessed 15 January, 2014).

Covic, A., Seica, A., Gusbeth-Tatomir, P., Gavrilovici, O. and Goldsmith, D.J. (2004). Illness representations and quality of life scores in haemodialysis patients. Nephrology Dialysis Transplantation, 19(8), 20782083.

Cupisti, A., Ferretti, V., D'Alessandro, C., Petrone, I., Di Giorgio, A., Meola, M., Panichi, V., Conti, P., Lippi, A., Caprioli and R. and Capitanini, A. (2012). Nutritional knowledge in hemodialysis patients and nurses: focus on phosphorus. Journal of Renal Nutrition, 22(6), 541-546.

de Brito-Ashurst, I. and Dobbie, H. (2003). A randomized controlled trial of an educational intervention to improve phosphate levels in hemodialysis patients. Journal of Renal Nutrition, 13(4), 267-274.

Denhaerynck, K, Manhaeve, D., Dobbels, F., Garzoni, D., Nolte, C. and De Geest, S. (2007). Prevalence and consequences of nonadherence to hemodialysis regimens. American Journal of Critical Care, 16(3), 222235.

Durose, C.L., Holdsworth, M., Watson, V. and Przygrodzka, F. (2004). Knowledge of dietary restrictions and the medical consequences of noncompliance by patients on hemodialysis are not predictive of dietary compliance. Journal of the American Dietetic Association, 104(1), 35-41.

Eknoyan, G., Lameire, N., Barsoum, R., Eckardt, K.U., Levin, A., Levin, N., Locatelli, F., MacLeod, A., Vanholder, R., Walker, R. and Wang, H. (2004). The burden of kidney disease: improving global outcomes. Kidney International, 66(4), 1310-1314.

Finckenor, M. and Byrd-Bredbenner, C. (2000). Nutrition intervention group program based on preactionstage-oriented change processes of the Transtheoretical Model promotes long-term reduction in dietary fat intake. Journal of the American Dietetic Association, 100(3), 335-342.

Ford, J.C., Pope, J.F., Hunt, A.E. and Gerald, B. (2004). The effect of diet education on the laboratory values and knowledge of hemodialysis patients with hyperphosphatemia. Journal of Renal Nutrition, 14(1), 3644.

Gregory, M.C. (2009). Cost-Effective dialysis for the developing world. Ethnicity \& Disease, 19(1), 65.

Griva, K., Mooppil, N., Seet, P., Krishnan, D.S., James, H. and Newman, S.P. (2011). The NKF-NUS hemodialysis trial protocol- a randomized controlled trial to determine the effectiveness of a self management intervention for hemodialysis patients. BMC Nephrology, 12(1), 4.

Han, H., Burrowes, J.D., Houser, R., Chung, M.C. and Dwyer, J.T. (2012). What is the impact of nutritional status on health-related quality of life in hemodialysis patients? Journal of Renal Nutrition, 22(2), 237243.

Hoelscher, D.M., Day, R.S., Kelder, S.H. and Ward, J.L. (2003). Reproducibility and validity of the secondary level School-Based Nutrition Monitoring student questionnaire. Journal of the American Dietetic Association, 103(2), 186-194.

Kalantar-Zadeh, K., Kopple, J.D., Block, G. and Humphreys, M.H. (2001). A malnutrition-inflammation score is correlated with morbidity and mortality in maintenance hemodialysis patients. American Journal of Kidney Diseases, 38(6), 1251-1263. 
Karavetian, M. and Ghaddar, S. (2013). Nutritional education for the management of osteodystrophy (NEMO) in patients on haemodialysis: a randomised controlled trial. Journal of Renal Care, 39(1), 19-30.

Karavetian, M., El Zein, H., Hwalla, N. and de Vries, N. (2013). Dietetic practices in hemodialysis units in lebanon and their conformity with KDOQI nutrition guidelines. International Journal of Health \& Nutrition, $4(2), 1-8$

Kaveh, K. and Kimmel, P.L. (2001). Compliance in hemodialysis patients: multidimensional measures in search of a gold standard. American Journal of Kidney Diseases, 37(2), 244-266.

Kimmel, P.L., Emont, S.L., Newmann J.M., Danko, H. and Moss, A.H. (2003). ESRD patient quality of life: symptoms, spiritual beliefs, psychosocial factors, and ethnicity. American Journal of Kidney Diseases, 42(4), 713-721.

Kugler, C., Maeding, I. and Russell, C.L. (2011). Non-adherence in patients on chronic hemodialysis: an international comparison study. Journal of Nephrology, 24(3), 366-375.

Lam, L.W., Twinn, S.F. and Chan, S.W. (2010). Self-reported adherence to a therapeutic regimen among patients undergoing continuous ambulatory peritoneal dialysis. Journal of Advanced Nursing, 66(4), 763773.

Lee, S.H. and Molassiotis, A. (2002). Dietary and fluid compliance in Chinese hemodialysis patients. International Journal of Nursing Studies, 39(7), 695-704.

Lim, S. and Gun, N.T. (2007). Secondary hyperparathyroidism and calcium phosphate control in a hemodialysis population. Acta Med Indones, 39(2), 71-74.

Locatelli, F., Fouque, D., Heimburger, O., Drueke, T.B., Cannata-Andia, J.B., Horl, W.H., Ritz, E. (2002). Nutritional status in dialysis patients: a European consensus. Nephrology Dialysis Transplantation, 17(4), 563572.

Mallat, S., Hatoum, A., Kabalan, S., Elzein, H., and Abdallah, A. (2011). Demographic and Clinical profile of patients initiated on hemodialysis in Lebanon. American Journal of Kidney Diseases, 57(4), B62.

Mason, J., Khunti, K., Stone, M., Farooqi, A. and Carr, S. (2008). Educational interventions in kidney disease care: a systematic review of randomized trials. American Journal of Kidney Diseases, 51(6), 933-951.

Mayne, T.J., Benner, D., Ricketts, K., Burgess, M., Wilson, S., Poole, L., Smyth, M., Colson, C. and Krishnan, M. (2012). Results of a pilot program to improve phosphorus outcomes in hemodialysis patients. Journal of Renal Nutrition, 22(5), 472-479.

McCann, L. (2009). Pocket guide to nutrition assessment of the patient with chronic kidney disease. 4th ed. New York: National Kidney Foundation.

Mochari-Greenberger, H., Terry, M.B. and Mosca, L. (2010). Does stage of change modify the effectiveness of an educational intervention to improve diet among family members of hospitalized cardiovascular disease patients? Journal of the American Dietetic Association, 110(7), 1027-1035.

Morais, A.A., Silva, M.A., Faintuch, J., Vidigal, E.J., Costa, R.A., Lyrio, D.C., Trindade, C.R. and Pitanga, K.K. (2005). Correlation of nutritional status and food intake in hemodialysis patients. Clinics, 60(3), 185-192.

Muehrer, R.J., Scahtell, D., Witten, B., Gangnon, R., Becker, B.N. and Hofmann, R.M. (2011). Factors affecting employment at initiation of dialysis. Clinical Journal of the American Society of Nephrology, 6(3), 489-496.

National Kidney Foundation -Kidney Disease Outcomes Quality Initiative (NKF KDOQI) (2000) Clinical Practice Guidelines for Nutrition in Chronic Renal Failure http://www.kidney.org/professionals/kdoqi/guidelines_updates/doqi_nut.html Accessed on 3 February 2014.

National Kidney Registry. (2012), "Dialysis Centers and Patients / Prevalence of ESRD in Lebanon", available at: http://www.kidneyregistrylb.com/pages/wp-content/uploads/2013/09/Upload-NKRCh319Sep13.pdf. (accessed 15 January, 2014).

Nerbass, F.B., Morais, J.G., Santos, R.G.D., Kruger, T.S., Koene, T.T. and Luz Filho, H.A.D. (2010). Adherence and knowledge about hyperphosphatemia treatment in hemodialysis patients with hyperphosphatemia. Jornal Brasileiro de Nefrologia, 32(2), 149-155.

Prochaska, J.O. (2008). Decision making in the transtheoretical model of behavior change. Medical Decision Making, 28(6), 845-849.

Qunibi, W.Y. (2004). Consequences of hyperphosphatemia in patients with end-stage renal disease (ESRD). Kidney International, 66, S8-S12. 
Rambod M, Bross R, Zitterkoph J, Benner D, Pithia J, Colman S, Kovesdy CP, Kopple JD, Kalantar-Zadeh K. Association of Malnutrition-Inflammation Score with quality of life and mortality in hemodialysis patients: a 5-year prospective cohort study. Am J Kidney Dis 2009;53:298-309.

Rambod, M., Peyravi, H., Shokrpour, N. and Sareban, M.T. (2010). Dietary and fluid adherence in Iranian hemodialysis patients. The Health Care Manager, 29(4), 359-364.

Reddy, V., Symes, F., Sethi, N., Scally, A.J., Scott, J., Mumtaz, R. and Stoves, J. (2009). Dietitian-led education program to improve phosphate control in a single-center hemodialysis population. Journal of Renal $\mathrm{Nu}$ trition, 19(4), 314-320.

Richard, C.J. (2006). Self-care management in adults undergoing hemodialysis. Nephrology Nurses' Journal: Journal of the American Nephrology Nurses' Association, 33(4), 387-394.

Sabbah, I., Drouby, N., Sabbah, S., Retel-Rude, N. and Mercier, M. (2003). Quality of Life in rural and urban populations in Lebanon using SF-36 health survey. Health and Quality of Life Outcomes, 1(1), 30.

Shaw-Stuart, N.J. and Stuart, A. (2000). The effect of an educational patient compliance program on serum phosphate levels in patients receiving hemodialysis. Journal of Renal Nutrition, 10(2), 80-84.

Sun, C.Y., Chang, K.C., Chen, S.H., Chang, C.T. and Wu, M.S. (2008). Patient education: an efficient adjuvant therapy for hyperphosphatemia in hemodialysis patients. Renal Failure, 30(1), 57- 62.

Tayyem, R.F. and Mrayyan, M.T. (2008). Assessing the prevalence of malnutrition in chronic kidney disease patients in Jordan. Journal of Renal Nutrition, 18(2), 202-209.

Ware Jr, J.E. and Sherbourne, C.D. (1992). The MOS 36-item short-form health survey (SF-36).I. Conceptual framework and item selection. Medical Care, 30, 473-483.

Welch, J.L. (2001). Hemodialysis patient beliefs by stage of fluid adherence. Research in Nursing \& Health, 24(2), 105-112. 



\section{CHAPTER 6}

\section{Effect of Behavioral Stage-Based Nutrition Education on Hyperphosphatemia Management among Hemodialysis Patients: NEMO Trial, Lebanon}

Submitted for Publication as: Karavetian, M., Elzein, H., Bechwaty F. de Vries, N. Effect of Behavioral Stage-Based Nutrition Education on Hyperphosphatemia Management among Hemodialysis Patients: NEMO Trial. 


\section{ABSTRACT}

The study aims to assess the effect of a dedicated dietitian (DD) on hyperphosphatemia management among hemodilaysis (HD) patients using stage-based nutrition education. The study was a randomized control multicenter trial; units randomly assigned to cluster $1(n=6)$ and cluster $2(n=6)$ of HD units. Cluster 1 patients were randomly assigned according to dialysis shift to: DD protocol $(n=88)$ and Existing Practice (EP) $(n=96)$. Cluster 2 patients were assigned to Trained Hospital Dietitian (THD) protocol $(n=210)$. DD patients received individualized bi-weekly stage-based nutrition education for 6 months by trained study dietitians. THD patients were educated upon the availability of the trained hospital dietitian. EP patients (usual care/control group) were educated by the hospital dietitian, who was blinded to the study. Knowledge (\%) on Phosphorus (P) restricted diet, stages of behavioral change (1-5), serum $P(\mathrm{mg} / \mathrm{dl})$ were assessed at baseline (t0), at $6^{\text {th }}$ month -post-intervention (t1) and at $12^{\text {th }}$ month- follow-up (t2).General linear model for repeated measures and Friedman tests were used to analyze the parametric and non parametric data respectively, using SPSS version 16, and significance at $p<0.05$. Results showed that DD protocol was the only one to achieve significant improvement in knowledge (t0:40.3, t1:64, t2:63); in the stages (t0: Preparation, t1: Action, t2: Preparation); and in serum P (t0: 5.55, t1: 5.11, t 2: 5.29). In conclusion, DD protocol showed to be superior over the others; and can be used as a model to be adapted within HD units in Lebanon. 


\section{INTRODUCTION}

Lack of adherence to dietary restriction among hemodialysis (HD) patients is a common problem (Kaveh et al., 2001; Matteson et al., 2010). The prevalence of HD patients is on the rise nationally (NKR, 2012) and globally (Maurales et al., 2007). These patients often suffer from elevated serum phosphorus (P); a leading cause of Chronic Kidney DiseaseMineral and Bone Disorder (CKD-MBD) and mortality (Sun et al, 2008; Friedman et al, 2005). The management of this condition includes HD, using phosphate chelators, limiting dietary $P$ to $800-1000 \mathrm{mg} / \mathrm{d}$ and dietary P density (P/Protein) $12-14 \mathrm{mg} / \mathrm{g}$ (Caldeira et al., 2011; Noori et al., 2000). Consequently, adherence to $P$ restricted diet is the most difficult for HD patients (Durose et al., 2004).

Integrating behavioral change models in nutritional education facilitated adherence to dietary lifestyle changes (Spahn et al., 2010). The transtheoretical model (TTM stages) assesses the readiness to behavioral changes among individuals. There are 5 stages in the model: 1) pre-contemplation, 2) contemplation, 3) preparation, 4) action, 5) maintenance. To stimulate effective progression among stages, an appropriate stagebased intervention needs to be planned (Prochaska, 2008; Molaison et al., 2003; Mochari-Greenberger et al., 2010). Whitelaw et al (2000) demonstrated the superiority of the latter over the traditional non-stage-matched educations.

A recent review (Karavetian $\mathrm{M}$, de Vries $\mathrm{N}$ et al., 2014) on effective dietary counseling intervention for hyperphosphatemia management in HD patients identified the following key tools to enhance behavioral change: 1) multidisciplinary team approach coupled with a decisional partnership with the patient, 2) behavioral theory based individualized education with frequent reinforcement sessions 3) easy to comprehend educational material targeting simple skills using booklets, live demonstrations, posters and recipes adapted to culture preference.

In Lebanon, HD units are exclusively hospital based; the hospital dietitian is responsible for nutritional education among other duties in the hospital. Moreover they are overloaded and do not have the optimal competencies needed to manage HD patients in Lebanon (Karavetian M et al., 2013).

The current study primarily aimed at assessing the effect of having a trained dedicated dietitian in the HD unit compared to 1) trained and 2) non-trained partially dedicated dietitians on hyperphosphatemia management of HD patients. The secondary aim was to study the effectiveness of an intensive, individualized, stage-based psychoeducational nutrition intervention focused on $\mathrm{P}$ compared to the non-stage based model given in routine care. 


\section{METHODS}

\section{Subjects and Methods}

This was a randomized control multicenter trial in 12 hospital based HD units. Half of the HD units were randomly assigned to cluster 1 and the rest to cluster 2 .

Hospital and patient selection criteria, randomization method, ethical approval and group baseline characteristics are detailed in Karavetian M, Saade A et al (2014). After attrition there were 184 patients in Cluster 1 and 210 in cluster 2.

Each participant received a written consent form describing the study. It included participants' permission to review the medical chart for demographic information and current laboratory values. Confidentiality was maintained by use of coding. The institutional review board (IRB) of each hospital approved the study.

Patients in Cluster 1 were randomly assigned according to their dialysis shift to the following study protocols: Dedicated Dietitian (DD) and Existing Practice (EP). DD group patients received individualized education as per the study protocol by 5 externally recruited research dietitians. These dietitians were clinicians who received an intensive training by the study's principal investigator (PI) on renal dietetics. The patient and dietitian education protocol are detailed later in this article; this protocol was considered the optimal one being studied. EP group patients did not receive any intervention by the research team; they were only evaluated on study parameters, and continued receiving dietetic care by the hospital dietitian who was blinded to study protocol, thus serving as controls and representing the situation of usual care.

Cluster 2 patients were assigned to the Trained Hospital Dietitian (THD) study protocol. In this group, the general hospital dietitian responsible for the selected hospital's $\mathrm{HD}$ unit received the same training as that of the DD group by the PI; after which they were asked to educate the HD patients for 6 months. No educational protocol or patient education material was imposed on them. They were informed that their practice in the HD unit would be monitored by the PI. This group represented the viable alternative for the DD protocol. There was no control within this cluster since it was not ethical to ask the hospital dietitian to provide different standards of care to the HD patients of the same unit.

After the completion of the study, EP and THD patients received study educational material.

\section{DD protocol Patient Education}

Semi structured qualitative interviews were conducted with a focus group of 15 HD patients and 3 dietitians working with renal patients in Lebanon. This revealed their perspectives on facilitators and barriers for optimal adherence to $\mathrm{P}$ restricted diet. Patient interviews included 1) barriers to adherence to the prescribed diet, 2) their 
level of health consciousness, 3) family support, 4) work pressure, 5) degree of usefulness of advice given by hospital dietitian, 6) effect of frequency of dietitian's visit on adherence. Answers are detailed in Table 1. As for the dietitians, they were asked about 1) barriers to dietary adherence among patients, 2) barriers in achieving adequate and successful dietary consultations to HD patients adequately, 3) solution for both previously addressed problems, 4) frequency of visits to the HD unit. Results are presented in Table 2.

Table 1. Patient Focus Group Answers ( $n=15)$

\begin{tabular}{ll}
\hline$\%$ of patient & Opinion \\
\hline 100 & The need for more self management skills and alternatives to forbidden foods. \\
100 & $\begin{array}{l}\text { Eating in group (healthy family / friends) makes it more difficult to comply with restricted } \\
\text { diet. }\end{array}$ \\
90 & Need for more dietitian encounters. \\
50 & Need practical advice from health care professionals. \\
40 & Family brings forbidden foods, makes it available at home; difficult to avoid them. \\
20 & Inability to buy or prepare uremic diet. \\
13 & Adherence becomes easier when symptoms appear. \\
13 & Bored of restrictions, want to live like everyone \\
7 & $\begin{array}{l}\text { Depression leading to indifference. "No matter what I do, I will still be on HD, so why } \\
\text { comply?" }\end{array}$ \\
\hline
\end{tabular}

Table 2. Dietitian Focus Group Results ( $n=3)$

\begin{tabular}{ll}
\hline$\%$ of dietitians & Opinion \\
\hline 100 & Overload in the hospital duties; limited time for HD unit. \\
100 & Nurses and doctors should be educated about the diet. \\
100 & Need of simplified culturally fit ready-made diet. \\
66 & Need for more family involvement. \\
66 & Nutrition education should be given only by dietitians. \\
66 & Need for awareness in the community on diet and clinical outcomes of HD patients \\
66 & Psychologists should be involved in HD patient care. \\
66 & It is difficult for patients to prepare palatable meals and adhere to restriction. Food indus- \\
& try needs to develop renal food items available in supermarkets and restaurants (low \\
& potassium, low phosphorus, ... ) \\
\hline
\end{tabular}

According to the focus group results and the principles of the TTM stages, patient educational material was developed. Moreover, the structure of the lessons was adapted from Fickenor et al (2000), after the approval of the main author, although the latter addressed a different but also chronically ill population.

For practicality and following Fickenor et al (2000), the TTM stages were grouped into 3 and accordingly educational material was prepared: Pre-action (pre- 
contemplation, contemplation, and preparation), Action, and Maintenance. Each stage had several topics discussed and integrated within 9, 5 and 5 lesson plans respectively. Table 3 gives a detailed description of the patient education material. Each lesson included a brief introduction, the lesson itself, and a brief conclusion. At the end of the study, all participants received a folder that included the used material. The educational materials were printed in low literacy level, in bold and in illustrative photos. Language used for oral explanation and on all printed material was Arabic and sentences were 5 th grade level to facilitate comprehension among patients from all educational levels as recommended by Aldridge (2004). Along with the lessons, 4 other educational tools were used: 1) A recipe book which contained 7 recipes for each of the 3 meals of the day, restricted in $\mathrm{P}$, potassium and salt yet adapted for the Lebanese cuisine. 2) Booklets of alternatives: contained photos of high $\mathrm{P}$ food items along with their low $\mathrm{P}$ alternatives. 3) Posters representing high P food and low P food were hung in the HD unit's waiting room. 4) Patients entered an in-center achievement contest of having the best serum $P$ for 6 consecutive months. This was recorded on a track chart which was hung in the HD waiting room. The objective of the contest was to foster a competitive spirit and raise awareness of adherence in an effort to facilitate patients in attaining their serum P value goals. Evidence shows the effectiveness of these types of the educational tools on improving patient dietary adherence (Shaw-Stuart et al., 2000).

These educational materials were used only in the DD protocol. After the completion of the study, EP and THD patients received study educational material.

The patient education protocol comprised of twice weekly 15 minute sessions for 6 months, amounting to a total of 12 hours per patient. The session duration was adapted from the " 2 hour per month dietitian-to-renal patient time" recommendation of Academy of the Nutrition and Dietetics (2010); the 6 month duration from Paul and Sneed (2004), the minimum time needed for behavioral change to take place. The lack of dedicated dietitians in the Lebanese HD units led us to believe that none of the patients had received a formal and complete dietary counseling; thus, at start, patients were educated on "pre-action" material irrelevant of their TTM stage. When patients progressed in TTM stages, accordingly educational material progressed; otherwise, the education was repeated till a change was noted. During the 1st weekly session, the theme of the week was explained. In the 2 nd weekly session, the patient was asked to recall the previous lesson afterwards the lesson was re-explained using individualized feedback, making sure that the patient understands of the new information. And finally, at the beginning of each month, new monthly blood tests related to CKD-MBD were evaluated and discussed with each patient and an action plan was designed in coordination with the patient to achieve better results for the next month. 
Table 3. Lesson Plan as per TTM Stages

\begin{tabular}{|c|c|c|c|}
\hline Stage & Pre - Action & Action & Maintenance \\
\hline Concepts & $\begin{array}{l}\text { Raise awareness } \\
\text { Identify benefits of change } \\
\text { Provide personalized in- } \\
\text { formation } \\
\text { Resolve ambivalence } \\
\text { Identify small steps taken } \\
\text { before and praise patient. }\end{array}$ & $\begin{array}{l}\text { Set action plan \& short-term } \\
\text { goals } \\
\text { Identify support needed } \\
\text { Solve barriers to adherence } \\
\text { Create consequences for } \\
\text { failure. } \\
\text { Continue development of } \\
\text { skills to implement the plan. }\end{array}$ & $\begin{array}{l}\text { Provide relapse manage- } \\
\text { ment } \\
\text { Solve difficulties to adher- } \\
\text { ence } \\
\text { Identify local re- } \\
\text { sources/support } \\
\text { Empower self control. } \\
\text { Encourage commitment. }\end{array}$ \\
\hline \multirow{6}{*}{$\begin{array}{l}\text { Lessons } \\
\text { (equivalent topics } \\
\text { of each phase are } \\
\text { in the same row) }\end{array}$} & $\begin{array}{l}\text { Small Lifestyle Changes to a } \\
\text { Better Quality of Life }\end{array}$ & Dietary sources of $\mathrm{P}$ & $\begin{array}{l}\text { Benefits of lifestyle changes } \\
\text { on health }\end{array}$ \\
\hline & $\begin{array}{l}\text { High P diet and health } \\
\text { High P diet and bone } \\
\text { High P diet and heart }\end{array}$ & $\begin{array}{l}\text { How to live on a low P diet } \\
\text { Booklet and poster: P rich } \\
\text { foods and low P alternatives* }\end{array}$ & $\begin{array}{l}\text { The cons of } \mathrm{P} \text { rich diet and } \\
\text { Pros of } \mathrm{P} \text { restricted one. }\end{array}$ \\
\hline & $\begin{array}{l}\text { Normal Ranges of Calcium, } \\
\text { P, PTH } \\
\text { Role of P chelators }\end{array}$ & $\begin{array}{l}\text { P chelator administration } \\
\text { methods }\end{array}$ & Benefits of $\mathrm{P}$ chelators \\
\hline & $\begin{array}{l}\text { Exercise and P clearance in } \\
\text { HD }\end{array}$ & Types of exercise safe for HD & Importance of the exercise \\
\hline & Vitamin D and bone & $\begin{array}{l}\text { Vitamin D therapy and serum } \\
\text { P }\end{array}$ & Importance of Vitamin D \\
\hline & $\begin{array}{l}\text { Holistic management of } \\
\text { CKD-MBD }\end{array}$ & $\begin{array}{l}21 \mathrm{P} \text { restricted Lebanese } \\
\text { recipes for breakfast, lunch, } \\
\text { dinner; }\end{array}$ & \\
\hline
\end{tabular}

* educational materials with star were adapted from Karavetian \& Ghaddar (2013), where by the educational tools were validated on adult HD patients in Lebanon using local language (Arabic).

\section{Dietitian Educational Program}

The dietitian education program covered all Kidney Disease Outcomes Quality Initiative (KDOQI; 2000) nutritional guidelines for HD patients and the application of the TTM. The training was provided by the PI and included 8 sessions; 4 hours each using lectures, case studies and discussions. Pre and post training exam was used to mark progress. Additionally, research dietitians were trained on outcome parameters collection and data entry; aiming to minimize inter-collector variations and errors.

\section{Instruments and Measures}

All data were collected at the 3 moments: baseline (T0), at post intervention (T1 $=\mathrm{T} 0+6$ months) and at follow up ( $\mathrm{T} 2=\mathrm{T} 1+6$ months). This was conducted by research dietitians under the supervision of the PI.

A knowledge questionnaire, adapted from Karavetian \& Ghaddar (2013) was used. Through 18 questions (multiple choice answers), it assessed the patient's knowledge 
about kidney disease, renal diet, $\mathrm{P}$ chelators, vitamin $\mathrm{D}$ therapy and their perception of the importance of diet in their treatment. The total score ranged from 0-18 which was converted into a percentage, where a cut-off score of $60 \%$ was assumed to represent sufficient knowledge.

Serum $\mathrm{P}$ was collected from all patients throughout the 6 months prior to each study phase; afterwards, the mean value of the 6 months was computed to give strong information on the effect of the dietary behavioral change of each phase. At the end one mean value of serum $P$ represented each study phase, and those numbers were analyzed with each other.

TTM stage of each patient was assessed at each study phase using an algorithm (Figure 1) inspired by Welch (2000). In addition to this, DD group was assessed for TTM stage weekly throughout the 6-month of the intervention. One of the components of the algorithm was daily dietary intake of $\mathrm{P}(\mathrm{mg})$ and $\mathrm{P}$ density $(\mathrm{P}(\mathrm{mg}) /$ protein $(\mathrm{g})$ ratio); thus 24 hour recall was conducted. Dietary intake of 3 non-consecutive days was collected weekly; the mean intake was considered the actual intake. This was analyzed through the renal exchange systems and the USDA (version 25) nutrient analysis; edible portion of the food was analyzed.

Figure1: TTM Staging Algorithm

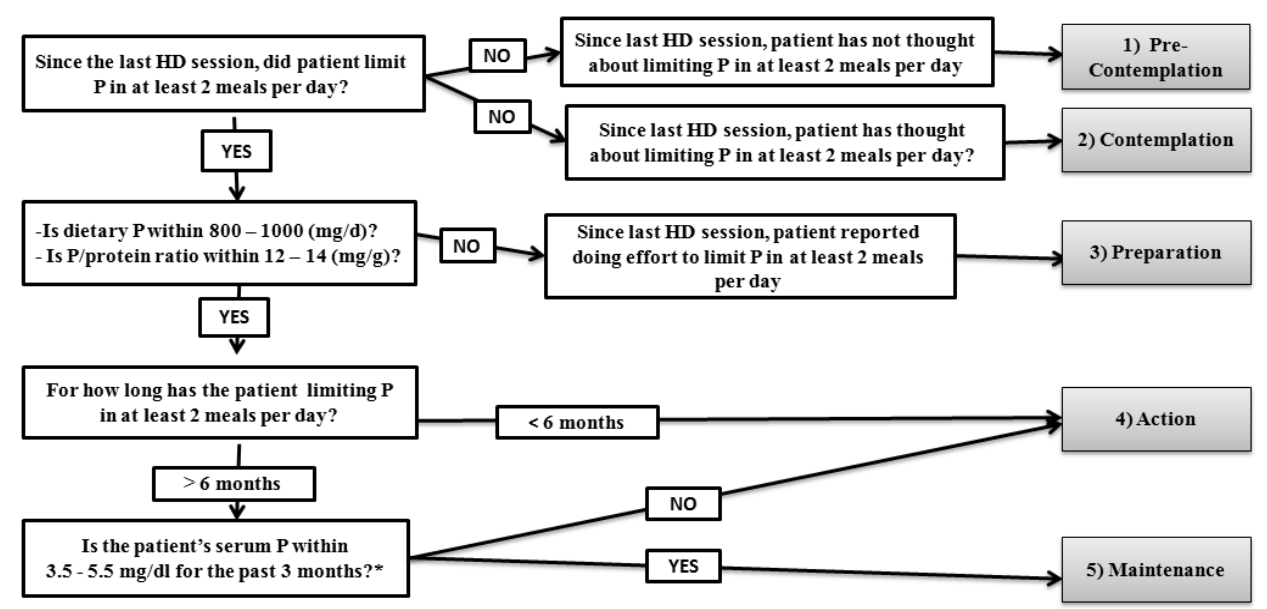

*since serum $\mathrm{P}$ doesn't respond immediately to dietary change, it is expected that a patient following $\mathrm{P}$ restricted diet for 6 months should have a normalized serum $P$ within the past 3 months.

\section{Data Analysis}

Collected data was entered into Statistical Package for Social Sciences (SPSS) version 16, IBM. A 0.05 significance level was utilized. Within group differences were studied using general linear model (GLM) repeated test ANOVA was used for repeated parametric 
measurement over the three study time points; if significant, analysis was followed by a post hoc test (Bonferoni) to test the differences in means for all possible pairs (T0 \&T1, T0\&T2, T1\&T2) within the treatment condition.

Within group differences for the repeated non-parametric measurements included the Friedman test. It was used to detect statistical difference between the 3 time points measurements (T0, T1, T2) within the same treatment condition; If significant, analysis was followed by a Post Hoc test (Wilcoxon Signed Rank test) to test the differences in average ranks for all possible pairs (T0 \&T1, T0\&T1, T1\&T2) within the treatment condition.

\section{RESULTS}

The following number of patients completed the study and provided sufficient data for analysis: DD ( $n=88), \operatorname{EP}(n=96)$, THD ( $n=210)$.

Baseline data (demographics and study parameters) are shown in detail in Karavetian et al (2014), whereby between group differences revealed that the DD group's mean serum $\mathrm{P}$ was significantly higher than the rest and THD group had more patients in the "action" and "maintenance" stages than the rest of the groups.

Knowledge of patients in the DD group improved significantly at post intervention, reaching a satisfactory percentage; this was maintained at follow up. The EP group had a significant drop in knowledge post intervention which significantly elevated at follow up but still did not reach satisfactory levels. As for patients in the THD group, knowledge scores had significantly improved at follow up, but did not reach satisfactory levels. Serum P significantly improved post-intervention (Table 7) only in the DD group. There was a significant elevation at follow up, but the value remained within the KDOQI optimal level. No significant improvement was seen in the other 2 groups.

$\mathrm{P}$ density in food was measured through P/Protein ratio (Table 8 ). This ratio approached normal levels post intervention in the DD group, but the change was not significant. At follow up, DD group had a significantly elevated ratio. There was no significant change in the EP group as for the THD group, the score remained unchanged at post intervention yet significantly increased at follow up (Table 4). 
Table 4. Effect of NEMO Trial on Knowledge, serum $P$ and Dietary $P$ density $(n=394)$ : DD group $(n=88)$, EP group $(n=96)$, THD group $(n=210)$

\begin{tabular}{|c|c|c|c|c|}
\hline \multicolumn{5}{|c|}{ Knowledge (\%) } \\
\hline DD group & $40.3^{\mathrm{a}} \pm 13.0$ & $64^{b} \pm 9.1$ & $64^{\mathrm{ab}} \pm 16.9$ & $<0.001$ \\
\hline EP group & $38.7^{\mathrm{a}} \pm 12$ & $30.1^{b} \pm 20.8$ & $51.2^{c} \pm 21.0$ & $<0.001$ \\
\hline THD group & $39.4^{\mathrm{a}} \pm 12.9$ & $39.9^{\mathrm{a}} \pm 19.1$ & $55.3^{b} \pm 20.8$ & $<0.001$ \\
\hline \multicolumn{5}{|c|}{ Serum $P(\mathrm{mg} / \mathrm{dl})$} \\
\hline DD group & $5.5 \pm 1.6^{\mathrm{a}}$ & $5.1 \pm 1.4^{b}$ & $5.2 \pm 1.7^{\mathrm{ab}}$ & $<0.01$ \\
\hline EP group & $5.4 \pm 1.5^{\mathrm{a}}$ & $5.3 \pm 1.5^{\mathrm{a}}$ & $5.6 \pm 2.0^{a}$ & 0.08 \\
\hline THD group & $5.18 \pm 1.5^{\mathrm{a}}$ & $5.05 \pm 1.5^{\mathrm{a}}$ & $5.13 \pm 1.5^{\mathrm{a}}$ & 0.17 \\
\hline \multicolumn{5}{|c|}{ Dietary P (mg)/Protein (g) } \\
\hline DD group & $15.5 \pm 5.3^{\mathrm{ab}}$ & $14.7 \pm 3.9^{a}$ & $16.1 \pm 2.1^{b}$ & 0.006 \\
\hline EP group & $15.7 \pm 4.4$ & $15.5 \pm 4$ & $15.7 \pm 1.4$ & 0.91 \\
\hline THD group & $14.62^{\mathrm{a}} \pm 4.5$ & $14.9^{\mathrm{a}} 3.4$ & $16.04^{b} \pm 2.3$ & $<0.001$ \\
\hline
\end{tabular}

Values are shown in mean \pm SD

$p$ value in the table indicates significance as per GLM-Repeated Measure ANOVA.

Different superscripts indicate statistical difference between each pair as per posthoc Bonferoni test $p<0.05$.

Post intervention results (Table 5) show that the median of the DD group improved from Preparation stage to Action stage and dropped back to Preparation at follow-up. No significant change was seen in the EP group. As for the THD group, there was no improvement post-intervention, moreover the median dropped even lower (Contemplation) at follow up.

The progression of patients from one TTM stage to another in the different study groups and phases, are reported in Table 6. The results show that 56 patients out of the 88 in the DD groups started the study at Pre-action stage; $90 \%$ of these patients progressed to either Action or Maintenance stages at post intervention, but at follow up all of them fell back to the Pre-Action stage. Moreover, 26/88 patients started the study in the Action phase, $73 \%$ of whom stayed in action and 15 progressed to Maintenance at post intervention; and almost all (92\%) regressed to Pre-Action at follow up. And finally, $13 / 88$ patients started the study in the Maintenance stage, most $(77 \%)$ stayed inbetween Action and Maintenance staged at post intervention, yet again dropped to Pre-Action at follow up. The results show positive effects of the intervention on patients of all TTM stages, and the detrimental effect of the absence of continuous reinforcement in the follow up phase of the study. Such improvement was not seen in the other study groups. 
Table 5. Effect of NEMO Trial on TTM Stages* on Diet Restricted in P ( $n=394)$

\begin{tabular}{|c|c|c|c|c|c|c|c|c|c|c|c|c|}
\hline & \multicolumn{4}{|c|}{ DD group $(n=88)$} & \multicolumn{4}{|c|}{ EP group $(n=96)$} & \multicolumn{4}{|c|}{ THD group $(n=210)$} \\
\hline & $25^{\text {th }}$ & $50^{\text {th }}$ & $75^{\text {th }}$ & $\begin{array}{c}\text { Mean } \\
\text { Rank }\end{array}$ & $25^{\text {th }}$ & $50^{\text {th }}$ & $75^{\text {th }}$ & $\begin{array}{c}\text { Mean } \\
\text { Rank }\end{array}$ & $25^{\text {th }}$ & $50^{\text {th }}$ & $75^{\text {th }}$ & $\begin{array}{c}\text { Mean } \\
\text { Rank }\end{array}$ \\
\hline TO & 2 & 3 & 4 & $1.9 a$ & 1 & 2 & 4 & $2 a$ & 2 & 3 & 4 & $2.2 a$ \\
\hline T1 & 3 & 4 & 5 & $2.5 b$ & 2 & 3 & 4 & $2 a$ & 2 & 3 & 4 & $2.1 a$ \\
\hline T2 & 2 & 3 & 3 & $1.6 c$ & 2 & 3 & 3 & $1.9 a$ & 1 & 2 & 3 & $1.7 \mathrm{~b}$ \\
\hline$P$ & \multicolumn{4}{|c|}{$<0.001$} & \multicolumn{4}{|c|}{0.42} & \multicolumn{4}{|c|}{$<0.001$} \\
\hline
\end{tabular}

TTM Stages are shown in their numbers

Values are shown in Quartiles, where 50th percentile indicates the median

$P<0.05$ indicated significance according to the Friedman test group statistics.

Ranks with different superscripts are statistically different from each other as posthoc Wilcoxon Signed Rank test with a $p<0.05$.

Table 6. Effect of NEMO Trial on Transition of Patients from One TTM Stage to Another $(n=394)$

\begin{tabular}{|c|c|c|c|c|c|c|c|c|c|}
\hline & \multicolumn{3}{|c|}{$\begin{array}{l}\text { DD group } \\
(n=88)\end{array}$} & \multicolumn{3}{|c|}{$\begin{array}{l}\text { EP group } \\
(n=96)\end{array}$} & \multicolumn{3}{|c|}{$\begin{array}{l}\text { THD group } \\
(n=210)\end{array}$} \\
\hline & TO & T1 & T2 & TO & T1 & T2 & TO & T1 & T2 \\
\hline Pre Action & $\begin{array}{c}56 \\
(100 \%)\end{array}$ & $\begin{array}{c}5 \\
(9 \%)\end{array}$ & $\begin{array}{c}37 \\
(66 \%)\end{array}$ & $\begin{array}{c}57 \\
(100 \%)\end{array}$ & $\begin{array}{c}48 \\
(84 \%)\end{array}$ & $\begin{array}{c}49 \\
(86 \%)\end{array}$ & $\begin{array}{c}124 \\
(100 \%)\end{array}$ & $\begin{array}{c}71 \\
(57 \%)\end{array}$ & $\begin{array}{c}105 \\
(85 \%)\end{array}$ \\
\hline Action & & $\begin{array}{c}23 \\
(41 \%)\end{array}$ & & & $\begin{array}{c}7 \\
(12 \%)\end{array}$ & & & $\begin{array}{c}33 \\
(26.6)\end{array}$ & $\begin{array}{c}2 \\
(2 \%)\end{array}$ \\
\hline Maintenance & & $\begin{array}{c}28 \\
(50 \%)\end{array}$ & & & $\begin{array}{c}2 \\
(4 \%)\end{array}$ & $\begin{array}{c}5 \\
(9 \%)\end{array}$ & & $\begin{array}{c}20 \\
(16.1 \%)\end{array}$ & $\begin{array}{c}9 \\
(7 \%)\end{array}$ \\
\hline Pre Action & & $\begin{array}{c}3 \\
(11.5 \%)\end{array}$ & $\begin{array}{c}24 \\
(92 \%)\end{array}$ & & $\begin{array}{c}24 \\
(77 \%)\end{array}$ & $\begin{array}{c}30 \\
(97 \%)\end{array}$ & & $\begin{array}{c}31 \\
(62 \%)\end{array}$ & $\begin{array}{c}37 \\
(74 \%)\end{array}$ \\
\hline Action & $\begin{array}{c}26 \\
(100 \%)\end{array}$ & $\begin{array}{c}19 \\
(73 \%)\end{array}$ & & $\begin{array}{c}31 \\
(100 \%)\end{array}$ & & & $\begin{array}{c}50 \\
(100 \%)\end{array}$ & $\begin{array}{c}13 \\
(26 \%)\end{array}$ & $\begin{array}{c}5 \\
(10 \%)\end{array}$ \\
\hline Maintenance & & $\begin{array}{c}4 \\
(15 \%)\end{array}$ & $\begin{array}{c}2 \\
(8 \%)\end{array}$ & & $\begin{array}{c}7 \\
(23 \%)\end{array}$ & $\begin{array}{c}1 \\
(3 \%)\end{array}$ & & $\begin{array}{c}6 \\
(12 \%)\end{array}$ & $\begin{array}{c}5 \\
(10 \%)\end{array}$ \\
\hline Pre Action & & $\begin{array}{c}3 \\
(23 \%)\end{array}$ & $\begin{array}{c}12 \\
(92 \%)\end{array}$ & & $\begin{array}{c}9 \\
(69 \%)\end{array}$ & $11(84.6 \%)$ & & $\begin{array}{c}32 \\
(62 \%)\end{array}$ & $\begin{array}{c}43 \\
(83 \%)\end{array}$ \\
\hline Action & & $\begin{array}{c}4 \\
(31 \%)\end{array}$ & & & $\begin{array}{c}3 \\
(23 \%)\end{array}$ & & & $\begin{array}{c}9 \\
(17 \%)\end{array}$ & $\begin{array}{l}n=1 \\
(2 \%)\end{array}$ \\
\hline Maintenance & $\begin{array}{c}n=13 \\
(100 \%)\end{array}$ & $\begin{array}{c}n=6 \\
(46 \%)\end{array}$ & $\begin{array}{l}n=1 \\
(8 \%)\end{array}$ & $\begin{array}{c}n=13 \\
(100 \%)\end{array}$ & & & $\begin{array}{c}n=54 \\
(100 \%)\end{array}$ & $\begin{array}{l}n=13 \\
(25 \%)\end{array}$ & $\begin{array}{c}n=7 \\
(14 \%)\end{array}$ \\
\hline
\end{tabular}

All percentages are rounded up.

At T2, numbers do not add up to $100 \%$ due to drop out rates by the end of the study. 


\section{DISCUSSION}

The nutritional psycho-education used in DD protocol improved all study parameters. The protocol was unique in its high dietitian-to-HD patient time, 6 month duration, individuated education using the TTM model, and use of culturally fit educational material. Despite an equal training for dietitians in the THD and DD groups, patient education style and duration in the THD group was left to the dietitian's initiative and time limitations.

Knowledge scores in the DD group improved post intervention and reached satisfactory scores, this improvement did not drop at follow up, showing the effectiveness of intensive education protocol; this was in line with other published nutrition education interventions (Ford et al., 2004; Niso et al., 2007; Karavetian and Ghaddar., 2013; Shi et al., 2013; Sullivan et al., 2009). The knowledge scores of the EP group improved at follow up only but did not reach satisfactory score; this was explained by contamination of information through patients and nurses. As head nurses explained afterwards, HD unit staff was blinded to study protocol so when patients were left with no interaction from the research team for 6 months for follow up, nurses assumed that the study was over, and photocopied the educational material from the DD group and distributed them to the EP group. This explains the superiority of the DD protocol and the effect of patients being educated by the dietitian and not by other health care providers.

As for the patients in the THD group, their knowledge also improved but only at follow up. A plausible explanation is that the dietitians in these hospitals, who were trained to educate the patients, did upgrade their nutrition educational methods after the training and possibly increased the frequency of their educational sessions with HD patients; but they did this for much shorter duration and in a less structured manner compared to the research team, thus achieving improvement in 12 months and not in 6. This explanation is supported by our data (not yet published) which showed that THD dietitians visited the patients at best once a month. The slower pace or the smaller effect in the THD group was expected, since the dietitians in this group had within their job description many other duties in the hospital in addition to the HD patients.

The improved knowledge of DD group patients led to a change in behavior and progress to the TTM stage of "Action" at post intervention. Even though EP and THD patients achieved some improvement in knowledge at follow up, our results clarify that distributing educational material can only improve knowledge but not change behavior. This is in line with several review articles focused on effective adherence methods among HD patients (Matteson et al., 2010; Karavetian Mb et al., 2013; Mason et al., 2008). In their findings, it is evident that education may improve knowledge but not necessarily behavior; emphasizing long term individualized and intensive education as the key to success. Our data also support the importance of continuous follow up, with reinforcement of information. Dietary lifestyle change is difficult to maintain over long periods of time; restricted diet on the long term has shown to be correlated with de- 
pression (Morey et al., 2008) and thus lead to relapse to old behavior. Patients need constantly to be reminded of the benefits of the new behavior to maintain it.

The Academy of Nutrition and Dietetics stated in a position paper that there is strong evidence for the beneficial effect of dietary education with behavioral theory in improving dietary adherence (Spahn et al., 2000). Furthermore, Matteson and Russell (2010) reviewed the literature on interventions that improve HD patient adherence, and concluded that integration of behavioral theory in patient education is highly effective and should be considered the method of education of the future. Our findings were in line with these review results. Our nutritional psycho-education helped patients improve serum $P$ significantly, thus providing an objective evidence on the effectiveness of the DD protocol over the other 2 . None of the other 2 groups showed any change in serum P. This and the lack of improvement in TTM stage direct us to see the inadequacy of the existing practice and that of the trained hospital dietitians. When dietitians are not provided sufficient support from administration, they won't be able to increase the frequency of their counseling sessions.

Needless to say that the special design of the educational material used in the DD group intervention had a strong positive effect on the results. The material empowered patients and was tailored to their stage of readiness to change and targeted multiple aspects of learning. The THD and EP group were not provided with that material till after the follow up phase. Thus, their dietitians used random educational material to educate their patients. Preparing effective educational material culturally fit to the specific patient population needs excellent knowledge of the topic, time, effort and access to literature; all of which are difficult to find among dietitians who are not specialized in renal care and are overwhelmed with various duties in the hospital; which is the case of Lebanese dietitians managing HD patients (Karavetian Mb et al., 2013).

The challenge of having patients follow a $\mathrm{P}$ restricted diet without driving them towards a protein restricted diet, which can lead to malnutrition and exacerbate the disease. Our results of dietary $\mathrm{P}$ density analysis, measured through P/Protein ratio, were maintained almost within the normal levels in the DD group. This demonstrates that even though the DD group restricted their $\mathrm{P}$ intake, evidenced by the drop in serum $P$, they were able to maintain a sufficient protein intake. The educational material used, had a large part of it focused on the $\mathrm{P} /$ protein balance, and helped patients identify the low P alternative of foods. Other similar studies also noted teaching patients' safe alternatives of restricted food items as a facilitator to dietary adherence (Karavetian and Ghaddar, 2013; Sullivan et al., 2009; Lou et al., 2012)

Often, patients complain that the dietary restrictions are too complicated to understand and leave them almost no options of allowed food (Breiterman, 2004). Our educational material did not only tell the patients what not to eat, but informed them on the safe alternatives, and how they can prepare them, so they do not feel deprived form their customary and traditional meals. The booklet of alternatives and the recipe books were highly valued among our patients. We suppose that this was because the 
information in these tools were easy to follow and gave practical information that facilitated adherence to the $P$ restricted diet. Chan et al (2012) confirmed the benefit if using easy to follow information over behavioral change. All of the 3 groups had an elevation of the $\mathrm{P} /$ protein ratio at follow up, and this change was significant among the DD and THD groups. This may be explained by the seasonal change. The last months of the 12 months duration study were winter where people tend to eat more than usual due to the cold weather (Lloyd et al., 2013). Since In Lebanon a highly consumed food item is dairy (Karavetian and Ghaddar, 2013), which is also high in P, we suppose that the increase in $\mathrm{P} /$ prot ratio is due to the increased consumption of food and especially dairy.

\section{CONCLUSION}

The results of the study indicate that a 6 month long intensive individualized stagebased nutrition education through a 2 hour per month dietitian-to-HD patient time leads to significant improvement in $\mathrm{P}$ among HD patients. This method can serve as a model to follow in HD units in Lebanon and other countries with similar health care systems. Its adoption may be the pillar of change towards better nutritional management in the HD unit. 


\section{REFERENCES}

Aldridge, M. (2004). Writing and designing readable patient education material. Nephrology Nursing Journal.31:4.

Academy of Nutrition \& Dietetics Evidence Based Library (AND -EAL). (2010). Is MNT provided by a Registered Dietitian for chronic kidney disease (CKD) in adults effective? ADA Evidence Analysis Library. 1-6.

Breiterman W.R. (2004). Adherence to the dialysis prescription: partnering with patients for improved outcomes. Nephrology Nursing Journal. 31:432-436.

Caldeira, D., Amaral, T., David, C., and Sampaio, C. (2011). Educational Strategies to Reduce Serum Phosphorus in Hyperphosphatemic Patients With Chronic Kidney Disease: Systematic Review With Meta-analysis. Journal of Renal Nutrition. 21(4): 285-294.

Chan YM, Zalilah MS, Hii SZ. (2012). Determinants of compliance behaviors among patients undergoing hemodialysis in Malaysia. PLOS ONE. 7(8):41362.

Durose, C.L. and Holdsworth, M. (2004). Knowledge of dietary restrictions and the medical consequences of noncompliance by patients on hemodialysis are not predictive of dietary compliance. Journal of American Dietetic Association. 104 (1): 35-41.

Fickenor M. and Byrd-Bredbenner C. (2000). Nutrition intervention group program based on preaction-stageoriented change processes of the Transtheoretical Model promotes long-term reduction in dietary fat intake. Journal of American Dietetic Association. 100: 3.

Ford JC, Pope JF, Hunt AE, Gerald B. (2004). The effect of diet education on the laboratory values and knowledge of hemodialysis patients with hyperphosphatemia. Journal of Renal Nutrition.14: 36-44.

Friedman E. (2005). An Intoduction to phosphate binders for the treatment of hyperphosphatemia in patients with chronic kidney disease. Kidney International. 96(68): 2-6

http://www.kidney.org/professionals/kdoqi/guidelines_updates/doqi_nut.html. Accessed on 3 February 2014.

Karavetian M \& Ghaddar S. (2013). Serum Phosphate Reduction with Diet: Randomized Controlled Trial in Hemodialysis Patients, Lebanon. Journal of Renal Care. 39(1): 19-30.

Karavetian M, El Zein H, Hwalla N, De Vries N. (2013). Conformity of Dietetic Practices with KDOQI Nutrition Guidelines in HD Units in Lebanon. Int J Health Nutr. 4(2):1-8.

Karavetian M, Abboud S, El Zein H, Haydar S, de Vries N. (2014). Nutritional education for management of osteodystrophy (NEMO) trial: Design and patient characteristics, Lebanon. Nutrition Research and Practice. $8:$ In Press.

Karavetian M, De Vries N, Rizk R, El Zein H,. (2014) Dietary Counseling Interventions for Hyperphosphatemia Management in Hemodialysis (HD) Patients: A Systematic Review and Meta-Analysis. Nutrition Reviews. Accepted

Kaveh, K. and Kimmel, P.L (2001). Compliance in hemodialysis patients: Multidimensional measures in search of a gold standard. American Journal of Kidney. 37(2): 244-266.

Lloyd L, Miller B. (2013). The impact of seasonality on changes in body weight and physical activity in Mexican-American women. Women Health. 53(3):262-81

Lou LM, Caverni A, Gimeno JA, et al. (2012). Dietary intervention focused on phosphate intake in hemodialysis patients with hyperphosphoremia. Clinical Nephrology. 77(6):476-83

Mason J, Khunti K, Stone M, Farooqi A, Carr S. (2008). Educational Interventions in Kidney Disease Care: A Systematic Review of Randomized Trials. American Journal of Kidney Disease. 51(6): 933-951.

Matteson, M. and Russel, C (2010). Interventions to improve hemodialysis adherence: A systematic review of randomized-controlled trials. Hemodialysis International. 14: 370-382.

Maurales Lopez C. , BurrowesJ., Gizis F. and Brommage D. (2007). Dietary Adherence in Hispanic Patients Receiving Hemodialysis. Journal of Renal Nutrition. 17: 138-147.

Mochari-Greenberger H., Terry M. and Mosca L. (2010). Does Stage of Change Modify the Effectiveness of an Educational Intervention to Improve Diet among Family Members of Hospitalized Cardiovascular Disease Patients? Journal of American Dietetic Association. 110: 1027-1035. 
Molaison E., Yadrick K. (2003). Stages of change and fluid intake in dialysis patients. Patient Education and Counseling. 49: 5-12.

Morey B, Walker R, Davenport A. (2008). More dietetic time, better outcome? A randomized prospective study investigating the effect of more dietetic time on phosphate control in end-stage kidney failure haemodialysis patients. Nephron Clinical Practice. 109(3): 173-80.

NKR (National Kidney Registry) www.kidneyregistrylb.com Accessed on June 29, 2012

Niso JM, Bazanelli AP, Kamimura MA, et al. (2007). The impact of a nutrition educational program on the control of the hyperphosphatemia in hemodialysis patients. Journal of Brasilian Nefrology. 29(3): 152157.

National Kidney Foundation Kidney Disease Outcomes Quality Initiative (NKF KDOQI) (2000) Clinical Practice Guidelines for Nutrition in Chronic Renal Failure https://www.kidney.org/professionals/kdoqi/guidelines_updates/doqi_nut.html. Accessed on January 20, 2011.

Noori N, Kalantar-Zadeh K,Kovesdy C, Bross R, Benner D, Kopple J. (2000) Association of Dietary Phosphorus Intake and Phosphorus to Protein Ratio with Mortality in Hemodialysis Patients. Clinical Journal of American Society of Nephrology. 5: 683-692.

Paul S. and Sneed N. ancee V.S. (2004). Strategies for Behavior Change in Patients with Heart Failure. American Journal of Critical Care. 13: 305-313.

Prochaska J. (2008). Decision Making in the Transtheoretical Model of Behavior Change. Medical Decision Making.

Shaw-Stuart N. and Stuart A. (2000). The effect of an Educational Patient Compliance Program on Serum Phosphate Levels in Patients Receiving Hemodialysis. Journal of Renal Nutrition. 10(2): 80-84.

Shi YX, Fan XY, Han HJ, et al. (2013) Effectiveness of a nurse-led intensive educational program on chronic kidney failure patients with hyperphosphataemia: randomised controlled trial. Journal of Clinical Nursing. 22(7-8):1189-97.

Spahn J. and Co. (2010). State of the Evidence Regarding Behavior Change Theories and Strategies in Nutrition Counseling to Facilitate Health and Food Behavior Change. Journal of American Dietetic Association. 10(6).

Sullivan C, Sayre SS, Leon JB, et al. (2009). Effect of food additives on hyperphosphatemia among patients with end-stage renal disease: a randomized controlled trial. JAMA. 301(6):29-35.

Sun, C., Chang, K., Chen, S., Chang, C. and Wu, M. (2008). Patient Education: An Efficient Adjuvant Therapy for Hyperphosphatemia in Hemodialysis Patients. Renal Failure. 30-57-62.

USDA (U.S. Department of Agriculture) National Nutrient Database for Standard Reference software Version 25. www.ars.usda.gov/ba/bhnrc/ndl

Welch J. (2000). Hemodialysis Patient Beliefs by Stage of Fluid Adherence. Research in Nursing and Health. 24: 105-112.

Whitelaw, S., Baldwin, S., Bunton, R. and Flynn, D. (2000). The status of evidence and outcomes in stages of change research. Health Education and Research. 15(6): 707-718. 


\section{CHAPTER 7}

The Nutritional Education for Management of Osteodystrophy (NEMO) Trial: Impact on Quality of Life and Malnutrition status

Submitted for publication as : Karavetian, M., El Zein, H., Jibai, R., De Vries, N. The Nutritional Education for Management of Osteodystrophy (NEMO) Trial: Impact on Quality of Life and Malnutrition status. 


\section{ABSTRACT}

Osteodystrophy management includes dietary phosphorus $(\mathrm{P})$ restriction which leads to limiting protein intake; this often exacerbates the malnutrition-inflammation syndrome (MIS) among hemodialysis (HD) patients and consequently the health-related quality of life (HRQOL) and hospitalization. The aim of this study is to assess the effect of intensive nutrition education focused on P-to-Protein balance, on MIS and HRQOL. It was a multi-center parallel group randomized control trial involving twelve HD units from Lebanon randomly assigned to the cluster $A(n=6)$ and cluster $B(n=6)$ and including 210 participants in cluster $A$ and 184 in B. Cluster A patients were assigned to the Trained Hospital Dietitian protocol (THD) protocol, and cluster B patients were randomly assigned according to their HD shifts to either Dedicated Dietitian (DD) or Existing Practice (EP) protocols. DD protocol included individualized stage-based nutritional education, focused on dietary phosphorus $(P)$ and protein management, with duration of 2 hour/patient/month for 6 months by dedicated renal dietitians. The THD protocol: education given by the trained hospital dietitian without a set protocol; the EP: usual care where hospital dietitian is blinded to study. Serum $P(\mathrm{mg} / \mathrm{dl}), \mathrm{MIS}, \mathrm{HRQOL}$ and length of hospital stay (LOS) (days) were measured at baseline (TO), at 6 months (T1) and in the 12 month (T2) post intervention. The study significantly improved serum $\mathrm{P}$ only in the $\mathrm{DD}$ group $(\mathrm{T} 0=5.55 \pm 1.57, \mathrm{~T} 1=5.11 \pm 1.43)$ and Mental Health domain of HRQOL at T2. Significant MIS deterioration was prevented only in the DD group at T1 but the score significantly increased for all groups at T2. All groups experienced a significant drop in LOS (around 1 day from T1 to T2). The DD protocol was superior over the others in improving serum $\mathrm{P}$ and slowed the decline of malnutrition and HRQOL. 


\section{INTRODUCTION}

Hyperphosphatemia is highly prevalent among hemodialysis (HD) patients (Yokum et al., 2008). Its management includes dietary phosphorus (P) restriction which needs to be balanced with a high protein intake to prevent malnutrition; a true challenge since all sources of protein are rich in P (Mathewson et al., 2010). As a consequence, the malnutrition-inflammation syndrome (MIS) is a common condition among HD patients (Kalantar-Zadeha et al., 2001). It represents the vicious cycle where inflammation leads to malnutrition (drop in appetite and increased catabolism) and vice versa. MIS is the main reason why overweight is better than underweight, and why low Body Mass Index (BMI) and low serum cholesterol increase the risk of mortality among HD patients (Kalantar-Zadeh et al., 2004; Rambod et al., 2009). MIS, in turn, is a strong predeterminant of low health-related quality of life (HRQOL), hospitalization and morbidity (Covic et al, 2004; Mazairac et al., 2011; Kalantar-Zadeh et al., 2004; Rambod et al., 2009; Zabel et al., 2009). HRQOL is a multidimensional concept that reflects a patient's perceived well-being and functioning in physical, psychological and social domains of health (Mazairac et al., 2011; Gabbay et al., 2010). HRQOL scores are between 0 (death) and 100 (perfect state of health) (Kalantar-Zadehb et al., 2001), where a healthy person mainly scores 95 (De Wit et al., 2002). HD patients seem to have lower HRQOL scores $(40-70)$ when compared to the general population, with a lower upper bound in specific countries (e.g. 38- 53 in Iran, Aghakhani et al., 2012).

One way of controlling MIS is dialysis, whereby the accumulated toxins, mainly blood urea nitrogen (BUN), are cleared out of the blood (McCann, 2009). Thus an adequate dialysis, if achieved, helps HD patients regain appetite and prevent MIS (Toigo et al., 2000). One of the barriers to adequate dialysis is dietary incompliance causing increased load of toxins in the blood above the possible clearance limit. Studies have shown that dietary adherence is achieved when patients are consulted frequently by the renal dietitian (AND -EAL, 2010)

In Lebanon, HD units are exclusively hospital based. The HD units do not have dedicated dietitians, but the hospital dietitian is required to provide nutritional education to these patients among other duties in the hospital. Karavetian et al. (2013) report on the high workload of these dietitians who fail to sufficiently consult HD patients and lack optimal competencies required for optimal management of HD patients.

The aim of the NEMO trial (Nutritional Education for Management of Osteodystrophy) was to assess the effect of an intensive individualized nutrition education, provided by a dedicated renal dietitian, on MIS and HRQOL, among HD patients. 


\section{METHODS}

NEMO is a randomized control multicenter trial in 12 hospital based MHD units, of which 6 were randomly assigned to the cluster $A$, and 6 others to the cluster B. Cluster A patients were assigned to a Trained Hospital Dietitian (THD) protocol. As for patients of Cluster B, half of them in each unit were randomly selected according to their dialysis shift and assigned to the Dedicated Dietitian (DD) protocol and the other half to the Existing Practice (EP) protocol; thus having 2 different protocols in each HD unit in Cluster B. Hospital and patient selection criteria, randomization method and group baseline characteristics are detailed in Karavetian, (2014). After attrition, the number of patients in each cluster was: Cluster A $(n=210)$ and Cluster B ( $n=184$; DD $n=88$, EP $n=96)$.

\section{Protocol per study group}

Trained Hospital Dietitian: This group represents the partial intervention of this study. The general hospital dietitian, responsible for the selected hospital's HD unit, was trained by the study's principal investigator (PI) on renal dietetics. The dietitians were then asked to educate their HD patients with a focus on management of hyperphosphatemia without a set of further educational protocol or tools provided. They were informed that their work in the HD unit would be monitored by the PI for 6 months. There was no control in this group since it was not possible to ask the hospital dietitian to provide patient care of different standards to the HD patients of that hospital.

Dedicated Dietitian: This group represents the full intervention of the study. Patients were educated by 5 externally recruited research dietitians who were clinicians and trained by the PI as those of the THD. The patient education protocol included individualized nutrition education on management of hyperphosphatemia. Dietitians met with the patients twice a week for 15 minutes each, for 6 months, adding up to a total of 12 hours of education per patient. The education was tailored to the stage of readiness to change of each patient using the Trans Theoretical model. During the 1st weekly session, the theme of the week was introduced; in the 2nd weekly session, it was reinforced. Details of the education are explained in Karavetian, El Zein et al (2014?).

Existing Practice: In the control group, patients did not receive any intervention by the research team; they continued receiving dietetic care as per existing practice of the hospital dietitian who was blinded to the study protocol.

\section{Outcome Measures}

Data were collected at baseline (T0), post intervention (T1 $=\mathrm{T} 0+6$ months) and at follow up ( $\mathrm{T} 2=\mathrm{T} 1+6$ months). This was conducted in all groups by the research dietitians under the supervision of the PI. 
Serum P (mg/dl) was collected from all patients throughout the 6 months prior to each measurement; the average of the 6 months was computed to give information on the effect of the dietary behavioral change of each study phase.

Urea Reduction Ratio (URR): an indicator of dialysis adequacy, was calculated from BUN (mg/dL) before and after the dialysis session: URR: 100*(1-post BUN/pre BUN). Optimal URR ( $\geq 65 \%$ ) indicated at least $65 \%$ of the urea clearance by the dialysis session (McCann, 2009). BUN being the direct metabolite of dietary protein in the blood (McCann, 2009), pre-dialysis BUN was used to detect adequacy of dietary protein intake; knowing that the acceptable range of pre dialysis BUN for renal failure patients is $60-80 \mathrm{mg} / \mathrm{dl}$ (McCann, 2009). Pre and Post BUN were collected for 6 months prior to each study phase and averaged for each measurement moment.

Anthropometrics: To establish an objective measure of nutritional status, anthropometrics were studied. Post dialysis weight (dry weight in $\mathrm{kg}$ ) of patients was taken at T0, T1 and T2 by the hospital nurses and it was recorded by the research dietitians. From the 3 scores of weight collected per patient, weight change $(\Delta w t)$ was calculated for each posttest: $\Delta$ wt1: wt T1- wtT0, $\Delta$ wt2: wtT2- wtT1. Height $(\mathrm{cm})$ was taken at T0 only by research dietitians using the forearm length (Mc Cann, 2009). It is the length between the elbow and the prominent wrist bone. Height was determined using a chart provided in McCann (2009). This method was used since it is a standardized valid method and can be carried out even when the patient is being dialyzed. Moreover, wrist size $(\mathrm{cm})$ was measured by research dietitians at T0. Height, wrist size, gender and age were used to estimate standard body weight (SBW) of patients through a chart (McCann, 2009).

Health Related Quality of Life (HRQOL) was measured using the short-form health survey (SF- 36) (Ware et al., 1992). It assesses eight health states: 1) physical functioning (PF) (10 items and 21 levels); 2 ) limitation in role physical (RP) (usual role activities (4 items and 5 levels); 3 ) social functioning (SF) (2 items and 9 level); 4) bodily pain (BP) ( 2 items and 11 levels); 5) general mental health (MH) (5 items and 26 levels); 6) role limitation due to emotional problems (RE) ( 3 items and 4 levels); 7 ) vitality ( 4 items and 21 levels); and 8) general health (GH) (5 items and 21 levels). Scoring of items in each health state was done by summing up the scores of the Likert scale ratings. High scores of each health state indicated better level of that specific aspect (Ware et al., 1992). The final score ranged between 0 (death) and 100 (full life). The Arabic, culturally specific and validated version of QOL was used (Karavetian et al., 2007).

Percent Daily Protein Intake was assessed through 24 hour recall, collected from patients on 3 nonconsecutive days of the week at each study phase. Content of protein (g) was calculated using the renal exchange system (McCann, 2009) and the USDA (version 25) database. Edible portion of the food was analyzed. The average value of the 3 days was taken to represent the actual daily protein intake of each patient. Daily protein need was calculated by multiplying $1.2 \mathrm{~g}$ with SBW (kg) (McCann, 2009). And finally, 
the \% Daily Protein Intake (compared to need) was calculated using the below formula: Actual daily protein (g) intake /daily protein (g) needs $* 100$.

Malnutrition Inflammation Score (MIS) was measured at T0, T1 and T2 using a comprehensive scoring system adapted from Kalantar-Zadeha et al. (2001). MIS has been shown to have significant associations with prospective hospitalization and mortality as well as measures of nutrition, inflammation, and anemia in MHD. The International Society of Renal Nutrition and Metabolism (ISRNM) Expert Panel recommends using MIS as predictor of protein energy malnutrition indicator among patients with kidney failure (Fouque et al., 2008). MIS has 10 components each with four levels of severity (0 -3) 10. The total score ranges from 0 to 30: 0 (normal), 1-10 (mildly malnourished), 11-20 (moderately malnourished) and 21-30 (severely malnourished). The scoring sheet consists of four sections: (A) Patients' medical history that includes change in dry (post dialysis) weight (overall change in past 3-6 months), dietary intake, gastrointestinal (GI) symptoms, functional capacity (nutritionally related functional impairment), co-morbidity and dialysis vintage, (B) physical examination that consists of assessment of subcutaneous body fat (below eyes, triceps, biceps), and signs of muscle wasting (temple, clavicle, scapula, quadriceps, knee, inter-osseous). (C) Body Mass Index BMI = Dry wt (Kg) / Ht2 (m), and (D) laboratory parameters: Serum albumin (Alb) and serum total iron binding capacity (TIBC) (Kalantar-Zadeha et al., 2001; Rambod et al., 2009).

Hospitalization was collected from patients' medical files as the number of days each patient was hospitalized including emergency and regular ward days: length of stay (LOS). The cumulative value for LOS was calculated for the 6 months prior to each study phase. Additionally, number of times a patient needed emergency dialysis was retrieved.

\section{Statistical Analysis}

Collected data was entered into the Statistical Package for Social Sciences (SPSS) version 16. A 0.05 significance level was utilized.

The effect of each protocol between the 3 study phases (T0, T1, T2) within the same treatment group was studied using the general linear model (GLM) repeated test ANOVA. Afterwards, Post Hoc Bonferoni test was carried on, to test the differences in means for all possible pairs (T0 \&T1, T0\&T1, T1\&T2) within the treatment condition. Paired t-test was used to analyze the change of weight between $\Delta \mathrm{wt1}$ and $\Delta \mathrm{wt2}$. One way ANOVA was used for between group differences, and Post Hoc Bonferoni test was carried on to study the differences in means for all possible pairs within the study phase. 


\section{RESULTS}

The following number of patients provided sufficient data to be included in the statistical analysis DD ( $n=88)$, EP ( $n=96)$, THD ( $n=210)$.

Baseline data are detailed in Karavetian M et al. (2014); below is a summary of the significant group differences at baseline. Serum $\mathrm{P}(\mathrm{mg} / \mathrm{dl})$ was significantly higher in the DD group $(5.57 \pm 1.53)$ compared to the EP $(5.39 \pm 1.48)$ and THD $(5.17 \pm 1.44)$ groups. At baseline the MIS score of the DD group (7.2 \pm 3.37$)$ was significantly higher than that of the other 2 groups, but all groups had an MIS $<10$ (mildly malnourished), thus there was no clinical difference. As for HRQOL domains, the only significant differences were noted in 2 domains: 1) physical functioning where the DD group had the lowest score $(52.32 \pm 34.59)$ compared to the EP $(59.6 \pm 31.91)$ and THD $(64.47 \pm 32.25)$ and in 2$)$ social functioning where the THD group had the lowest score (70.4 \pm 31.79$)$ compared to DD $(81.14 \pm 30.13)$ and EP (81.6 \pm 29.21$)$. As for the adequacy of dialysis; calculated URR was $>65 \%$ for most patients at all times (data not included in tables).

Table 1 shows the between and within group difference for study parameters. The groups with significant difference were undergone further post hoc analysis to identify the contributing pairs for the significance. 
Table 1. Effect of NEMO trial on study parameters

\begin{tabular}{|c|c|c|c|c|}
\hline & $\mathrm{DD}(\mathrm{n}=88)$ & $\operatorname{EP}(n=96)$ & THD $(n=210)$ & $\begin{array}{l}\text { Between group } \\
\text { analysis P Value }\end{array}$ \\
\hline \multicolumn{5}{|c|}{ Serum P (mg/dl) } \\
\hline TO & $5.55 \pm 1.57^{\mathrm{a}(¥)}$ & $5.35 \pm 1.48^{(¥ f)}$ & $5.18 \pm 1.49^{a(f)}$ & 0.027 \\
\hline $\mathrm{T} 1$ & $5.11 \pm 1.43^{b}$ & $5.30 \pm 1.56$ & $5.05 \pm 1.49^{\mathrm{a}}$ & 0.462 \\
\hline $\mathrm{T} 2$ & $5.29 \pm 1.67^{\mathrm{ab}(¥ \mathrm{f})}$ & $5.64 \pm 2.03^{(¥)}$ & $5.13 \pm 1.51^{\mathrm{a}(\mathrm{f})}$ & 0.036 \\
\hline \multicolumn{5}{|c|}{ Total MIS Score } \\
\hline TO & $7.26 \pm 3.51^{a(¥)}$ & $6.62 \pm 3.16 a^{(¥ f)}$ & $6.07 \pm 3.90^{a(f)}$ & 0.07 \\
\hline $\mathrm{T} 1$ & $7.68 \pm 3.49^{a}$ & $7.87 \pm 3.50^{b}$ & $7.49 \pm 3.33^{b}$ & 0.606 \\
\hline $\mathrm{T} 2$ & $9.20 \pm 3.90^{b(¥ f)}$ & $9.62 \pm 4.56^{c(¥)}$ & $8.24 \pm 4.07^{c(f)}$ & 0.016 \\
\hline \multicolumn{5}{|c|}{ Protein Intake (\%) } \\
\hline TO & $65.72 \pm 5.91^{\mathrm{a}}$ & $59.35 \pm 2.98^{\mathrm{a}}$ & $56.03 \pm 1.64^{\mathrm{a}}$ & 0.125 \\
\hline $\mathrm{T} 1$ & $50.81 \pm 2.48^{b(*)}$ & $55.06 \pm 2.76^{a(¥ f)}$ & $56.87 \pm 1.49^{\mathrm{a}(\mathrm{f})}$ & 0.047 \\
\hline $\mathrm{T} 2$ & $39.76 \mathrm{a} \pm 1.36^{\mathrm{c}(¥)}$ & $38.65 \pm 1.39 b^{(¥)}$ & $49.87 \pm 1.48^{\mathrm{b}(\mathrm{f})}$ & 0.00 \\
\hline \multicolumn{5}{|c|}{ BUN (mg/dl) } \\
\hline TO & $87.43 \pm 35.80^{\mathrm{a}}$ & $99.16 \pm 44.53^{a}$ & $116.56 \pm 3.39^{a}$ & 0.460 \\
\hline $\mathrm{T} 1$ & $81.33 \pm 32.58^{b}$ & $94.83 \pm 39.53^{b}$ & $109.11 \pm 3.27^{b}$ & 0.332 \\
\hline $\mathrm{T} 2$ & $83.30 \pm 31.77^{\mathrm{ab}}$ & $96.40 \pm 39.82^{a b}$ & $112.44 \pm 3.31^{\mathrm{ab}}$ & 0.921 \\
\hline \multicolumn{5}{|c|}{ Total HRQOL score } \\
\hline TO & $51 \pm 6.34$ & $52 \pm 6.53$ & $50 \pm 6.6 .30$ & 0.07 \\
\hline $\mathrm{T} 1$ & $53 \pm 7.25$ & $52 \pm 7.36$ & $52 \pm 6.51$ & 0.17 \\
\hline $\mathrm{T} 2$ & $51 \pm 7.56$ & $51 \pm 6.73$ & $52 \pm 7.39$ & 0.74 \\
\hline
\end{tabular}

Values are shown in mean \pm SD

${ }^{a b}$ superscripts (in columns) indicate within group significant differences using GLM-repeated measure ANOVA and posthoc Bonferoni test $(p<0.05)$.

${ }^{¥}$ superscripts (in rows) indicate statistical difference between different groups using One way ANOVA and posthoc Bonferoni test $(p<0.05)$.

The within group difference showed that the intervention significantly improved serum $\mathrm{P}$ of the DD group (Table 1): there was a significant elevation at follow up, but the value did not surpass the normal limits of serum P set by KDOQI. There were no significant changes in the other 2 groups. Between the 3 groups there was no significant difference at post intervention but at baseline and at follow up the THD had a significantly lower serum $P$ than other 2 groups.

Within group differences for the MIS score showed that the DD protocol was the only that prevented the significant increase of MIS at T1; but at T2 all groups had a significant increase of MIS score. The between group difference showed that the DD protocol had the highest MIS score at T0; this significant difference disappeared at T1. At T2 the EP had significantly the highest MIS score, followed by the DD and then the 
THD. However, at all times MIS values for all groups fell within the same malnutrition category indicating mild malnutrition.

Protein intake dropped significantly throughout the study (Table 1). At baseline, actual protein consumption of DD group was $66 \%$ and continued dropping during at T1 and T2. EP started with a $59 \%$ and THD with $56 \%$ but both significantly dropped at T2. The between group comparison showed that at T1, DD group had significantly the lowest protein consumption and at T2, the THD had the highest.

Post intervention patients weight was assessed. The change between $\Delta \mathrm{wt} 1$ and $\Delta \mathrm{wt} 2$ was analyzed for significance using a paired t-test. Changes in the DD and EP groups were non-significant. The THD group at $\Delta$ wt1 showed to have a mean weight gain of $0.29 \pm 2.40 \mathrm{~kg}$ and at $\Delta \mathrm{wt} 2$ a mean weight loss $-0.34 \pm 2.90 \mathrm{~kg}$; the change between the 2 phases was significant. But in general all patients did not gain or lose more than 1 $\mathrm{kg}$ as per the group mean. The between group analysis did now show any significant difference. For space limitation table not included.

BUN values dropped significantly at T1 among all groups and increased back towards baseline levels at T2. But this drop was not below the acceptable range for HD patients (Table 1). The between group analysis did now show any significant difference.

There was no significant difference in the total score of HRQOL for the within nor for the between group difference; thorough analysis for all the 8 domains of HRQOL was conducted, results in Table 2 and explained below.

Most HRQOL domains had their means around 50-60 at T1 and T2 except for SF, which had a mean of around 70 for all the 3 groups.

Within group differences showed a significant deterioration in many of the THD domains either at $\mathrm{T} 1$ or at $\mathrm{T} 2$ (PF, RP, RE, MH, BP) and no change in the rest of the domains. As for the DD group, there was significant change only in 4 domains ( $S F, M H, B P$, $\mathrm{GH}$ ) where they either had a minor drop at T1 or stayed unchanged, but they all improved at T2. And finally the EP group experienced a significant change in the course of the study in 2 domains (SF, BP) where the SF deteriorated at T1 but improved at T2, yet $\mathrm{BP}$ deteriorated at $\mathrm{T} 1$ and stayed so at $\mathrm{T} 2$.

The between group analysis revealed the following significant change at post intervention were: 1) SF improved only at T1 for THD group yet at T2, all groups had elevated yet similar scores; 2 ) $\mathrm{MH}$ at T1 significantly improved as compared to EP and achieved the highest score among the 3 groups at T2; 3) GH at T2 was the highest in the THD group. 
Table 2. Effect of NEMO on HRQOL (in-between group analysis)

\begin{tabular}{|c|c|c|c|c|c|}
\hline & & DD & EP & THD & $\begin{array}{c}\text { Between group } \\
\text { P Value }\end{array}$ \\
\hline \multirow[t]{3}{*}{$\mathrm{PF}$} & Pre & $55.92 \pm 34.27^{(*)}$ & $63.78 \pm 32.53^{(¥ \mathrm{f})}$ & $65.39 \pm 32.41^{\mathrm{a}(\mathrm{f})}$ & 0.05 \\
\hline & Post & $49.08 \pm 33.67$ & $54.8 \pm 31.93$ & $50.03 \pm 34.37^{b}$ & 0.97 \\
\hline & FU & $54.88 \pm 33.91$ & $58.59 \pm 34.94$ & $58.67 \pm 32.8^{\mathrm{ab}}$ & 0.84 \\
\hline \multirow[t]{3}{*}{$\mathrm{RP}$} & Pre & $45.38 \pm 49.19$ & $48.65 \pm 49.12$ & $53.55 \pm 49.5^{a}$ & 0.40 \\
\hline & Post & $51.54 \pm 47.16$ & $47.64 \pm 47.57$ & $42.6 \pm 48.76^{b}$ & 0.39 \\
\hline & FU & $46.54 \pm 49.58$ & $41.55 \pm 47.59$ & $37.72 \pm 44.9^{b}$ & 0.77 \\
\hline \multirow[t]{3}{*}{ RE } & Pre & $60 \pm 48.66$ & $70.72 \pm 45.15$ & $65.29 \pm 47.05^{\mathrm{a}}$ & 0.65 \\
\hline & Post & $70.77 \pm 45.84$ & $61.04 \pm 46.84$ & $58.19 \pm 48.66^{\mathrm{b}}$ & 0.07 \\
\hline & FU & $53.33 \pm 6.7$ & $54.5 \pm 47.33$ & $41.81 \pm 47.6^{\mathrm{c}}$ & 0.17 \\
\hline \multirow[t]{3}{*}{ Vitality } & Pre & $52.69 \pm 19.31$ & $50 \pm 18.23$ & $48.55 \pm 16.71$ & 0.47 \\
\hline & Post & $47.46 \pm 17.44$ & $47.23 \pm 17.48$ & $48.21 \pm 16.42$ & 0.82 \\
\hline & FU & $53.28 \pm 27.76$ & $49.44 \pm 26.9$ & $46.52 \pm 27.7$ & 0.32 \\
\hline \multirow[t]{3}{*}{ SF } & Pre & $85.19 \pm 27.68^{\mathrm{a}(¥)}$ & $85.64 \pm 28.79^{a(¥)}$ & $71.08 \pm 30.72^{(£)}$ & 0.01 \\
\hline & Post & $58.46 \pm 32.26^{\mathrm{b}(¥)}$ & $57.77 \pm 32.96^{\mathrm{b}(*)}$ & $76.92 \pm 29.94^{(f)}$ & 0.00 \\
\hline & FU & $70.19 \pm 29.12^{c}$ & $68.41 \pm 29.78^{\mathrm{c}}$ & $69.23 \pm 30.3$ & 0.91 \\
\hline \multirow[t]{3}{*}{$\mathrm{MH}$} & Pre & $56.71 \pm 16.63^{\mathrm{a}}$ & $57.91 \pm 19.84$ & $59.2 \pm 16.72^{a}$ & 0.33 \\
\hline & Post & $56.03 \pm 14.23^{\mathrm{a}(¥)}$ & $52.49 \pm 14.25^{(f)}$ & $58.4 \pm 16.72^{\mathrm{a}(*)}$ & 0.01 \\
\hline & FU & $63.91 \pm 23.60^{\mathrm{b}(¥)}$ & $60 \pm 27.23^{(¥)}$ & $48.77 \pm 25.1^{b(f)}$ & 0.00 \\
\hline \multirow[t]{3}{*}{ BP } & Pre & $76.85 \pm 29.57^{a}$ & $77.77 \pm 27.44^{a}$ & $79.59 \pm 27.07^{a}$ & 0.30 \\
\hline & Post & $56.62 \pm 36.65^{b}$ & $61.22 \pm 33.71^{b}$ & $65.06 \pm 33.11^{b}$ & 0.16 \\
\hline & FU & $65.12 \pm 29.11^{c}$ & $64.59 \pm 27.24^{b}$ & $59.53 \pm 34.5^{b}$ & 0.86 \\
\hline \multirow[t]{3}{*}{ GH } & Pre & $57.08 \pm 23.88^{\mathrm{a}}$ & $56.72 \pm 23.17$ & $52.31 \pm 21.87$ & 0.37 \\
\hline & Post & $47.6 \pm 23.92^{b}$ & $51.82 \pm 20.98$ & $55.04 \pm 23.09$ & 0.08 \\
\hline & FU & $50.02 \pm 21.07^{b(¥ f)}$ & $48.04 \pm 21.64^{(¥)}$ & $54.19 \pm 21.7^{(\mathrm{f})}$ & 0.03 \\
\hline
\end{tabular}

Values are shown in mean \pm SD

${ }^{\text {ab }}$ superscripts (in columns) indicate within group significant differences using GLM-repeated measure ANOVA and posthoc Bonferoni test $(p<0.05)$.

${ }^{¥}$ superscripts (in rows) indicate statistical difference between different groups using One way.

Table 3 shows the comparison between the mean of LOS between the 3 study phases for each group throughout the study. Overall, none of the groups had a mean LOS more than 3 days at any of the study phases. Moreover, all groups experienced a significant drop in mean LOS at T2. The mean number of times a patient needed emergency dialysis was much below 1 time per patient in the 6 months in all of the 3 study groups (not shown in tables). 
Table 3. Effect* of NEMO on LOS (in days)

\begin{tabular}{|c|c|c|c|c|c|c|c|}
\hline & \multicolumn{2}{|c|}{ DD group $(n=88)$} & \multicolumn{2}{|c|}{$\begin{array}{l}\text { EP group } \\
(n=96)\end{array}$} & \multicolumn{2}{|c|}{ THD group $(n=210)$} & \multirow{2}{*}{$\begin{array}{c}\text { Between } \\
\text { group P } \\
\text { value }\end{array}$} \\
\hline & mean $\pm S D$ & $\min / \max$ & mean $\pm S D$ & $\min / \max$ & mean $\pm S D$ & $\min / \max$ & \\
\hline TO & $2.08 \pm 6.44^{\mathrm{a}}$ & $0 / 59$ & $2.29 \pm 6.92^{\mathrm{a}}$ & $0 / 60$ & $2.23 \pm 5.91^{\mathrm{a}}$ & $0 / 44$ & 0.78 \\
\hline $\mathrm{T} 1$ & $2.74 \pm 5.80^{\mathrm{ab}(*)}$ & $0 / 86$ & $2.30 \pm 7.93^{\mathrm{a}(*)}$ & $0 / 33$ & $0.85 \pm 2.70^{b(¥ f)}$ & $0 / 18$ & 0.00 \\
\hline $\mathrm{T} 2$ & $0.91 \pm 3.47^{\mathrm{ac}}$ & $0 / 20$ & $0.78 \pm 2.86^{b}$ & $0 / 32$ & $1.06 \pm 5.16^{b}$ & $0 / 72$ & 0.81 \\
\hline
\end{tabular}

Values are shown in mean \pm SD

${ }^{a b}$ superscripts (in columns) indicate within group significant differences using GLM-repeated measure ANOVA and posthoc Bonferoni test $(p<0.05)$.

${ }^{¥}$ superscripts (in rows) indicate statistical difference between different groups using One way ANOVA and posthoc Bonferoni test $(p<0.05)$.

\section{DISCUSSION}

Intensive nutrition counseling by dedicated dietitians in the HD unit in Lebanon was able to: improve serum $\mathrm{P}$, LOS and BUN; maintain weight; but deteriorated dietary protein. As for HRQOL and MIS, the intervention minimized the deterioration when compared to the other groups.

The intensive nutrition education by a dedicated dietitian was able to guide patients to a healthy $\mathrm{P}$ restricted diet, whereby the DD protocol was the only one that achieved a significant reduction of serum $\mathrm{P}$ at $\mathrm{T} 1$, and this was almost maintained at $\mathrm{T} 2$.

Restricting dietary $\mathrm{P}$ often leads to restricting protein intake, an undesirable outcome for HD patients who are constantly in high risk of malnutrition. The different protocols used in this study were not able to improve malnutrition status in any of the groups, but the MIS deterioration was prevented by the DD protocol at T1, this effect was diminished at T2. This highlights the importance of having a dedicated dietitian at all times in the HD units. A major limitation of our study concerning the MIS score was the unavailability of monthly Alb and TIBC, integral parts of the MIS questionnaire, since these are collected either once or twice per year per patient in Lebanon in the HD units. Since the aim of the study was to check only the effect of DD protocol on the clinical outcomes of the patient without changing any other parameter in the HD unit, the research team depended on the available blood tests in the chart of the patients. Thus, at best, there was 1 value for each blood test per study phase. This might have contributed to some inaccuracy in the MIS scores.

Moreover, dietary protein was evaluated, through 24 hour recall; its levels continuously dropped in all groups throughout the study. Knowing that 24 hour recall is a subjective assessment tool and is often filled with error and bias (Burrowes et al., 2003), weight change was analyzed between the study phases. The mean change in weight for each group at all study phases never surpassed $1 \mathrm{~kg}$, leading us to believe that the nutritional status was not compromised. But one can speculate that the main- 
tained weight may be due to patients replacing fat for muscle (protein). Hence we determined Pre-dialysis BUN, an objective indicator of protein intake, which showed that even though all groups experienced a drop at T1, none of the values at any point in the study for any of the groups reached suboptimal levels. This helped us conclude that the dietary $\mathrm{P}$ restriction did not lead to a subsequent poor protein intake, and that our patients understood how to manage a diet maintaining the adequate Phosphorus to protein ratio.

A review in search of effective tools for dietary assessment in dialysis patients was conducted by Mathewson et al. (2010). The authors explained that 24 hour recall relies on the patients' ability to remember how much food was consumed and report it accurately. It underestimates actual intake; even when conducted by a trained interviewer, it can generate a variability of $31 \%$ to $79 \%$ in the mean daily intake of dietary nutrients. As for the 3 day recall, the variability range is $16.5 \%-20 \%$. The review concluded that dietary assessment methods should be replaced with appetite screening tools, which are faster to use and produce less variation and inaccuracies and distinctly show changes in general dietary intake and habits.

The only significant HRQOL improvement at T2 compared to baseline was in the mental health domain in the DD group. The association between improvements in mental health with lower hospitalization rates among HD patients was also reported by Kalantar-Zadehb et al. (2001). All other HRQOL domains deteriorated for all 3 groups over the course of the study, but this decline was less in the DD group. These findings were in line with that of Aghakhani et al. (2012) and reveal the strength of the DD protocol over the other 2 , in reversing the ongoing deterioration of QOL seen among HD patients over time as reported in the literature (Kalantar-Zadeh K \& Unruh M, 2005).

While conducting the survey, the research team faced a limitation in the HRQOL questionnaire and its applicability in the Lebanese culture. Most Lebanese are religious, interpreting sickness as "fate" and "will of God". When asked to rate their health, many of our patients used the word "Thank God" which was difficult to score. Patients were probed to choose one of the answers as stated in the questionnaire; often they concluded "With God's Will All is Good". This answer was translated to a "good" score for the related HRQOL domain. Such impact of religious beliefs blunting HRQOL differences among the chronically ill have been reported in the literature among other cultures as well (Buchholz, 1996). Further validation of the instrument in religion oriented cultures is recommended.

LOS for our patients dropped significantly at $\mathrm{T} 2$ in all study groups, and at all times the mean LOS per group did not reach 3 days. This is far below the average LOS (days/ patient/year) reported in the literature for this patient group, which varies from 8.5 (Schoonover et al., 2013) to 8.8 (Rocco et al., 1996), 10.5 (Becker et al., 1999), 14.8 (Funiaková et al., 2004 and Arora et al, 2000), up to 17.8 \pm 12.6 days (Utiel et al., 2011). Published articles have illustrated how hospitalization is the result of multi-factorial problems yet the NEMO study concentrated on nutritional education and controlled 
variables related to the dietetic care only. The literature has shown that dialysis access is considered as the leading cause of hospitalization among HD patients (Funiaková et al., 2004; Jones, 1991; Arora et al., 2000; Jones, 1992; Utiel et al., 2011); after which comes CVD (Utiel et al., 2011; Funiaková et al., 2004; Jones, 1992; Arora et al, 2000; Rocco et al., 1996; Jones, 1991) and diabetes (Becker et al., 1999; Arora et al., 2000; Rocco et al., 1996). Other factors included: 1) lower serum albumin (Kaysen et al., 2004; Arora et al., 2000; Rocco et al., 1996), 2) low serum P and protein levels (Jones, 1992; Jones, 1991), 3) arthritis (Jones, 1992; Jones, 1991), 4) decreased physical activity (Arora. et al., 2000; Rocco et al., 1996) , 5) white race (Arora et al., 2000; Rocco et al., 1996), 6) increasing age (Arora et al., 2000; Rocco et al., 1996), 7) smoking (Rocco et al., 1996; Arora et al., 2000), 8) lower functional status scores (Jones, 1992, Jones, 1991), psychiatric disorders, lung disease (Jones, 1991), 9) insurance related organizational deficiencies (Arora et al., 2000), 10) negative hepatitis antigen (Jones , 1991; Jones, 1992), 11) GI and not-fistula access related infection (Funiaková et al., 2004; Utiel. et al., 2011) and 12) low BMI (Kaysen et al., 2004). Controlling or studying all of the risk factors for hospitalization among HD patients was beyond the study's focus, thus it is difficult to draw a cause and effect line between the NEMO study and the drop in hospitalization in all study groups, especially since EP also showed the same effect. But the outlier LOS of this study compared to the literature may be explained by the differences in practice patterns of health care stuff in Lebanon, which is controlled by the overall management protocols imposed by the third party payers in the country. Dialysis is covered by the governmental insurance for all nationals, but hospitalization is covered by each patient's insurance coverage. In Lebanon, there are 2 types of insurance: private and governmental, the latter being the cheaper one. With the exception of very few, all participants depended on the governmental insurance. Due to budget limitations of their insurance, often physicians are compelled to solve cases without hospitalization; some patients are treated with medication at home or hospitalization is halted before full recovery and treatment is continued at home; moreover, many vascular access surgeries are considered same day surgery cases to avoid the cost of overnight stay.

The intensive dietetic consultation to HD patients focused on hyperphosphatemia management was able to improve serum $P$, prevent deterioration of malnutrition and HRQOL. As for LOS, the improvement was not specific to the group receiving the full intervention.

The 6 month dietary education (NEMO) achieved significant success but it has its limitations. Recommendation for future studies would be: 1) integrating multidisciplinary approach, 2) using appetite screening questionnaire instead of 3 day diary, 3) conducting blood test analysis for parameters needed for the study at the specific timings of the study, 4) longer intervention and 5) involving policy makers into a quality improvement plan on the health care and non -healthcare related aspects of management HD patients in Lebanon. 


\section{REFERENCES}

Academy of Nutrition and Dietetics Evidence Analysis Library (AND-EAL). (2010), "Is MNT provided by a Registered Dietitian for chronic kidney disease (CKD) in adults effective?" Available at: http://andevidencelibrary.com/template.cfm?key=2407 (accessed 25 February, 2013).

Aghakhani, N., Samadzadeh, S., Mafi, T., Rahbar, N. (2012). The impact of education on nutrition on the quality of life in patients on Hemodialysis: A comparative study from teaching hospitals. Saudi Journal of kidney Diseases and Transplantation, 23(1), 26-30.

Arora,P., Kausz,N., Obrador,G., Ruthazer,R., Khan,S., Jenuleson,C., Meyer,K., Pereira,B. (2000). Hospital Utilization among Chronic Dialysis Patients. Journal of the American society of nephrology, 11(4), 740-746.

Becker, B.N., Coomer, R.W., Fotiadis, C., Evanson, J., Shyr, Y., Hakim, R.M. (1999). Risk Factors for Hospitalization in Well-Dialyzed Chronic Hemodialysis Patients. American Journal of Nephrology, 19 (5), 565-570.

Buchholz, W.M., Bradlyn, A.S., Pollock, B.H., Meran, J.G., Testa, M. A., Simonson, D.C. (1996). Assessment of Quality of Life. The New England Journal of Medicine, 335, 520-521.

Burrowes, J.D., Larive, B., Cockram, D.B., Dwyer, J., Kusek, J.W., McLeroy, S., Poole, D., Rocco, M.V. (2003). Hemodialysis (HEMO) Study Group. Effect of dietary intake, appetite, and eating habits on dialysis and non-dialysis treatment days in HD patients: Cross-sectional results from the HEMO study. Journal of Renal Nutrition, 13, 191-198.

Covic, A., Seica, A., Gusbeth-Tatomir, P., Gavrilovici, O., Goldsmith, D. (2004). Illness representations and quality of life scores in haemodialysis patients. Nephrology Dialysis Transplantation, 19 (8), 2078-2083.

De Wit, G.A., Merkus, M., Krediet, R., De Charro, F. (2002). Health profiles and health preferences of dialysis patients. Nephrology Dialysis Transplantation, 17(1), 86-92.

Fouque, D, Kalantar-Zadeh, K., Kopple, J., Cano, N., Chauveau, P., Cuppari, L., Franch, H., Guarnieri, G., Ikizler, TA., Kaysen, G., Lindholm, B., Massy, Z., Mitch, W., Pineda, E., Stenvinkel, P., Treviño-Becerra, A., Wanner, C.A. (2008). Proposed nomenclature and diagnostic criteria for protein energy wasting in acute and chronic kidney disease. Kidney International, 73 (4), 391-398.

Funiaková, M., Funiaková, S., Jezíková, A., Holman, B., Mokán, M., Funiak, S. (2004). Causes of hospitalization in patients on chronic hemodialysis. Vnitrrní lékařství, 50(3), 213-217.

Gabbay, E., Meyer, K., Griffith, J., Richardson, M., Miskulin, D. (2010). Temporal Trends in Health-Related Quality of Life among Hemodialysis Patients in the United States. Clinical Journal of the American Society of Nephrology, 5(2), 261-267.

Jones, K. (1991). Factors Associated with Hospitalization in a Sample of Chronic Hemodialysis Patients. Health Services Research, 26(5), 671-699.

Jones, K. (1992). Risk of hospitalization for chronic hemodialysis patients. Image- The journal of nursing scholarship, 24(2), 88-94.

Kalantar-Zadeha, K., Kopple, J, Block, G., Humphreys, Mi. (2001). A Malnutrition-Inflammation Score Is Correlated With Morbidity and Mortality in Maintenance Hemodialysis Patients. American Journal of Kidney Diseases, 38 (6), 1251-1263.

Kalantar-Zadehb, K., Kopple, J., Block, G., Humphreys, Mi. (2001). Association among SF36 Quality of Life Measures and Nutrition, Hospitalization, and Mortality in Hemodialysis. Journal of the American Society of Nephrology, 12(12), 2797-2806.

Kalantar-Zadeh, K., Humphreys, Mi., Kopple, J, Block, G. (2004). Comparing outcome Predictability of Markers of Malnutrition-Inflammation Complex Syndrome in Hemodialysis Patients. Nephrology Dialysis Transplantation, 19 (6), 1507-1519.

Kalantar-Zadeh, K., Unruh, M. (2005). Health related quality of life in patients with chronic kidney disease. International urology and nephrology, 37(2), 367-378.

Karavetian M. (2007) Nutritional Intervention for Management of Osteodystrophy in Hemodialysis (HD): (NIMO trial). (Master's Thesis). Retrieved from: http://hdl.handle.net/10938/7448.

Karavetian M., El Zein, H., Hwalla, N., De Vries, N. (2013). Dietetic Practices in Hemodialysis Units in Lebanon and Their Conformity with KDOQI Nutrition Guidelines. International Journal of Health and Nutrition, $4(2), 1$. 
Karavetian M., Abboud S, De Vries, N., El Zein, H. (2014). Nutritional Education for Management of Osteodystrophy in Hemodialysis Patients (NEMO) trial Program, Lebanon: Design and Patient Characteristics. Nutrition Research and Practice.

Karavetian M., El Zein, H., Bechwaty, F., De Vries, N. Effect of Behavioral Stage-Based Nutrition Education on Management of Hyperphosphatemia among Hemodialysis Patients: NEMO Trial, Lebanon. Under review.

Kaysen, G.A., Müller, H.G., Young, B.S., Leng, X., Chertow, G.M. (2004).The influence of patient- and facilityspecific factors on nutritional status and survival in hemodialysis. Journal of Renal Nutrition, 14(2), 72-81.

Mathewson, A., Fouque, D., Toft, A. (2010). Dietary Phosphate Assessment in Dialysis Patients. Journal of Renal Nutrition, 20 (6), 351-358.

Mazairac, A., Grooteman, M., Blankestijn, P., Penne, L., Van der Weerd, N., Den Hoedt ,C., van den Dorpel, M., Buskens, E., Nube, M., ter Wee, P., De Wit, G.A., Bots, M. (2011). Differences in quality of life of hemodialysis patients between dialysis centers. Quality of Life Research, 21(2), 299-307.

McCann, L. (2009). Pocket guide to nutrition assessment of the patient with chronic kidney disease. 4th edition. New York: National Kidney Foundation.

Rambod, M., Bross, R., Zitterkoph, J., Benner, D., Pithia, J., Colman, S., Kovesdy, CP., Kopple, JD., KalantarZadeh, K. (2009). Association of Malnutrition-Inflammation Score with Quality of Life and Mortality in Hemodialysis Patients: A 5-Year Prospective Cohort Study. American Journal of Kidney Disease, 53(2), 298-309.

Rocco, M., Soucie, M., Reboussin, D., McClellan,W. (1996). Risk Factors for Hospital Utilization in Chronic Dialysis patients. Journal of the American Society of Nephrology, 7 (6), 889-896.

Schoonover, K., Hick son, L., Norby, S., Hogan, M., Chaudhary, S., Albright, R., Dillon, J., McCarthy, J., Williams, A. (2013). Risk Factors for Hospitalization Among Older, Incident Hemodialysis Patients. Nephrology, 18(11), 712-717.

Toigo, G., Aparicio, M., Oattman, P., Cano, N., Cianciaruso, B.,Engel,B., Fouque, D., Heidland, A.,Teplan, V.,Wanner, C.(2000). Expert working group report on nutrition in adult patients with renal insufficiency. Clinical Nutrition, 19(4), 281-291.

Utiel, B., Torres,S., Barrio, P., Perales,S., Cortes, G., Ángeles,S., Baldan,B., Canada, L.(2011). How do disorders related to hospitalisation influence haemodialysis patients' nutrition? Nefrologia, 31(4), 471-83.

Ware, J., Sherbourne, C.D. (1992).The MOS 36-Item Short-Form Health Survey (SF-36): I. Conceptual Framework and Item Selection. Medical Care, 30(6), 473-483

Yokum, D., Glass, G., Cheung, C.F., Cunningham, J., Fan, S., Madden, A.M. (2008). Evaluation of a phosphate management protocol to achieve optimum serum phosphate levels in hemodialysis patients. Journal of Renal Nutrition, 18(6), 521-529.

Zabel, R., Campbell, K., Ash, S., Mcfarlane, C., Juuffs, P., Bauer, J. (2009). Implementation of Standardized Nutrition Guidelines by Renal Dietitians Is Associated With Improved Nutrition Status. Journal of Renal Nutrition, 19(2), 136-144. 

CHAPTER 8

General Discussion 
CHAPTER 8 


\section{GENERAL DISCUSSION}

The present thesis dealt with the development of two educational modules; one to empower dietitians on renal nutrition standards and another to be used by a competent renal dietitian to educate HD patients on hyperphosphatemia management.

The concept was built on a few critical building blocks: 1) a pilot study was developed, where a renal dietitian educated half of the patients in the HD unit on dietary management of hyperphosphatemia; the findings of this pilot revealed the need for a thorough needs assessment and a larger sample study thus 2) a cross-sectional study on the dietetic practices in the HD units in Lebanon and their knowledge in managing HD patients. This was compared to KDOQI nutrition guidelines (NKF-KDOQI, 2000); thus representing the gap analysis in the dietetic competencies; moreover, 3) a literature review was done on the most effective strategies in nutrition education for this specific patient population with a focus on hyperphosphatemia; after which 4) a focus group analysis was done with HD patients and dietitians working with these patients, to identify the window of opportunity in improving the dietetic practices and patient adherence to treatment; 5) subsequently the study protocol and the educational material were prepared for empowering dietitians first and then patients. The effectiveness of the protocol and educational material were examined in chapter 6 and 7. All chapters included discussion, limitations and future recommendations for further research.

\section{Part 1: Pilot study: Nutritional education for the management of osteodystrophy (NEMO) in patients on haemodialysis: a randomized controlled trial (Karavetian \& Ghaddar, 2013).}

This study was a small scale randomized controlled trial on 122 patients divided into 3 groups that examined the effect of self-management dietary counseling on adherence in hyperphosphatemia management among HD patients. This study represented the pilot of the current thesis. The results of the study showed the importance of such an intervention, since the full intervention participants were the only ones that experienced a significant improvement in serum $\mathrm{P}$ and knowledge on dietary restrictions needed to achieve self management.

\section{Part 2: Dietetic Practices in HD Units in Lebanon and Their Conformity with KDOQI Nutrition Guidelines (Karavetian et al., 2013)}

This study was the first to address practice patterns and knowledge of KDOQI nutrition guidelines in the management of HD patients by dietitians in Lebanon. Results show that the dietitians responsible for management of HD patients had multiple hospital duties, were very young and almost $50 \%$ had only 2 years of experience. The described 
situation highlights high turnover due to work overload, exhaustion and thus job dissatisfaction; a scenario very similar to the one described in the literature (Wolfe, 2012).

Moreover, the participating dietitians had adequate university education in general dietetics but scored low on renal dietetics related knowledge. This can be explained by the lack of advanced trainings for dietitians to specialize in renal dietetic care as part of their general internship. A certifying body for such specialization found in countries like the United States (US) is non-existent in Lebanon. Taking the US as a country model to follow, where KDOQI standards were developed and renal dietetics is a specialty provided by a national certifying body, the standards of practice among Lebanese dietitians was benchmarked with KDOQI guidelines and compared to the practice level of US dietitians. Results showed that $97 \%$ applied at least one guideline compared to that 91\% in US (Burrowes et al., 2005); 64\% and 36\% used 5 and 10 guidelines respectively compared to somewhat higher numbers of $72 \%$ and $55 \%$ in US (Burrowes et al., 2005). Five percent applied all guidelines, similar to that in US (Burrowes et al. 2005). This may indicate that in the face of all the limitations imposed on Lebanese hospitals, dietitians are still trying to update themselves with their own resources and in their own time. Dietitians reported barriers to better practice standards as lack of time, lack of integration in the health care system, lack of support from the physician, lack of ready-made culturally sensitive patient educational material in Arabic. Literature has emphasized the need of organization wide supporting policies and resources for the improvement of health care professionals' practice standards and thus clinical patient outcome (Epping-Jordan et al., 2004; Wolfe, 2012).

\section{Part 3: Determinants of Effective Nutritional Education for HD Patients on Hyperphosphatemia Management}

Pubmed, Medline and Embase databases were used to search educational dietary interventions focusing on hyperphosphatemia management among HD patients with serum phosphorus (P) as the main outcome variable (detailed in chapter 4). Eighteen studies with a structured educational intervention met the inclusion criteria. Except for one of them (Karamanidou et al., 2008), all achieved a reduction of serum P and 12 had a significant improvement. This reduction ranged from $0.4 \mathrm{mg} / \mathrm{dl}$ to $1.6 \mathrm{mg} / \mathrm{dl}$ (average: $1 \mathrm{mg} / \mathrm{dl}$ ). Eight of the studies (de Brito Ashurst \& Dobbie, 2003; Ford et al., 2004; Karavetian \& Ghaddar, 2013; Shi et al., 2013; Lou et al., 2012; Baraz et al., 2010; Campbell et al., 2009; Nisio et al., 2007) achieved the KDOQI target level of $<5.5 \mathrm{mg} / \mathrm{dl}$ serum P post intervention. The review identified enhancers and barriers to educational methods needed to achieve optimal dietary P management among HD patients. Demographic enhancer included: 1) young age, 2) high educational level and 3) unemployment. Moreover, it drew the roadmap to effective dietary education in hyperphosphatemia management among HD patients: Individualized education through a multidisciplinary team, provided before the HD session, with interactive educational materials that fo- 
cuses on easy-to-learn skills through the use of behavioral theories, for duration of at least 6 months, with a minimum of monthly dietitian- to- HD patient meetings.

In further search for enhancers of adherence within the culture of the study population, focus group discussions were conducted with HD patients and dietitians working with renal patients in Lebanon (discussed in chapter 6). Patients highlighted the following needs: 1) more self-management skills, 2) information on alternatives of "forbidden foods", 3) frequent dietitian visits and 4) need for practical advice. Dietitian focus group results confirmed the findings of chapter 1 , where the main barrier to better HD patient management was the dietitian's work overload.

\section{Part 4: Development of Study Protocol and Educational Material}

According to the findings of the previous parts, the study protocol and educational material were prepared. The Trans-Theoretical Model (TTM) was used to construct the patient directed educational material. The study had 3 study protocols: Dietitian dedicated (DD), Existing Practice (EP) and Trained Hospital Dietitian (THD). Baseline patient characteristics were studied and group differences were analyzed. At baseline $40 \%$ of participants in all groups had hyperphosphatemia, majority were at the pre-action stage for readiness to start the $P$ restricted diet and the frequency of dietitian's consults amounted to less than once in the 6 months prior to the study.

\section{Part 5: The Effectiveness of the Intervention on Study Parameters}

The intensive stage based, individualized nutrition counseling by dedicated dietitians in the HD unit in Lebanon was able to improve: serum P, TTM stage, the mental health domain of the HRQOL and LOS; maintain adequate P/protein ratio, BUN, weight and MIS; however, it led to a deteriorated dietary protein \%. This change is explained in detail in chapter 4 and 5 and summarized in figure 1. 




Figure 1: Effect of each study protocol on all study parameters

$(V$ indicates significant improvement; $X$ indicates significant deterioration and Đindicates absence of change).

The intensive education protocol assigned to the DD group was the most effective in improving most study parameters. The DD group was the only with improved serum $P$ and progressed in readiness to change to "Action" stage. Moreover, the DD group had a significant improvement in knowledge score, but a slight elevation in knowledge was also seen in the other 2 groups. In the EP group this could be related to contamination of information from the DD patients since they shared the HD unit. As for the THD group, we assume that the training the dietitians received improved their practice patterns and were able to slightly improve the knowledge of their patients but not the behavior.

The above mentioned results support our hypothesis; providing brief education is not enough to change behavior in this group. Long term intensive, individualized nutrition counseling based on a patient's readiness to change is effective in increasing knowledge and results in lifestyle behavior change and thus clinical outcome improvement. This was in line with the findings of several review articles (Mason et al., 2008, Matteson \& Russell, 2010).

Literature advocates the role of behavioral theories in facilitating dietary adherence (Spahn et al., 2010; Matteson \& Russell, 2010). Our findings were in line with the literature. Our nutritional psycho-education helped patients improve serum P significantly, thus providing an objective evidence on the effectiveness of the DD protocol over the other 2 .

Often, patients complain that the dietary restrictions are too complicated to understand and leave them almost no options of allowed food (Breiterman, 2004). The educational material used in the DD protocol, not only informed patients what not to eat, but informed them on the safe alternatives, and how they can prepare them; thus minimizing feelings of deprivation from customary and traditional meals. Similar studies 
noted this method as a facilitator to dietary adherence (Lou et al., 2012; Sullivan et al., 2009; Karavetian \& Ghaddar, 2013). The booklet of alternatives and the recipe books were highly valued among our patients. As a result, patients in the DD group improved their serum $\mathrm{P}$ but maintained an adequate $\mathrm{P} /$ Protein ratio; indicating the smart choices they had taken in choosing foods high in protein but low in P.

Restricting dietary $\mathrm{P}$ often leads to restricting protein intake, an undesirable outcome for HD patients who are constantly in high risk of malnutrition. The study was not able to improve the malnutrition status in any of the groups, but the MIS score did not deteriorate and was maintained at "mild malnutrition" for all patients in all groups throughout the study.

The only parameter that the DD protocol failed to improve was the \% Dietary Protein intake; which was based on the result of a 3 day 24 hour recall. The literature highlights on the weakness of the latter for the amount of bias in it and dependence on patients' recall (Burrowes et al., 2003). The reliability of the 24 hour recall was checked first with the weight change among participants and second with the serum pre-BUN, an objective indicator of protein intake; both stayed almost unchanged all through the study. This also supported our conclusion that the dietary $\mathrm{P}$ restriction did not lead to a subsequent poor protein intake, and that our patients understood maintain the adequate dietary $\mathrm{P} /$ protein ratio.

The DD protocol was able to improve he mental health domain at T2. All other HRQOL domains deteriorated for all 3 groups over the course of the study, but this decline was less in the DD group. These findings were in line with that of Aghakhani et al., (2012) and reveal the strength of the DD protocol over the other 2, in reversing the ongoing deterioration of QOL seen among HD patients over time as reported in the literature (Kalantar-Zadeh \& Unruh; 2005). A limitation in the applicability of the HRQOL questionnaire in the Lebanese population was the difficulty of this religious patient group to objectively evaluate health.

LOS for our patients dropped significantly at $\mathrm{T} 2$ in all study groups, and at all times the mean LOS per group did not reach 3 days. This was far below the average LOS (days/ patient/year) reported in the literature which varied from a minimum of 8.5 (Schoonover et al., 2013) to 8.8 (Rocco et al., 1996), to a maximum of $17.8 \pm 12.6$ days (Utiel et al., 2010). This lower LOS may be due to the insurance limitation factor provided to Lebanese HD patients, which restricts the budget of expenses other than the HD session itself; moreover, the medical team's practice pattern has a leading role on the LOS of patients which was beyond the study's focus to study.

\section{Limitations of the study:}

The 6 month dietary education (NEMO) achieved significant success but it had its limitations. 


\section{Sampling}

The strength of the sample was 1) in the way it was calculated: based on a previous pilot study conducted on the same population; 2 ) it total number of study participants amounted to $30 \%$ of all HD patients in the country, 3) that came from 12 different HD units from all major cities of the country. Thus the sample was highly representative of the HD patients in Lebanon. Moreover, the initial sample was magnified at the start of the study to protect the sample from possible attrition; which was justified by the actual patient attrition: 780 patients were selected from the 12 hospitals, 571 of whom entered the study and only 394 completed the study. As for the sample size of THD that was double that of $\mathrm{DD}$, this was done to account for the weakness of the former protocol; which was proven to be reasonable by the study results: the larger size of THD did not serve as an advantage to its results and the only 2 improvements seen in this protocol were knowledge and LOS, which occurred at T2.

The sampling had its downsides. Patients of cluster 1 from the same HD unit were assigned into 2 different protocols (EP and DD), which led to contamination of information. Sources of such contamination were: posters hung in the waiting room of the unit; the nursing staff that heard the research team's education and consequently modified their instructions given to patients on diet. Matching between study groups was done in HD unit size but not in the rest of the parameters like socioeconomic status (SES) and health care staff. After start of the study, the research team noticed major differences in the latter 2 aspects.

Future studies can prevent these problems by :1) minimizing exposure of the control group to the study intervention, 2) educating the participating HD unit's staff on potential harms of transmitting information between groups, 3) matching patients between groups on demographic characteristics, 4) focusing on choosing only hyperphosphatemics, which would add strength to the results. The latter point was not done in the current thesis, because the main objective of the study was to identify a better way of practice, realistic to current situations in HD units in Lebanon, so it can pose as a model to be adapted for better patient care.

\section{Tools used:}

The dietetic practice was assessed through a self-administered survey containing questions with multiple answer choices. The self administration may have caused reporting bias and thus affected the results. Moreover, the availability of response choices for each knowledge and practice question may have hinted the correct answer to the respondent. Open ended questions are recommended when assessing (Choi \& Pak; 2005).

The assessment of dietary intake with 3 day 24 hour recall was one of the limitations in the methodology. A review of relevant literature was conducted by Mathewson et al. (2010); it reported that this tool underestimates actual intake by up to $80 \%$ and 
that this dietary assessment methods should be replaced with appetite screening tools, which are faster to use, produce less variation and inaccuracies, and distinctly show changes in general dietary intake and habits.

LOS was retrieved from patient files at TO and T2. But since most patient files on this aspect were not filled accurately, the HD unit's head nurse was the main reference. As for the data at $\mathrm{T} 1$, since the research dietitians were present all the time in the HD units of the EP and DD groups, they retrieved the information directly from the patient on the day of the hospitalization, thus in this phase in these 2 groups, LOS was represented more accurately. This difference of data collection did not exist in the THD groups since the research dietitians were not there so data continued to be retrieved from patient files. For future studies, the presence of the research team in all hospitals at all times would be recommended, which however needs a larger budget.

Results of blood tests were collected from patient files, and these were done according to the financial availability and policies imposed by the ministry of health on the HD units. It was not possible to collected Alb and TIBC in the required frequency since they were measured only twice or at best 3 times a year per patient, thus whatever was available closest to each data collection phase was used as the Alb and TIBC representing these patients. Moreover, for a more accurate inflammation assessment, C-reactive protein would have been ideal to be collected, but due to budget restrictions, the study was based on blood tests available in the HD units.

The study was pure nutritional and did not involve any other disciplines in the patient education process. Integrating multidisciplinary teams in the patient education and health care would have increased the chances in improving MIS and more domains of HRQOL.

As for the effect of stage based education; it is difficult to point out whether the DD protocol was superior over the others due to its intensity or the competence of the renal dietitian or the used of the special patient education material or the use of TTM. The integration of the TTM into the patient education was easy to conduct and the actual patient education process passed smoothly where patients were content; but to identify the actual effect of the TTM, a different study should be conducted where 2 groups would be provided a patient education protocol where the only difference would be stage matched and non staged matched education, controlling the rest of the variables.

The only evaluation for the study was outcome evaluation, process or impact evaluation was not done due to resource limitations. The PI throughout the study, continuously conducted informal process evaluations and upon need modified some minor aspects in tools used or training given to dietitians so the intervention meets its main study objectives. Moreover, informal impact evaluation was also conducted; patients of the DD protocol did express fondness to the research team and how it was pleasant to be visited frequently by a dietitian, who educated them, gave them feedback on their daily activities and advice on lifestyle. Unfortunately, both process and impact evalua- 
tions were conducted informally with no survey or documentation. Future studies should integrate within their outcome measured impact and process evaluations which may direct researchers on improving study protocols to better serve the target patient population.

\section{Implications}

\section{Implication for Future Practice:}

Our results clearly showed that the current status of dietetic services in HD units in Lebanon is far from KDOQI standards; moreover, HD units do not have a dedicated renal dietitian for the unit as is the ADA recommendation. The supply of dietetic services and demand of renal patients is not in balance. The role of the MOPH is critical in improving the current status. The following are steps suggested by the research team of this study: 1) provide specialized training to dietitians on KDOQI standards, 2) consider renal dietitians as key health care professionals in the management of HD patients, 3) integrate the standards of dietetic care of renal patients $n$ the accreditation standards of hospitals, and 4) allocate budget for employing renal dietitians dedicated to the HD unit.

\section{Implication for Future Research:}

Recommendation for future studies would be: 1) A better separation of the EP group from the DD to prevent contamination of data, 2) better selection of patients and HD units, using demographic matching between groups, 3) using appetite screening questionnaire instead of 3 day diary, 4) conducting blood test analysis for parameters needed for the study at the specific timings of the study, 5) integrating multidisciplinary approach 6) conducting a cost-effectiveness analysis and 7) involving policy makers into a quality improvement plan on the health care and non -healthcare related aspects of management HD patients in Lebanon.

\section{Concluding Remark:}

In conclusion, the NEMO study met its main objectives in improving clinical indicators among HD patients. HD patients do benefit from intensive individualized nutrition counseling through a 2 hour per month dedicated dietitian-to-HD patient time. Integrating behavioral theory and tailoring education to the patient's readiness to change enhances behavior. Partnering with patients in their health management is effective in improving their adherence to the assigned treatment. Stage based dietary education can be considered a viable option in managing hyperphosphatemia among HD patients, subsequently decreasing mortality. It can play the role of a model to follow in most 
Arabic speaking countries that face the same cultural and health care issues. The educational material can easily be adopted in the regular dietetic care of HD patients. The main outcomes of the present thesis are outlined below:

- Dietetic practices in Lebanon in HD units are lagging behind KDOQI nutrition practice guidelines. Knowledge of dietitians in renal dietetics is insufficient. Frequency of dietitians consults to HD patients is less than 1 time per year. Multidisciplinary team approach to manage HD patients does not exist. Future studies should look into cost effectiveness analysis of dietary treatments in HD units; to build the pillars of change towards better support from administration on favorable conditions for optimal dietitian-to- HD patient ratios.

- TTM is widely used in dietary behavior change interventions but not in renal failure patients. The current study can be considered the first to pave the way to many similar studies in the aim of building a solid ground for future evidence based recommendations.

- Focus group discussion with the target population (patient and dietitian) facilitated the process of constructing effective educational material. Future studies should strive to attain the opinion of the target population before planning interventions.

- The study was effective on changing biochemical parameters among HD patients related to hyperphosphatemia, decreased hospital length of stay, and advanced the stage of readiness to change in lifestyle behavior to the "action" stage. Future studies should focus on opening lines of communication between dietitians, psychologist and education professionals which may result in highly efficient and effective nutrition education. 


\section{REFERENCES}

Aghakhani, N., Samadzadeh, S., Mafi, T.M. and Rahbar, N. (2012). The impact of education on nutrition on the quality of life in patients on hemodialysis: a comparative study from teaching hospitals. Saudi Journal of Kidney Diseases and Transplantation, 23(1), 26-30

Arora, P., Kausz, A. T., Obrador, G. T., Ruthazer, R., Khan, S., Jenuleson, C. S., . . and Pereira, B. J. (2000). Hospital utilization among chronic dialysis patients. Journal of the American Society of Nephrology, 11(4), 740-746.

Baraz, S., Parvardeh, S., Mohammadi, E., and Broumand, B. (2010). Dietary and fluid compliance: an educational intervention for patients having haemodialysis. Journal of Advanced Nursing, 66(1), 60-68.

Becker, B.N., Coomer, R.W., Fotiadis, C., Evanson, J., Shyr, Y. and Hakim, R.M. (1999). Risk Factors for Hospitalization in Well-Dialyzed Chronic Hemodialysis Patients. American Journal of Nephrology, 19 (5), 565570.

Breiterman, W.R. (2004). Adherence to the dialysis prescription: partnering with patients for improved outcomes. Nephrology Nursing Journal: Journal of the American Nephrology Nurses' Association, 31(4), 432436.

Buchholz, W. M., Bradlyn, A. S., Pollock, B. H., Meran, J. G., Testa, M. A., and Simonson, D. C. (1996). Assessment of quality of life. New England Journal of Medicine, 335, 520-521.

Burrowes, J.D., Russell, G.B. and Rocco, M.V. (2005). Multiple factors affect renal dietitians' use of the NKFK/DOQI Adult Nutrition Guidelines. Journal of Renal Nutrition, 15(4), 407-426.

Burrowes, J. D., Larive, B., Cockram, D. B., Dwyer, J., Kusek, J. W., McLeroy, S., . . and Rocco, M. V. (2003). Effects of dietary intake, appetite, and eating habits on dialysis and non-dialysis treatment days in hemodialysis patients: cross-sectional results from the HEMO study. Journal of Renal Nutrition, 13(3), 191-198.

Campbell, K.L., Ash, S., Zabel, R., Mcfarlane, C., Juffs, P. and Bauer, J.D. (2009). Implementation of standardized nutrition guidelines by renal dietitians is associated with improved nutrition status. Journal of Renal Nutrition, 19(2), 136-144

Choi B \& Pak A. (2005). A Catalog of Biases in Questionnaires. Prev Chronic Dis 2005

http://www.cdc.gov/pcd/issues/2005/jan/04_0050.htm accessed on 22 feb 2014

Cupisti, A., Ferretti, V., D’Alessandro, C., Petrone, I., Di Giorgio, A., Meola, M., . . and Capitanini, A. (2012). Nutritional knowledge in hemodialysis patients and nurses: focus on phosphorus. Journal of Renal Nutrition, 22(6), 541-546.

de Brito Ashurst, I. and Dobbie, H. (2003). A randomized controlled trial of an educational intervention to improve phosphate levels in hemodialysis patients. Journal of Renal Nutrition, 13(4), 267-274.

Durose, C.L., Holdsworth, M., Watson, V. and Przygrodzka, F. (2004). Knowledge of dietary restrictions and the medical consequences of noncompliance by patients on hemodialysis are not predictive of dietary compliance. Journal of the American Dietetic Association, 104(1), 35-41.

Epping-Jordan, J.E., Pruitt, S.D., Bengoa, R. and Wagner, E.H. (2004). Improving the quality of health care for chronic conditions. Quality \& Safety in Health Care, 13(4), 299-305.

Finckenor, M. and Byrd-Bredbenner, C. (2000). Nutrition intervention group program based on preactionstage-oriented change processes of the Transtheoretical Model promotes long-term reduction in dietary fat intake. Journal of the American Dietetic Association, 100(3), 335-342.

Ford, J.C., Pope, J.F., Hunt, A.E. and Gerald, B. (2004). The effect of diet education on the laboratory values and knowledge of hemodialysis patients with hyperphosphatemia. Journal of Renal Nutrition, 14(1), 3644

Kalantar-Zadeh, K., Kopple, J.D., Block, G. and Humphreys, M.H. (2001). A malnutrition-inflammation score is correlated with morbidity and mortality in maintenance hemodialysis patients. American Journal of Kidney Diseases, 38(6), 1251-1263

Kalantar-Zadeh, K., and Unruh, M. (2005). Health related quality of life in patients with chronic kidney disease. International urology and nephrology, 37(2), 367-378. 
Karamanidou, C., Weinman, J., and Horne1, R. (2008b). Improving haemodialysis patients' understanding of phosphate-binding medication: a pilot study of a psycho-educational intervention designed to change patients' perceptions of the problem and treatment. British Journal of Health Psychology, 13(2), 205-214

Karavetian, M. and Ghaddar, S. (2013). Nutritional education for the management of osteodystrophy (NEMO) in patients on haemodialysis: a randomised controlled trial. Journal of Renal Care, 39(1), 19-30.

Karavetian, M., Elzein, H., Hwalla, N. and de Vries, N. (2013). Dietetic Practices in Hemodialysis Units in Lebanon and Their Conformity with KDOQI Nutrition Guidelines. International Journal of Health \& Nutrition, $4(2), 1-8$

Kaveh, K. and Kimmel, P.L. (2001). Compliance in hemodialysis patients: multidimensional measures in search of a gold standard. American Journal of Kidney Diseases, 37(2), 244-266.

Kimmel, P.L., Emont, S.L., Newmann J.M., Danko, H. and Moss, A.H. (2003). ESRD patient quality of life: symptoms, spiritual beliefs, psychosocial factors, and ethnicity. American Journal of Kidney Diseases, 42(4), 713-721.

Kugler, C., Maeding, I. and Russell, C.L. (2011). Non-adherence in patients on chronic hemodialysis: an international comparison study. Journal of Nephrology, 24(3), 366-375.

Lam, L.W., Twinn, S.F. and Chan, S.W. (2010). Self-reported adherence to a therapeutic regimen among patients undergoing continuous ambulatory peritoneal dialysis. Journal of Advanced Nursing, 66(4), 763773.

Lou, L.M. Caverni, A., Gimeno, J.A., Moreno, R., Perez,J., Alvarez, A., Campos, B., Garcia,M., Gutiérrez, A., Bielsa, S., Castilla, J., Sanz A., and Martin, F. on behalf the Aragon CKD Research Group. (2012). Dietary intervention focused on phosphate intake in hemodialysis patients with hyperphosphoremia. Clinical Nephrology. 77(6), 476-483.

Mason, J., Khunti, K., Stone, M., Farooqi, A. and Carr, S. (2008). Educational interventions in kidney disease care: a systematic review of randomized trials. American Journal of Kidney Diseases, 51(6), 933-951.

Mathewson, A. M., Fouque, D., and Toft, A. J. (2010). Dietary phosphate assessment in dialysis patients. Journal of Renal Nutrition: the official journal of the Council on Renal Nutrition of the National Kidney Foundation, 20(6), 351

Matteson, M.L. and Russell, C. (2010). Interventions to improve hemodialysis adherence: a systematic review of randomized-controlled trials. Hemodialysis International, 14(4), 370-382.

Mochari-Greenberger, H., Terry, M.B. and Mosca, L. (2010). Does stage of change modify the effectiveness of an educational intervention to improve diet among family members of hospitalized cardiovascular disease patients? Journal of the American Dietetic Association, 110(7), 1027-1035

National Kidney Foundation -Kidney Disease Outcomes Quality Initiative (NKF KDOQI) (2000) Clinical Practice Guidelines for Nutrition in Chronic Renal Failure http://www.kidney.org/professionals/kdoqi/guidelines_updates/doqi_nut.html Accessed on 3 February 2014.

Nisio, J. M., Kamimura, M. A., and Bazanelli, A. P. (2007). The effects of a nutrition education programme on phosphorus control in hemodialysis patients.J Brasileiro de Nefrologia, 29 152-157

Qunibi, W.Y. (2004). Consequences of hyperphosphatemia in patients with end-stage renal disease (ESRD). Kidney International, 66, S8-S12.

Rambod, M., Bross, R., Zitterkoph, J., Benner, D., Pithia, J., Colman, S., . . . and Kalantar-Zadeh, K. (2009). Association of Malnutrition-Inflammation Score with quality of life and mortality in hemodialysis patients: a 5-year prospective cohort study. American Journal of Kidney Diseases, 53(2), 298-309.

Rambod, M., Peyravi, H., Shokrpour, N. and Sareban, M.T. (2010). Dietary and fluid adherence in Iranian hemodialysis patients. The Health Care Manager, 29(4), 359-364

Reddy, V., Symes, F., Sethi, N., Scally, A.J., Scott, J., Mumtaz, R. and Stoves, J. (2009). Dietitian-led education program to improve phosphate control in a single-center hemodialysis population. Journal of Renal $\mathrm{Nu}$ trition, 19(4), 314-320.

Rocco, M. V., Soucie, J. M., Reboussin, D. M., and McClellan, W. M. (1996). Risk factors for hospital utilization in chronic dialysis patients. Southeastern Kidney Council (Network 6). Journal of the American Society of Nephrology,7(6), 889-896. 
Spahn, J. M., Reeves, R. S., Keim, K. S., Laquatra, I., Kellogg, M., Jortberg, B., and Clark, N. A. (2010). State of the evidence regarding behavior change theories and strategies in nutrition counseling to facilitate health and food behavior change. Journal of the American Dietetic Association, 110(6), 879.

Schoonover, K. L., Hickson, L. J., Norby, S. M., Hogan, M. C., Chaudhary, S., Albright, R. C., . . . and Williams, A. W. (2013). Risk factors for hospitalization among older, incident haemodialysis patients. Nephrology, 18(11), 712-717

Shaw-Stuart, N.J. and Stuart, A. (2000). The effect of an educational patient compliance program on serum phosphate levels in patients receiving hemodialysis. Journal of Renal Nutrition, 10(2), 80-84.

Shi, Y. X., Fan, X. Y., Han, H. J., Wu, Q. X., Di, H. J., Hou, Y. H., and Zhao, Y. (2013). Effectiveness of a nurse-led intensive educational programme on chronic kidney failure patients with hyperphosphataemia: randomised controlled trial.Journal of clinical nursing, 22(7-8), 1189-1197.

Sullivan, S., Sayre, S. S., Leon, J. B., Machekano, R., Love, T. E. Porter, D., Marbury, M., and Sehgal, A. R. (2009). Effect of food additives on hyperphosphatemia among patients with end-stage renal disease. A randomized controlled trial. Journal of the American Medical Association, 301(6), 629-635

Utiel, F. B., Torres, P. S., del Barrio, M. P., Ángeles, P. S., Perales, M. S., Cortés, M. G., . . . and Linares, C. D. D. N. (2010). Loss of weight in hemodialysis patients after hospitalisation is related with length of stay and degree of inflamation La pérdida de peso en pacientes en hemodiálisis tras su hospitalización tiene relación con la duración de la estancia y con el grado de inflamación. Nefrologia, 30(5), 557-566.

Vergili, J.M. and Wolf, R. L. (2010). Nutrition practices of renal dietitians in hemodialysis centers throughout the United States: a descriptive study. Journal of Renal Nutrition, 20(1), 8-e1.

Wolfe, W.A. (2012). Moving the issue of renal dietitian staffing forward. Journal of Renal Nutrition, 22(5), 515-520. 
CHAPTER 9

Study Summary 
CHAPTER 9 


\section{STUDY SUMMARY}

The aim of the study was to assess the effect of implementing Self Management Dietary Counseling (SMDC) on improved adherence of HD patients and achieving chronic kidney disease related mineral bone disorder (CKD-MBD) management.

This was done through an integrated two-prong research study:

1. Patient-directed track: Effect of optimal nutritional awareness in HD patients through specialized dietetic education programs conducted by trained professionals, on improving adherence to therapy and thus clinical, quality of life and cost outcomes.

2. Health care staff-directed track: Effect of training key health care professionals (especially dietitians) in hospitals on management of CKD-MBD.

\section{Sample selection:}

Through a randomization process, $12 \mathrm{HD}$ units were selected from the national sample and randomly assigned into 2 clusters. Patients in cluster A were randomly assigned according to their dialysis shift to Dedicated Dietitian (DD) protocol $(n=133)$ and Existing Practice (EP) protocol $(n=138)$. Cluster B patients $(n=299)$ received Trained Hospital Dietitian (THD) protocol. Inclusion criteria for patients were: stable (free of acute diseases) HD patients $\geq 18$ years, able to comprehend the study and sign a consent form were included to the study.

\section{Staff Training:}

Eleven dietitians were trained by the principle investigator (PI) on KDOQI nutrition standards for HD patients. The PI met with the dietitians on a weekly basis for 2 hours over 8 weeks. Five of these dietitians were externally recruited research dietitians and 6 of them were hospital dietitians responsible for managing HD patients.

\section{Patient Education Material Development:}

Focus group discussions were conducted with HD patients and renal dietitians from Lebanon to explore the barriers and facilitators to dietary adherence in the renal diet. According to the results of these discussions and using the Trans Theoretical Model (TTM), the patient education material was developed. The main aim was to increase knowldge and self managemenet skills of patients on phosphorus $(P)$ restricted diet, and emphasize the importance of balancing low $\mathrm{P}$ with adequate protein intake to prevent malnutrition. 


\section{Conduct of study and data collection.}

\section{Study Protocols:}

- Dedicated Dietitian Protocol: Each patient in this group received an individualized twice per week 15 minutes education, by the trained research dietitian, for 6 months, a total of 12 hours of education per patient. The patient educational material designed in this study were used only for these patients.

- Existing Practice Protocol: Considered as control, where patients received education from hospital dietitians, who was blinded the study.

- Trained Hospital Dietitian Protocol: Patients were educated by the trained hospital dietitian. The dietitian was not given educational material or any protocol to follow for patient care.

\section{Study phases:}

The study had 3 consecutive phases: baseline (t0), intervention (t1), follow-up (t2), where each had a duration of 6 retrospective months. During the follow up period the research team had no contact with any of the participants.

\section{Data collection:}

From the medical chart he following were collected: demographics, weight, length of hospital stay (LOS) in days, blood urea nitrogen (BUN) (mg/dL) and serum P (mg/dL). Moreover, 4 questionnaires were used in this study: 1) Knowledge questionnaire (KnQ); score of less than $60 \%$ indicated insufficient knowledge; 2) Malnutrition Inflammation Score (MIS), the score ranged from 0 (normal) to 30 (severely undernourished); 3) Stages of Behavioral Change (TTM stage) for P restricted diet, the score was from 1 to 5 indicating the stages of behavioral change and health related Quality of life (HRQOL). Moreover through a 24 hour recall, daily dietary protein consumption as compared to needs and dietary $\mathrm{P}$ density were calculated.

\section{Results:}

Results showed that the DD protocol was superior over the other 2 protocols, as it improved significantly most study parameters as summarized in figure 1. 


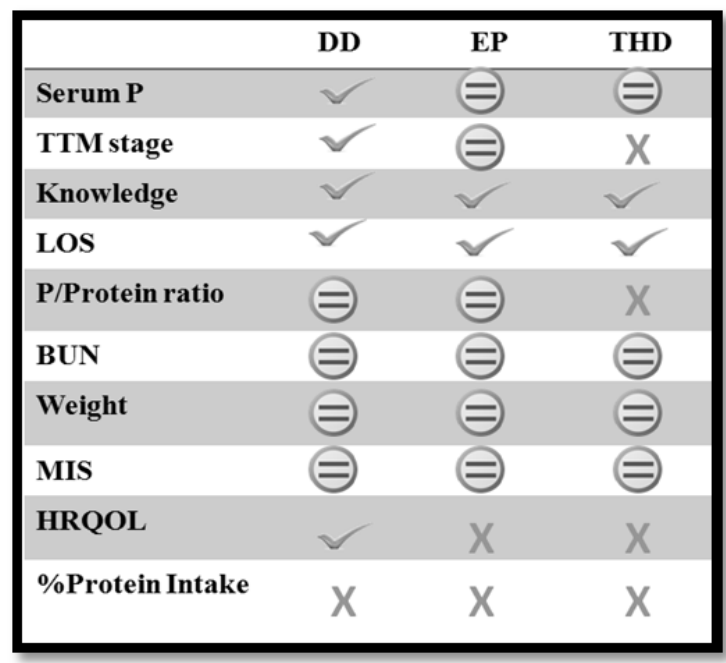

Figure 1: Effect of each study protocol on all study parameters

$(V$ indicates significant improvement; $X$ indicates significant deterioration and Đindicates absence of change).

The objective of the this trial was to determine the role of a trained and dedicated dietitian in the HD unit on patient clinical outcomes in Lebanon.

The study can serve as a developing country model. The findings show that there is room for improvement among Lebanese HD patients regarding osteodystrophy management and relevant biochemical and clinical parameters, justifying an effort to improve nutritional advice.

In conclusion, dietetic services in HD units in Lebanon are lagging behind although professionals involved do their very best. Hospitals that operate a HD unit do not seem to equip their dietitians with sufficient time, training, or empowerment to follow KDOQI standards of care in the management of HD patients. The supply of dietetic services and demand of renal patients is not in balance; due to the lack of specialized renal dietitians in the face of the ever-rising numbers of renal failure and HD patients in Lebanon. The MOPH is encouraged to promote the integration of renal dietitians as a core member of the health care team for the optimal cost effective management of HD patients in Lebanon. This can be done by: the following steps: 1 ) hospitals provide specialized training to hospital dietitians on KDOQI standards, 2) reinforce their implementation, 3) continuously audit and assess compliance to KDOQI nutrition guidelines in routine practice, 4) allocate extra time for management of HD patients either by decreasing responsibilities of already existing dietitians or recruiting new ones to be fully dedicated to the HD unit and finally 5) consider renal dietitians as key health care professionals in the management of HD patients. 

Chapter 10

Valorization 
CHAPTER 10 


\section{VALORIZATION}

Hemodialysis (HD) is well known to be the leading resource-consuming renal replacement therapy worldwide, posing heavy health and economic burdens on the individual, societal and health care system levels.

Nutrition care of HD patients is a crucial part in their management and treatment. Existing evidence shows that poor adherence to medical nutrition therapy is associated with negative outcomes on all the above-mentioned levels, i.e.: increased frequency and length of hospitalization, decreased quality of life, frequent need for emergency dialysis, increased need for medication, in addition to the need for more physician and patient caregiver time...

Therefore, achieving optimal hemodialysis patient adherence is a suggested key means for improving health outcomes and subsequently decreasing health care costs. However, despite advances in behavioral and health research, increasing patient adherence to treatment in this specific population remains a major challenge facing the health care professionals and posing tremendous burden on the health care systems.

In terms of patient health gains, the current project explored an understudied area for improving patient outcomes, i.e. phosphatemia, adherence to treatment and quality of life and offered simple, practical and patient-friendly strategies in this aim.

From the health care provider view, this project pioneered in validating the effectiveness of the transtheoretical theory, as a counseling model in the management of hemodialysis patients. It also offered novel key knowledge, practical strategies and tools and new insights for health care professionals to improve their patients' adherence to treatment and health outcomes without the need for increased resources, except for ensuring adequate counseling time. Within this scope, this projects identified optimal health care provider- hemodialysis patient time and ratio for optimal patient outcomes.

Moreover, nutrition therapy is a type of preventive medicine, and it is assumed that significant healthcare cost savings and reduction of global burden of disease can be achieved when a population is healthier. Thus, from this broader perspective and given the scarcity of governmental resources and the rapidly escalating hemodialysis health costs, the need for novelties in the health care systems is on the rise. This is especially true for Lebanon, where data show that in 2009, $8 \%$ of the Lebanese Ministry of Public Health's budget was spent on HD patients. The current study validated a model that suggests recruiting a dedicated dietitian to each HD unit and in return have patients improve their dietary self management and adherence to medical nutrition therapy; thus improve their clinical outcomes and quality of life. In addition, it provided evidence that this model is superior to existing practices in terms of the above-mentioned pa- 
rameters, thus questioning the adequacy of the current policies in Lebanon and other developing countries with similar health care systems.

Finally, this project presented a new healthcare model, validated its clinical effectiveness, and showed that it is worthy to be economically evaluated. In fact, to put a monetary value for the improvement of each patient due to better nutritional management is difficult and needs studies focusing directly on its economic evaluation. If found costeffective, this model would be subsequently suggested to the public health decision makers as a feasible health care innovation.

The direct benefit of this study was to the HD patients; but indirectly it did improve the general welfare of the society. The only loss in this system was the financial compensation for the dedicated dietitian yet the return on investment was evident for the patient, the caregiver, the medical staff, and the healthcare cost.

In conclusion, this project presents a rigorous evaluation of the clinical effectiveness of the use of this model in the management of hemodialysis patients and offers key findings to the health care professionals and to the public health policy makers as well.

We hope that the knowledge gained from this project, together with existing and future suggested research findings could jointly result in useful outcomes in the management of hemodialysis patients, in an attempt to lighten the health, social and economic burdens of hemodialysis. 


\section{Acknowledgements}

I would never have been able to finish my dissertation without the guidance of my committee members, help from colleges, and support from my family.

I will start by thanking UM for providing the non-resident PhD program, without which my PhD degree would have remained just a dream. Next, I would like to express my gratitude to Dr Nanne de Vries for believing in me, taking that leap of faith and accepting me as a PhD candidate under his supervision. Dr Vries thought me how to become a researcher; with his compassion and understanding, thought me how to be humble and accepting; I learned from him professionalism and promptness. The past 4 years had many downfalls, when I lost the faith in my abilities; he was always able to boost my confidence with constructive words and get me back stronger than before and running.

Dr Hafez el Zein has taken many roles in my life, sometimes a caring advisor in life decisions, on other occasions a teacher, a colleague, a thesis supervisor since my masters thesis, just to name a few. Without him, I would have never been able to have the courage to start this thesis study in Lebanon. He opened doors when they were completely closed, patiently dealt with my mistakes and impatience, believed in me more than I did in myself.

Dr Bernadette Afifi Mounayyar, chairperson of nutrition department in Lebanese university. When all hospitals in Lebanon had their doors closed and did not allow me to deal with patients, with a small phone call she got that solved, arranged a letter from ministry of health that obliged all hospitals in Lebanon to cooperate. She provided me with around 20 master's thesis students to conduct the data collection and entry of all of these patients throughout the 12 month study period. In the face of all the logistic limitations, without Dr Mounayyar's assistance, this study would not have even started.

Dr Khalil Helou, chairperson of nutrition department in University Saint Joseph, Lebanon. He trusted in me 5 of his graduate students to become the research dietitians of this study. They were the top students of their class: Fida Bechwaty, Liliane said, Rime Jibai, Mona Wehbe and Sarah Haydar. Each of them, with persistence and endeavor for excellence, worked hard to get trained and conduct the 6 month patient education. Often they had to travel to another city to educate patents, and they did this in the face of all the political insecurities of the country.

Lovely Marja Vissers, secretary of Dr Nanne de Vries. She made all weird complicated procedures look simple, facilitated my travel and stay in Maastricht, added humor and smile to every awkward situation, making them look like a piece of cake!

Dr Sanna Ghaddar, for implanting the passion for renal dietetics in me. 
The patients and the staff of each HD unit, for patiently cooperating with the study team.

National Council for Scientific Research, Lebanon for covering part of the study costs.

Iyamed Sarl., Lebanon for funding the printing of the patient educational material.

And finally I reach to my family. I could write a whole thesis on that! I thank my parents for believing that education is priority in life, that to be the best in your field is the only way to be. I thank them for supporting me and bearing with me. My mother became a mother to my son when I had to work for long hours! My husband barely saw me yet still loved me. My sister had to deal with all my downs. I believe I am blessed to have them in my life and I would not have been who I am and where I am without them! 


\section{Curriculum vitae}

Mirey Karavetian earned her degree in dietetics from American University of Beirut and is a PhD candidate in "Health Promotion" in Maastricht University. She has extensive experience: 1 ) in medical nutrition therapy in critical care and hemodialysis units in hospitals; 2 ) in teaching nutrition and health quality in universities and continuing education workshops for dietitians (Lebanon and UAE); 3 ) in community nutrition in school nutrition programs and 4) in quality management of clinical units (setting policies and procedures and training staff on the new set of rules). Her research is focused on finding effective strategies to change dietary behavior in chronically ill patients. Her publications focus on dietary management of hemodialysis patients and finding the optimal dietitian-to-patient ratio needed in the hemodialysis unit in the Arab world for optimal clinical outcomes. She has shared her experience in national and international conferences. Currently she is an assistant professor in Natural Sciences in Public health Department, Zayed university, United Arab Emirates. 


\section{Full Articles:}

- Karavetian M, Ghaddar S: Serum Phosphate Reduction with Diet: Randomized Controlled Trial in Hemodialysis Patients, Lebanon. Journal of Renal Care. 2013 Mar;39 (1):19-30

- Karavetian M , El Zein H, Hwalla N, De Vries N. Conformity of Dietetic Practices with KDOQI Nutrition Guidelines in HD Units in Lebanon. International Journal of Health and Nutrition. 2013 4(2):1-8

- Karavetian M, Abboud S, El Zein H, Haydar S, De Vries N. Nutritional Education for Management of Osteodystrophy (NEMO) Trial Lebanon: Design and Patient Characteristics. Nutrition in Research and Practice, February, 2014; (8):103 - 111

- Karavetian M, El Zein H, Rizk R, De Vries N Dietary Education Interventions for Hyperphosphatemia Management in Hemodialysis (HD) Patients: A Systematic Review and Meta-Analysis. Nutrition Reviews (in Press)

\section{Abstracts:}

1. Karavetian M, Ghaddar S, El Zein H, Nutritional Intervention For Management Of CKD-MBD In Hemodialysis Patients: A Developing Country Model (Lebanon) National Kidney Foundation, Spring Clinical Meetings 2009

2. Karavetian M, De Vries N, El Zein H: Dietetic Practices In Adult Hemodialysis Units Compared To K/DOQI Guidelines, Lebanon. Kidney Res Clin Prac, 31(2), 2012

3. Karavetian M, De Vries N, El Zein H: Nutritional Intervention for Management of Osteodystrophy (NIMO) Program In Hemodialysis Patients, Lebanon And Baseline Data. Kidney Res Clin Prac, 31(2), 2012

4. Karavetian M, De Vries N, El Zein H, Abboud S: Nutritional Educational Model for Hemodialysis Patients, Lebanon. $2^{\text {nd }}$ American Society for Nutrition Middle East Congress, Feb $20-22,2013$

5. Abboud S, Karavetian M, De Vries N, El Zein H : Nutritional Education for Management of Osteodystrophy (NEMO) Trial: Impact on Quality of Life. ERA-EDTA-50th Congress, May 18-21,2013

6. Rizk, R., Karavetian M., Elzein H. \& Abboud, R. Effect of a Dietitian-Run StageBased Nutritional Education on Hyperphosphatemia among Hemodialysis Patients, Lebanese. The $2^{\text {nd }}$ USEK International Nutrition Conference- Health and Food Security. April 17 - 18, 2013.

7. Rizk R, Karavetian M, Elzein H, Abboud R. Dedicated Renal Dietitian in the Hemodialysis Unit Controls Serum Phosphorus and Malnutrition, Lebanon. XVII International Congress on Nutrion and metabolism in renal disease. May 6-10, 2014

8. Rizk R, Karavetian M, Elzein H, Abboud R. Effect of Intensive Stage-Based Nutrition Education by A Dedicated Renal Dietitian on Phosphatemia Management Among Lebanese Hemodialysis Patients. Journal of Renal Nutrition Vol. 24(2) p 137 March 2014 